\title{
THE EVIDENTIARY USES OF NEUTRON ACTIVATION ANALYSIS†
}

Triplets!! Not one suspect, in the shooting of a storekeeper and a policeman, but three!

Dick Tracy: . . . We've got problems! Who fired that gun?

Lizz: A PARAFFIN test?

Dick Tracy: NEVER! That test is DEAD as the dodo! -Never was dependable. Today's test, known as the neutron activation analysis, is brand new and accurate.

Will it reveal the guilty triplet?*

Neutron activation analysis (NAA) is a method of detecting with great sensitivity ${ }^{1}$ the presence and concentrations of most chemical elements in materials, without, in most cases, destroying the sample analyzed. NAA permits identification and measurement of concentrations of elements which are present in only minute or trace quantities, such as specks of pamt, ${ }^{2}$ which because of their size are not susceptible to other techniques. Also, under appropriate circumstances, NAA can identify both large and small pieces of material by accurately analyzing their trace element concentrations. Such identifications rely on the fact that, although concentrations of the major constituents of similar specimens such as two pieces of glass may be nearly the same, impurity trace elements sometimes show a wide variation from one source to another because manufacturers make no effort to control the quantities of these elements in their products. ${ }^{3}$ Besides its high sensitivity, NAA's potential for nondestructive measurement provides the further advantage that the samples which are measured can be preserved for

$\dagger$ The author gratefully acknowledges the reading of the manuscript by W.S. Lyon and F.F. Dyer of the Oak Ridge National Laboratories and L. Leventhal of the LFE Corporation, Trapelo Division/West (Richmond, Cal.).

* San Francisco Sunday Examiner \& Chronicle, August 22, 1971 (Comics, Part 2, Dick Tracy).

1. For a detailed discussion of the sensitivity of NAA see text accompanying notes 70-74 infra. Atomic absorption spectronetry, a technique which requires destruction of the sample, achieves a sensitivity comparable to that of NAA for many elements and has been used in conjunction with NAA in some applications. See, e.g., Hoffman, Brunelle \& Snow, Forensic Comparisons of Soils by Neutron Activation and Atomic Absorption Analysis, 60 J. CRIM. L.C. \& P.S. 395 (1969). Although this Comment deals specifically only with activation analysis, it should be recognized that the forensic applications of any technique which measures the elemental compositions of materials will involve many of the interpretation problems discussed herein.

2. See People v. Woodward, No. 108551 (Cal. Super. Ct., San Mateo County, July 7,1964 ), discussed in detail in the text following note 96 infra.

3. See, e.g., Lenihan, Activation Analysis, 207 Nature 347, 349 (1965). Part III of this Comment is devoted to a discussion of both the accuracy of this assumption and its implications in particular cases. 
production in court or for further tests. ${ }^{4}$

Although its use is fraught with numerous pitfalls, conclusions based on neutron activation analyses had been accepted as evidence in at least 50 trials in the United States by $1968 .{ }^{\circ}$ As is the case with inany new scientific techniques, almost no pattern has developed for the introduction of this type of evidence, with the result that on some occasions the technique has been abused and the trier of facts misled. ${ }^{\circ}$ This Comment analyzes the considerations involved in the forensic use of neutron activation analysis.

\section{The Single NAA Measurement ${ }^{7}$}

At its best, NAA is simply a method of quantitative chemical analysis. ${ }^{8}$ It measures the elemental composition of materials, that is, the amount of each chemical element in a given sample of material. As such it is a well-established scientific technique, ${ }^{0}$ and it may be helpful to set out a moderately detailed description of the method and the technical problems involved. This preliminary discussion will establish the terminology, and it may provide useful background material for the lay lawyer who finds it necessary at some time to turn to the scientific literature for more complete information. ${ }^{10}$ However, it should be borne in mind that most of the legal problems surrounding NAA do not involve its validity as a technique of chemical analysis. Rather, interpretation of the results of the chemical analysis-the relevance of the results to a particular legal issue-causes most of the difficulties. Succeeding parts of this Comment deal with these questions.

4. See text accompanying notes 60-69 infra.

5. An informal list of cases through 1968 has been compiled by M.J. Pro (Internal Revenue Service, Washington, D.C. 20224) and V.P. Guinn (Department of Chemistry, University of California, Irvine, California 92664).

6. Maletskos, Problems in the Use of Activation Analysis Evidence in Court, 12 Trans. Am. Nuc. Soc'y 508 (1969). See also Guinn, The Activation Analysis Expert in Court-An Inside View, 12 Trans. AM. Nuc. Soc'y 506, 507 (1969).

7. This part discusses only the determination of the elemental composition of a single piece of material. It does not refer to the set of single measurements on the different materials that are involved in a typical forensic problem.

8. It is not, of course, the only niethod of elemental analysis. See, e.g., Guinn, Non-biological Applications of Neutron Activation Analysis in Forensic Studies, in III METHods of Forensic ScIence 47, 47 (A.S. Curry ed. 1964).

9. Thousands of papers in pure and applied chemistry have been publislied either studying the technique itself or applying it as a tool in the solution of other problems. See National Bureau of Standards, U.S. Dep'T of Commerce, ActivaTION ANALYSIS: A BIBLIOGRAPHY, (NBS Technical Note No. 467, 1969).

10. A biblography of papers dealing solely with some aspect of forensic applications has also been published. See National BUREaU of Standards, U.S. Dep'T OF COMmerce, Forensic Science: A Bibliography of Activation ANalysis papers, (NBS Technical Note No. 519, 1970). 


\section{A. The Basic Theory ${ }^{11}$}

The detection of elements by activation analysis is possible because most elements can be made artificially radioactive. The resulting radioactive products can be identified by observation of the ways in which they undergo radioactive decay. ${ }^{12}$ Radioactive decay is a fairly complicated process ${ }^{13}$ during whicl the nuclei of most radioactive atoms (these nuclei are often referred to as radionuchides) emit a pulse of high-energy electromagnetic radiation called a gamma-ray ${ }^{14}$ whicl has an energy characteristic of the emitting nucleus. The activation analyst usually tries to count the number of gamma-rays of each energy which are emitted from a sample of activated material. ${ }^{15} \mathrm{He}$ also observes the half-life ${ }^{16}$ of each emitting radionuclide. These measurements tell him what kind of radionuclide produced the gamma-rays, and from the number of gamma-rays of each energy he deduces the number of radioactive nuclei of that particular type which are present in the activated sample. ${ }^{17}$ From this information he can determine the pre-

11. A very readable article is Wahl \& Kramer, Neutron Activation Analysis, 216 ScIENTIFIC AM., Apr. 1967, at 68. More complete treatment is given by Guinn \& Lukens, Nuclear Methods, in Trace ANAIxsis 325 (G.H. Morrison ed. 1965). See also Guide to Activation ANalysis (W.S. Lyon ed. 1964).

12. Radioactivity is the property of the nuclei of some atoms to decompose spontaneously into lighter fragments. R.B. LeIGHTON, PRINCIPLES OF MODERN PHYsics 512 (1959).

13. For a general description of radioactivity see id. at 512-45. See also Lenihan, Radioactivity, in Activation Analysis Principles and Applications 3-7 (J.M.A. Lenihan \& S.J. Thomson eds. 1965).

14. A gamma-ray is not fundamentally different from a radio wave or a light ray. All three are forms of clectromagnetic radiation. See, e.g., F.A. JENKINS \& H.E. White, FundaMentais of Optics 203 (3d ed. 1957). It should be noted that some radionuclides emit two or more characteristic gamma-rays. See, e.g., Ross, Basic Nuclear Properties and Activation Analysis, in GUIDE to ACtIVATION ANALYsis, supra note 11 , at $1,4-5$.

15. Most radionuclides also emit beta particles (electrons or positrons), and the analyst sometimes wishes to observe them. However, beta particles are generally not as helpful as gamma-rays in distinguishing one element from another because not all beta particles are emitted with the same energy for a given radionuchide. See, e.g., Ross, supra note 14, at 3 .

16. A given radionuclide is characterized by a time period, called the lialf-life, during which lalf of the radioactive atoms present at a given instant will decay. See, e.g., R.B. Leighton, supra note 12, at 513. Thus, the lialf-life is a measure of the rate of decay, and from it one can infer the length of time a particular radionuctide will remain detectable. (Simce 210 is approximately equal to 1,000 , the number of radioactive nuclei remaining after 10 lalf-hives will only be about 0.1 percent of the original number.) Knowledge of the half-hives of the radionuclides being sought is crucial to most activation analyses, since it enters into the choice of the irradiation time (the time inside the reactor), the beginning and duration of the observation period, and the calculation of the composition. This is discussed throughout the remainder of this part.

17. Not all of the atoms originally present become radioactive during the activation process. Therefore, a calculation or other means is required to deduce the number of activated atoms. Usually, the number of gamma-rays of the particular 
activation elemental composition of the sample. ${ }^{18}$

In practice, most samples are activated by insertion inside a nuclear reactor. ${ }^{19}$ There they are exposed to a more or less steady stream of neutrons, and some of the nuclei of each stable eleinent present in the sample become radioactive by asborbing a neutron. ${ }^{20}$ The sample is then removed from the reactor, and the number of gamma-rays emitted at eacli energy as well as the respective half-lives of the emitting radionuclides are observed by an appropriate detection system.

\section{B. The Detection Process}

\section{An Ideal Detection System}

The ideal detection system would be one that singles out and measures each gamma-ray emitted by the activated sample and that keeps track of how many gamma-rays of each energy it had detected in any given time period. By comparing the number of "counts" at each energy in one time period to the number of counts at the same energy in a later time period, the analyst could determine the half-life of the radionuclide producing that particular gamma-ray. Using elementary mathematical formulas ${ }^{21}$ he could then determine the total number of

energy is compared with the number of the same energy gamma-rays emitted by a standard sample, a known quantity of the element being sought, which is activated at the same time as the unknown. See text accompanying notes 22-25 infra.

18. The composition is usually described in terms of concentrations by weight. Thus, if the analyst finds 10 micrograms (a microgram is one-milhonth of a gram or $1^{-6}$ grams) of a particular element in 1 gram of the sample material, the concentration is expressed as 10 parts per million (10 ppin).

19. There are other means of making stable elements radioactive, and not all use neutrons. See Guinn \& Lukens, supra nore 11, at 332-33. However, neutron activation in a reactor is the usual choice because reactors provide, at lowest cost, an abundant supply of neutrons whose energy makes absorption most probable (so-called thermal neutrons) for a wide range of elements. See Lenihan, Nuclear Activation Analysis, in 1 Instrumentation IN Nuclear Medicine 309, 310 (G.J. Hine ed. 1967). All forensic apphications to date have involved neutron activation.

20. The nuclei of atoms are made up of neutrons and protons, and it is the number of protons (the atomic number) that determines what element the atom is. If a stable, nonradioactive atoin can be induced to absorb another neutron into its nucleus, the chemical properties do not change, and the new atom is called an isotope of the original element. Often this new isotope is radioactive, so that it can be detected and the presence of the original stable isotope inferred.

Not all elements will absorb a neutron, and some of those that do will decay so rapidly that there is no time for the activation analyst to detect them. This is particularly true for elements of low atomic number. Lenihan, supra note 19, at 310 . Furthermore, some elements form another stable isotope upon absorbing a neutron. Guinn \& Lukens, supra note 11, at 329. Neither of these types of elements can be detected by neutron activation analysis. Moreover, elements that become radioactive but do not emit gamma-rays clearly cannot be detected by gamma-ray observation. These elements must be detected, if at all, by separating the radionuclide cheinically [see text accompanying notes 52-59 infra] and then observing the beta particles with a Geiger counter or some similar device. See, e.g., Ricci, Practical Examples of Activation Analysis, in GUIDE To Activation ANALYSIS, supra note 11, at 116, 121-27.

21. If there are $\mathrm{N}_{0}$ radioactive atoms of a particular type at the time the ma- 
atoms of that radionuclide present when the sample was removed from the reactor.

Having deduced the concentration of each radioactive element in the sample after irradiation, the analyst could calculate the corresponding amounts of each stable element prior to activation. In principle, he could calculate this knowing the number of neutrons to which the material had been exposed and the probability that an atom of eacli particular stable element would absorb a neutron when exposed to one. ${ }^{22}$ However, these factors, especially the latter, are usually not accurately known, ${ }^{23}$ and therefore another approach is employed. In addition to irradiating the unknown material in the reactor, the analyst also irradiates a set of standards, which are known quantities of the stable elements he seeks to detect. The sample and all the standards are placed as close together as possible in the same reactor and irradiated for the same time, so that they are exposed to the same number and energy of neutrons. ${ }^{24}$ They are renoved from the reactor together and the number of radioactive atoms of each isotope present at the time of removal in both the unknown material and in the standards is determined as described above, by counting the number of gamma-rays that have the energy characteristic of the radionuclide. ${ }^{25}$ For each element, the number of radioactive atoms created in the unknown and in the standard is proportional, with the same proportionality constant, to the number of stable atoms that were originally present in each. Since the number of atoms in each standard is known, the quantity of each stable element im the unknown can be calculated.

\section{Actual Detection Systems}

The key to this method of analysis is a detector which counts the

terial comes out of the reactor ( $t=0$, where $t$ is the time), the number at a later time $t$ is $N=N_{0} e^{-0.093(t / T)}$ where $T$ is the half-life. R.B. LEIGHTON, supra note 12, at 516-17. Since neither $N$ nor $N_{0}$ is known, the analyst must determine them by observing the counting rates at later time periods aud relating these to the time derivatives of the above formula. In order for this determination to be valid, these later countingrate-observation periods must be much shorter than one half-life, because the counting rates continuously decrease with time and remain approximately constant only over such short periods.

22. See, e.g., Ross, supra note 14 , at 9.

23. Id.

24. The flow of neutrons inside the reactor is not usually uniform. Therefore, if the unknown and standard are at different positions spatially, there may be variations in the numbers or energies of the neutrons to which they are exposed. When this is the case, corrections have to be made. An interesting solution used in some reactors is a rack that rotates circularly around the core, so everything on the rack is exposed to the same average neutron flow. See Guinn \& Lukens, supra note 11, at 348.

25. Counting of the unknown and the standard does not have to go on at the same time because time corrections can be handled directly by the formula in note 21 supra. This is very useful and important, because it allows both to be counted on the same counter. 
number of gamma-rays at each energy emitted by the unidentified sample, often referred to as the unknown. All detectors include a device which absorbs gamma-rays and produces a pulse of electric current that is proportional to the energy of the absorbed gamma-ray. ${ }^{20}$ This current pulse is measured electronically by a device called a multichannel pulse height analyzer, ${ }^{27}$ which in spite of its formidable name is conceptually very simple. The range of possible current pulse sizes is broken down into a number of increments or channels, and the analyzer measures the size of the pulse and decides which channel it falls in. A count is then recorded as having arrived in that channel, and the number of counts in each channel is stored in the memory of a computer.

Realistic detectors, however, differ in several important respects from the ideal. In the first place, as one can see from the typical detector arrangement shown in Figure 1, even if the detector were able to measure and record every gamma-ray which reaches it, it would clearly miss many which go off in other directions. Thus, no detector can record every gamma-ray emitted by the sample, although the analyst can usually account for this by ensuring that the unknown and all standards have the same size and shape, so that the same fraction of gamma-rays reach the detector from each. ${ }^{28}$

A much nore serious problem is raised by the very complicated ways that actual detectors respond to gamma-rays, even when only one radionuchide is present and emitting gamma-rays of a single energy. One major difficulty results fron the imperfect resolution of the detector system: the inability to distinguish gamma-rays of one energy from those of a shightly different energy. It should be noted, however, that great advances have been made in this area in recent years. ${ }^{20} \mathrm{~A}$ second inajor problem is spurious responses: a fraction of identical gamma-rays which enter the detector will be "measured" and recorded as having energies different from their actual energy ${ }^{30}$

26. There are two major types of such device. The first is a combination of a scintillator (usually a sodium iodide crystal), which converts the energy of the gammaray into a pulse of light, and a photomultiplier, which couverts the light pulse into a current pulse. See Eldridge, Scintillation Counting Techniques, in Guide to Activation ANALYsIs, supra note 11 , at $80,80-84$. The second type is a semiconductor radiation detector (usually a germanium crystal into which a sinall amount of lithium has been diffused), which absorbs the incident gamma-ray and converts it directly into a proportional current pulse. The status of such detectors lias recently been reviewed. Goulding \& Stone, Semiconductor Radiation Detectors, 170 SCIENCE 280 (1970). The development of semiconductor detectors, which have much better resolution than the scintillators, may soon make the scintillators obsolete, if it has not done so already. See note 40 infra and accompanying text.

27. See, e.g., Eldridge, supra note 26 , at 87.

28. Guinn \& Lukens, supra note 11 , at 349.

29. See the discussion of semiconductor radiation detectors accompanying notes $36-40$ infra.

30. See text accompanying notes 41-48 infra. 


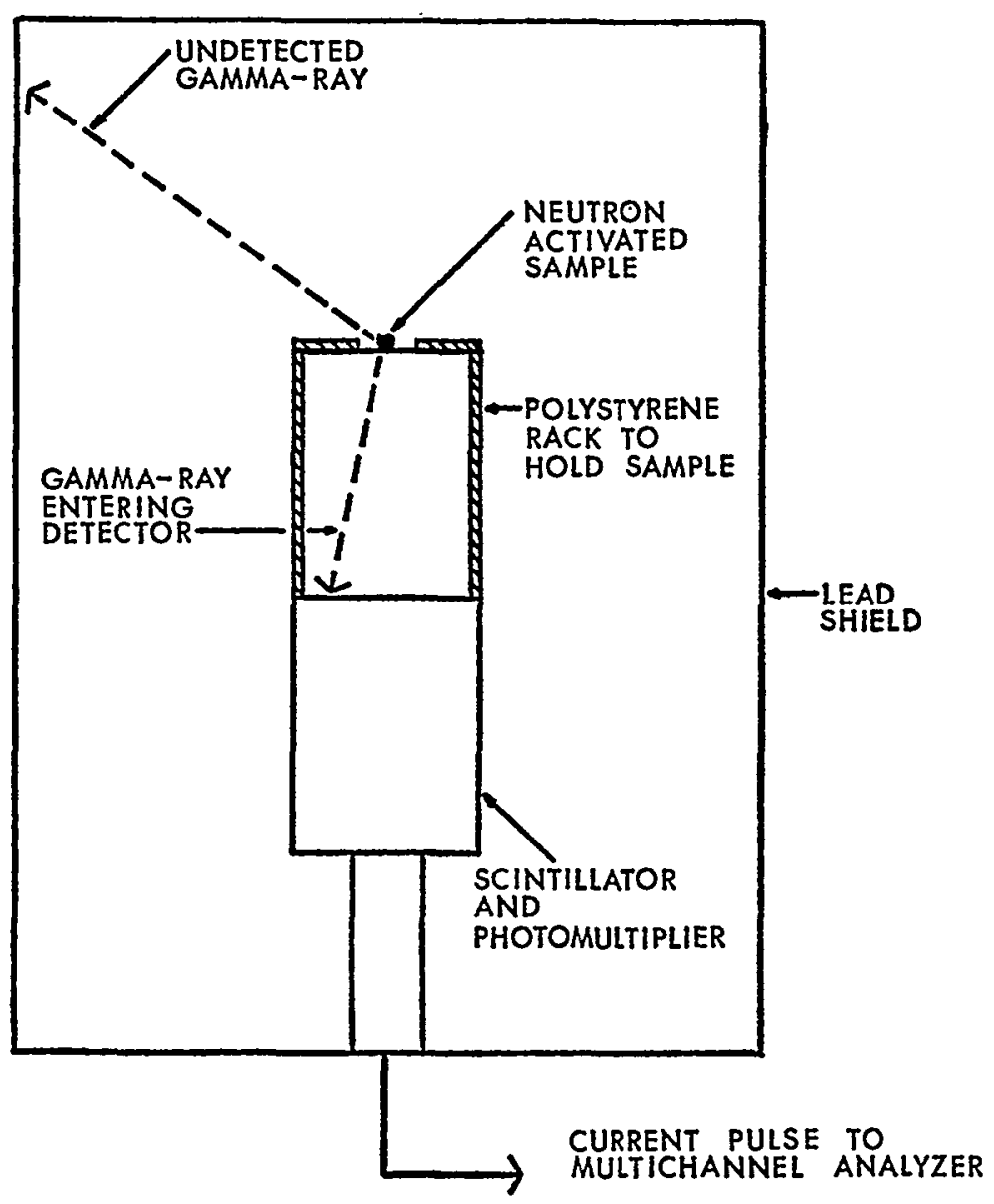

Figure 1. Typical Arrangement for Detection of Activated Sample. (Adapted from Guide to Activation Analysis by W.S. Lyon. Copyright (C) 1964 by Litton Educational Publishing Inc. Printed with permission of Van Nostrand Reinhold Company.)

The effect of the detection system's imperfect resolution ${ }^{31}$ is illustrated in Figure 2.32 A single radionuclide is present in the activated sample, and it emits gamma-rays each having an energy of $1.00 \mathrm{MeV} .^{33}$ If 300 of these gamma-rays enter the detector, an ideal system will

31. This discussion of imperfect resolution refers primarily to scintillation detectors, described in note 26 supra.

32. The actual numbers of gamma-rays shown in each channel in Figure 2 do not purport to be realistic.

33. $\mathrm{MeV}$ is the notation for the unit of energy "milhon electron volts." A single electron volt $(\mathrm{eV})$ is the energy an electron would gain by falling through a potential difference of one volt. Another common symbol is that for one thousand electron volts, $\mathrm{KeV}$. The gamma-rays encountered in activation analysis range from around a few tens of thousands of electron volts $(10-20 \mathrm{KeV})$ to over $4 \mathrm{MeV}$. 
record 300 counts in the channel which corresponds to $1.00 \mathrm{MeV}$ (channel 100 at $0.01 \mathrm{MeV} /$ channel $^{34}$ ). Figure 2 shows a nearly ideal system, in which 250 counts are recorded in channel 100 and 25 counts each are recorded in channels 99 and 101. (Note that the axis labelled "Gamma-Ray Energy in MeV" is greatly expanded, so that the zero of gamma-ray energy is far to the left, off the diagram.) A realistic detection system might give a result like the other curve in Figure 2, where the same 300 counts are spread out over many channels- 50 in channel 100, 40 each in channels 99 and 101,30 each in channels 98 and 102 , etc. It is apparent that a radionuclide which emits $0.99 \mathrm{MeV}$ gamma-rays would be difficult to distinguish from the actual radionuclide present, and unless care is taken by the analyst these two radionuclides could be mistaken for one another. ${ }^{35}$

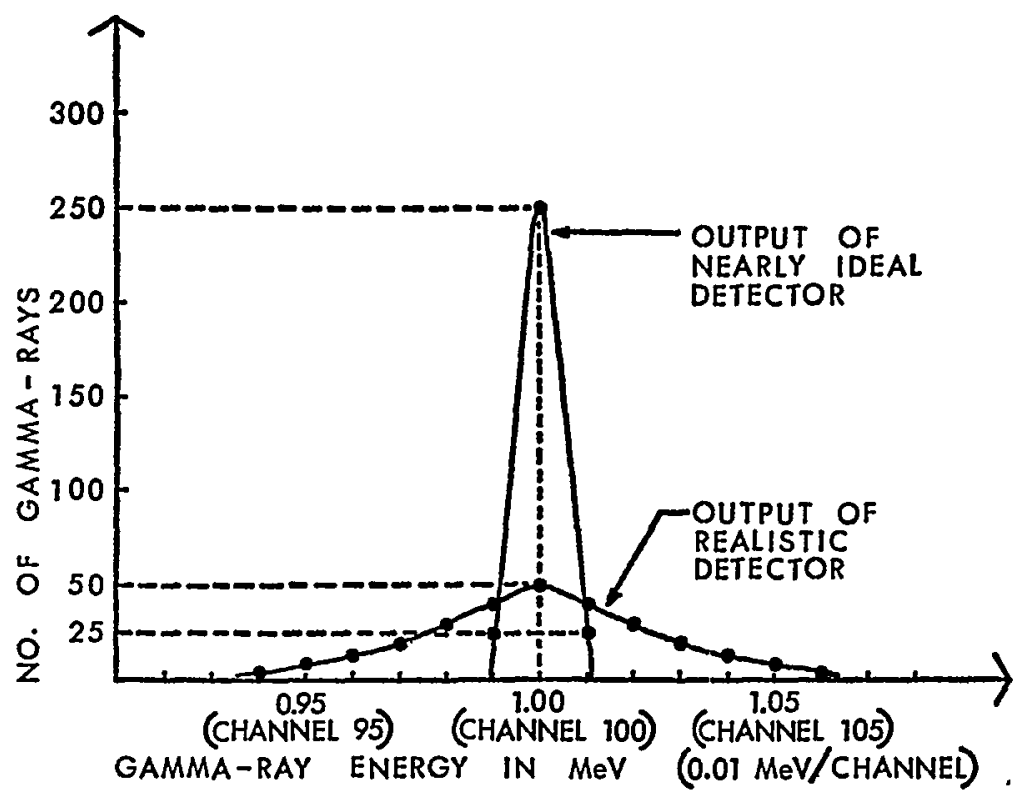

Figure 2. Comparison of the Resolutions of a Nearly Ideal Detection System and a Realistic Detection System. (Energy axis greatly expanded.)

A vast improvement in resolution has been achieved by the development of semiconductor radiation detectors. ${ }^{36}$ The difficulty with these devices, however, has been that they are less sensitive than the scintilla-

34. A detection system could be set up to count gamma-rays of any given energy range im any channel desired. A simple relationship (a 1:100 ratio) between the channel number and the energy range to which it corresponds is assumed here for convenience only.

35. For the ways to distinguish two such unresolvable radionuclides see the text accompanying notes $52-59$ infra.

36. See Goulding \& Stone, supra note 26; Lyon, Physical Techniques of Activation Analysis, in Nuclear Activation Techniques IN the Life ScIences 13, 23 (STI/ 
tors, ${ }^{37}$ requiring more of the radionuclide to be present before they can detect it. ${ }^{38}$ This can be a serious handicap in attempts to identify by trace element characterization, because the analyst wants to measure especially those elements present in very minute quantities. ${ }^{39}$ As the technology of semiconductors continues to develop, however, it is expected that there will be considerable improvement in their sensitivity, and with this, much of the resolution problem will be solved. ${ }^{40}$

The peak shown in Figure 2, centered on the energy of the emitted gamma-ray, is usually referred to as a photopeak, ${ }^{41}$ and the resolution problem involves the broadening of such peaks by imperfect detectors. Even if that problem is solved by advanced semiconductor detectors, however, the problein resulting from the fact that a detector does not register just a single peak, even when exposed to many identical gamma-rays, will remain. The actual graphical output of a detection system that is responding to a single radionuclide emitting nothing but $1.00 \mathrm{MeV}$ gamma-rays might appear as shown in Figure 3. Taken literally, Figure 3 would indicate that in addition to the $1.00 \mathrm{MeV}$ gamma-rays composing the pliotopeak, there are also approximately equal numbers of gamma-rays of all energies up to approximately 0.80 $\mathrm{MeV}$. Thus, the systein "detects" the presence of gamma-rays that are not even there. This is because not all of the gamma-rays that enter the scintillator are actually absorbed. Soine of thein are not detected at all and pass right through, very much as hight passes through glass. The

PUB/155, International Atomic Energy Agency 1967) [this volume hereinafter cited as LIFE SCIENCES].

37. See, e.g., Voigt, Becknell \& Menapace, Comparison of Solid State and Scintillation Gamma-Ray Spectrometry in Analysis, in 2 MODERN TRENDS IN ACTrvatToN ANALYsis 1035, 1035 (Spec. Pub. 312, National Bureau of Standards 1969) [these volumes hereinafter cited as MODERN TRENDS IN Actrvation ANALYSIS].

38. A long counting time will eliminate the statistical errors that would otherwise result from receiving only a few counts. See, e.g., V.P. Guinn, Forensic Neutron Activation Analysis, Oct. 1969, at 7 (Report No. GA-9677, Gulf General Atomic, Inc., P.O. Box 608, San Diego, Cal. 92112). But this may not be possible, or it may at best be very difficult. Voigt, Becknell \& Menapace, supra note 37, at 1035. See also Coleman, The Precision of Multi-Element Techniques in Activation Analysis, in 2 MOdern TRENDS IN ACtivation ANALYsis, supra note 37, at 1262, 1266.

39. See text accompanyimg note 3 supra.

40. Even now some scientists believe that the semiconductor detectors are vastly superior to the scintillator systems for almost all radionuchde detection measurements. W.S. Lyon, comments on the author's manuscript, Jan. 13, 1971.

41. It should be remembered that each channel has recorded a discrete number of pulses and that the total number of pulses due to the radionuchide which emits the $1.00 \mathrm{MeV}$ gamma-ray is the sum of the number of pulses in each channel. When the numbers for each channel are plotted on a graph and connected to make a smooth curve, as is usually done, it is the area under the curve (the photopeak) that is proportional to the number of gamma-rays. Thus, when analysts speak of "photopeak areas" they are referring essentially to the number of gamma-rays emitted by the radionuclide which produced the photopeak. 
more troublesome gamma-rays are those that give off only a portion of their energy to the crystal (the active part of the detector), by "glancing off" an electron, a process known as Compton scattering, ${ }^{42}$ and then pass completely out of the crystal without further detection. For these gamma-rays only the energy transferred to the electron is detected, and that can be any fraction of the original gamma-ray energy from zero up to some maximum value. ${ }^{43}$ This range of the graph, which is called the Compton distribution, ${ }^{44}$ is often not as smooth as shown im Figure 3, so the graph can get even more complicated.

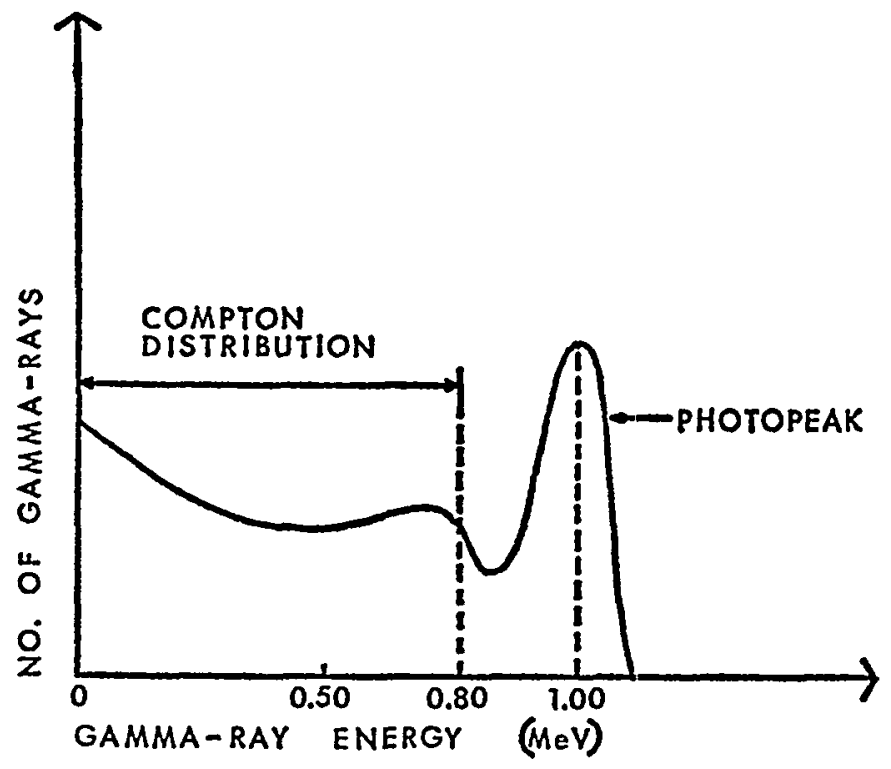

Figure 3. Gamma-Ray Spectrum of a Single Radionuclide Emitting a Single Gamma-Ray with an Energy of $1.00 \mathrm{MeV}$.

Frequently, superimposed upon the Compton distribution are "bumps" resembling minor photopeaks, which result from other types of interactions between the gamma-rays and the detector apparatus, both inside and outside the crystal. ${ }^{45}$ If a high-energy gamma-ray emitter is present in the material, its Compton distribution may "mask" the photopeak of a radionuclide which emits a lower-energy gamma-ray.

42. See Eldridge, supra note 26, at 89-91.

43. Id. It is, of course, possible that the Compton-scattered gamma-ray will be absorbed by the crystal before it can escape. This entire process happens so fast that what is detected in this case is simply a single pulse equal in height to the pulse resulting from a nonscattered gamma-ray.

44. Id.

45. Id. at 91-95. When a single radionuclide such as sodium, which emits two gamma-rays, is detected, the result is even more coinplex, despite the fact that only a single radionuclide is present. Such a result is shown id. at 95 . 
Conversely, one of the "bumps" in the Compton distribution can be mistaken for a lower-energy gamma-ray photopeak, in which case the analyst would conclude an absent radionuclide was present. ${ }^{46}$ An example of masking is shown in Figure 4. When a large number of radionuclides are present, the gamma-ray spectrum ${ }^{47}$ can become very complex indeed. ${ }^{48}$

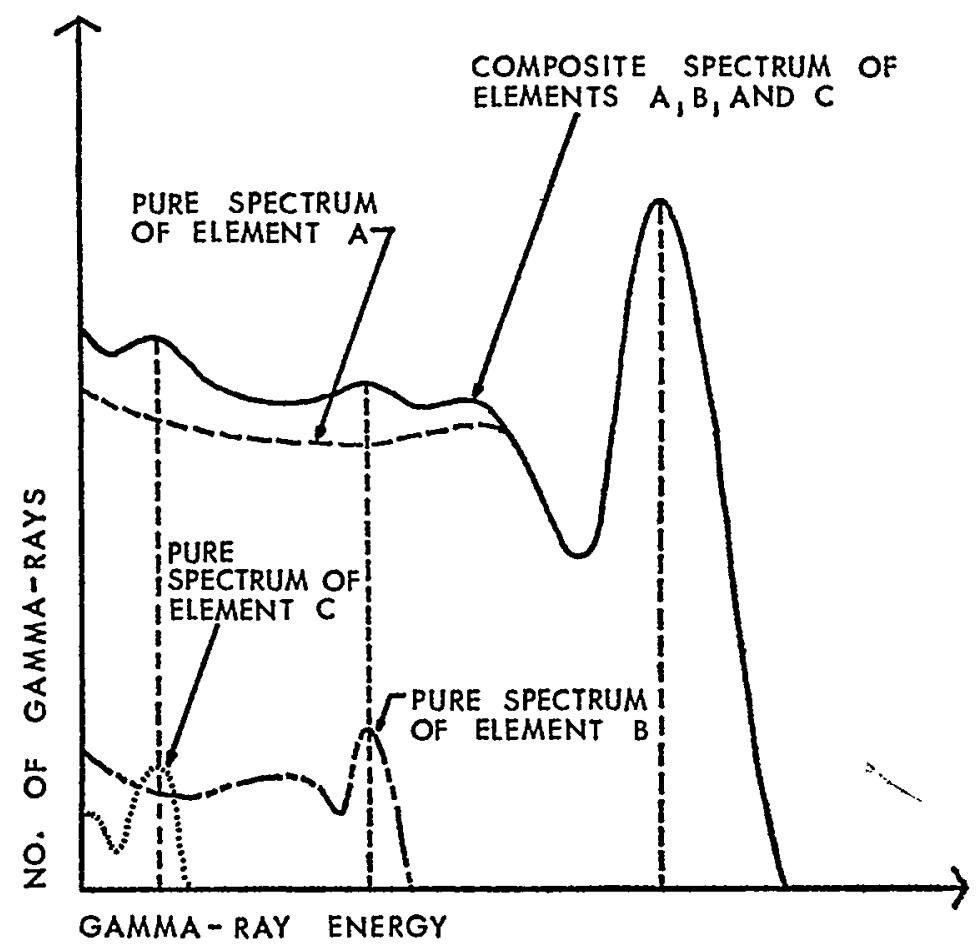

Figure 4. Composite Gamma-Ray Spectrum of Three Elements Showing the Masking Effect of a Relatively Intense High-Energy Gamma-Ray Emitting Radionuclide (Element $A$ ).

46. See, e.g., Perkons \& Jervis, Individualization by Neutron Activation Analysis, in 1 LAW ENFORCEMENT Science and Technology 257, 265 (Proceedings of the First National Symposium on Law Enforcenent Science and Technology 1967) [this volume hereinafter cited as LAW ENFORCEMENT ScIENCE and Technology].

47. Pictures such as that shown in Figure 4, essentially pictures of what the detecting system has recorded, are called gamma-ray spectra. In principle, they are supposed to show simply the number of gamma-rays emitted at each energy (or channel). However, because of the imperfect detection system discussed in the text, they also include additional undesirable features such as the Compton distributions of the various radionuchides present. These features often complicate the interpretation of the spectra, which in principle is aimed simply at determining how many gamma-rays were responsible for each of the various photopeaks.

48. Examples of gamma-ray spectra can be found practically anywhere in the literature on activation analysis. For a comparison of the gamma-ray spectra of semiconductor detectors and scintillators, see Perkons \& Jervis, Recent Forensic Applications of Instrumental Activation Analysis, in 1 MODERN TRENDS IN ACTrvation ANALYSIS, supra note 37, at 256; Goulding \& Stone, supra note 26, at 281. 


\section{Analysis of the Spectra}

a. Use of the half-lives. Knowledge of the half-lives of radionuclides is often a major factor $i m$ the interpretation of the spectra. As an illustration, in the example discussed in connection with resolution of the detector system, ${ }^{49}$ the analyst could measure the number of counts in the pliotopeak centered near $1.00 \mathrm{MeV}$ for various time periods of equal length ${ }^{50}$ but delayed from each other by some known time interval. If the radionuclide that emits the $0.99 \mathrm{MeV}$ gamma-ray has a lialf-life of, say, ten minutes while the radionuclide that emits the $1.00 \mathrm{MeV}$ gamma-ray lias a half-life of ten lours, the analyst can measure the number of counts in the pliotopeak a few minutes after the first spectrum is taken and again a few lours later. If the radionuclide present is the $0.99 \mathrm{MeV}$ emitter, the number of counts will have decreased by one-half after ten minutes, and will be virtually zero by the time several lours liave passed. On the other hand, if the $1.00 \mathrm{MeV}$ radionuclide is actually present, the rate of activity will be substantially unchanged after ten minutes, and half of the original annount will still be present after ten hours. Thus, different half-lives provide a means of distinguishing radionuclides which emit gamma-rays of nearly equal energies and of reducing masking problems. ${ }^{51}$

b. Radiochemical separations. If two radionuclides with nearly equal half-hives emit gamma-rays of nearly the same energy, it is usually necessary to get the two radionuclides physically (that is, spatially) separated before attempting the counting process. ${ }^{52}$ Sucl a separation is accomplished by ordinary cliemical means; it is possible because any chemicals necessary to the separation process but added after irradiation are not activated and therefore will not be observed by the detector. ${ }^{53}$ The radiocliemical approach is usually the most ac-

49. See text accompanying note 35 supra.

50. The information from this measurement is enough to determine the half-life of the emitting radionuclide. See note 21 supra.

51. Gamma-ray spectra taken at later times will always show peaks of lower heights, because some of the radiation lias died out. However, peaks due to shortlived radionuchdes die out faster than long-lived ones, so if the analyst is searching for the longer-lived nuclide, he can just wait until he knows any contribution from the shorter-lived one has died out. See note 61 infra.

52. Such separations are also necessary when the unknown contains large amounts of a slowly decaying radionuclide whose spectrum masks the gamma-rays from more significant elements, or when the concentration of a radionuclide that does not emit a gamma-ray must be measured. See, e.g., Ross, Radiochemical Separations, in GumE to Activation ANalysis, supra note 11 , at 55,55 .

53. The detector detects only the activated elements. Anything added by mistake later will not show up. See generally Guinn, Neutron Activation Analysis and Its Forensic Applications, in Proceedings of the First International Conference on Forensic Activation Analysis 7, 20-22 (Report No. GA-8171, Sept. 1966, Gulf General Atomic, Inc., P.O. Box 608, San Diego, Cal. 92112) [this volume hereinafter cited 
curate way of doing activation analysis, ${ }^{54}$ but it has a number of drawbacks: it is often much more costly; ${ }^{55}$ it is usually much more time consuming; $;^{56}$ and in order to perform the separations it is necessary to destroy the sample, ${ }^{57}$ so that it is not preserved for presentation in court $^{58}$ or for further testing by the adverse party. ${ }^{59}$

c. Instrumental activation analysis. Instrumental activation analysis is the name that is applied to analyses not employing any chemical separations. ${ }^{60}$ The analyst makes full use of his knowledge of the laalf-lives of the various radionuclides ${ }^{61}$ to simplify the spectra for

as Forensic Activation Analysis]. An example of the importance of this is given in Lenihan, supra note 19, at 322 (arsenic in hair is present in amounts about equal to the impurity amounts of arsenic in chemical reagents).

54. With all the other elements chemically removed, there is no danger that counts actually due to other radionuclides will mistakenly be imcluded in the calculation. It should be noted that the word "accurate" here refers to the determination of the elemental composition, in the sense that the experimental error is less. However, in the estimation of the various probabilities discussed in the later parts of this Comment, in which the NAA elemental composition measurement of a particular sample is compared against statistical background information based on measurements of similar materials, the experimental error usually enters only in an indirect way, and often the estimate of the probability will hardly be improved by further decrease in the experimental error. Therefore, the accuracy of these probability estimates usually cannot be attacked simply on the ground that radiochemical separations were not used. See note 265 infra.

55. See Wainerdi \& DuBeau, Nuclear Activation Analysis, 139 ScIEnce 1027, 1030 (1963), which points out the almost prohibitive cost of large-scale surveying by radiochemical uneans. However, a team of analysts in England is now using an automated technique for "group" radiocliemical separations and trace-element concentration measurements on glass. See G.C. Goode, G.A. Wood \& R.F. Coleman, infra note 312 , at 4 .

56. See Wainerdi \& DuBeau, supra note 55, at 1029.

57. This is not necessary in the case of purely instrumental activation analysis. See text accompanying notes 60-69 infra.

58. This can be important when the material being tested is evidence such as a strand of hair found at the scene of a crime. In other cases it is not so important. See text accompanying notes 436-37 infra.

59. Leaving this option open can be very important, if the measurement purports to be "scientific." See text accompanying note 185 infra.

60. Wamerdi \& DuBeau, supra note 55, at 1029.

61. The half-life is important in the activation process as well as in the decay process, because when a quantity of a particular element has been exposed to neutron irradiation for a time much longer than the element's half-life, it becomes "saturated" in the sense that it has as many radioactive atoms decaying in a given time as are created by the neutron flow. See Ross, supra note 14, at 8-9. On the other hand, when the irradiation time is much shorter than one half-life of a particular radionuchide, its level of activity will reach only a small fraction of its maximum. See id. and the example given id. at 11 . Therefore, when the analyst seeks to determine the presence and concentrations of as many elements as possible, he usually performs a number of irradiations and obtains gamma-ray spectra from each. The first irradiation will be on the order of seconds or minutes, and gamma-ray spectra are taken (that is, the gamma-rays are counted) after a few short periods of decay. The next irradiation is for an intermediate period, 30 minutes to an hour, and spectra are taken at inter- 
interpretation, but he is nevertheless often left with a rather complex spectrum from which he must determine the elements present. ${ }^{62}$

There are a number of ways instrumental activation analysis can be conducted, ${ }^{03}$ but they all depend basically on knowledge of the spectra produced by the pure or standard radionuclides. Often these standard spectra are stored in the memory of a computer, and a computer program is written which directs the computer to try various combinations of the standard spectra, corresponding to various amounts of the standard radionuclides thought likely to be present. The result of each combination is compared with the actual spectrum which has been obtained, and after running through the ranges of possibilities as instructed by the program, the computer tells the analyst which combination gives the closest "fit." ${ }^{4}$ The accuracy of this method obviously depends on the accuracy of the stored standard spectra. Errors will also result if the cliaracteristics of the detection system change between the time the standard spectra are measured and the time of the analysis in question, ${ }^{65}$ a very real possibility. ${ }^{66}$ Furthermore, additional errors can result if the analyst chooses too simple a model for combination and comparison by the computer with the spectrum under investigation. Oversimplifications such as mclusion of too few standard spectra can not only prevent detection of elements present in the sainple, but also may result in "detection" of an element that is in fact absent. ${ }^{\circ 7}$ Nevertheless, there is a wide range of circumstances in which instrumental activation analysis is feasible, ${ }^{68}$ and this method is usually

mediate decay times, after the shorter-lived radionuclides have died out. The last irradiation may go for many lours or days, and gamma-ray spectra from it are taken at very long decay times, days or weeks later. See V.P. Guinn, supra note 38, at 6 .

62. Using the procedure discussed in the previous note, the analyst sometimes seeks to detect the presence and concentrations of 15-20 elements. Id. This clearly leaves a sizable number of elements together in each spectruin.

63. See, e.g., Wainerdi \& DuBeau, supra note 55, at 1029.

64. A detailed discussion of the various ways of doing this is given in Gibbons, Computer Methods in Activation Analysis, in Activation ANaLYSIS PRINCIPLES AND APPLICATIONS, supra note 13, at 97.

65. Lenihan, supra note 19 , at 321.

66. This is true even if the unknown and the standards are irradiated together, as is almost always the case since the analyst wants both to be exposed to the same number of neutrons. See text accompanying note 24 supra. The unknown and the standards cannot be counted at the same time, because the detector has no way of separating the gamma-rays of one from those of the other. The general problem of the drift of detector-system claracteristics is discussed in Gibbons, Scintillation Spectrometry, in Activation Analysis Principles and Applications, supra note 13, at 27, 34-37.

67. See National Bureau of Standards, U.S. Dep't of Commerce, Summary of Activities of the Radiochemical ANalysis Section, July, 1968 to June, 1969, at 52-59 (NBS Technical Note No. 501, 1970).

68. In an international conference on forensic activation analysis, the proceedings 
the choice in forensic applications because of the speed and ease of the analysis and because it preserves the sample. ${ }^{69}$

\section{Advantages and Limitations of NAA}

\section{Sensitivity}

Sensitivity refers to the minimum amount of an element that a technique is capable of detecting. Although the amount of a given element that can be detected by neutron activation analysis depends on many variables, ${ }^{70}$ some rough estimates of interference-free sensitivities have been made. There are 76 elements that can be determined in the microgram $\left(10^{-6}\right.$ gram $)$ range, with many capable of detection in much smaller quantities. ${ }^{71}$ NAA can often detect amounts 100 or 1,000 times smaller than the minimum detectable by other methods, and in some instances the minimum amount detectable by NAA is one million times smaller. ${ }^{22}$ It is this tremendous sensitivity that makes NAA especially useful for elemental analysis of very small quantities of materials, such as a single hair ${ }^{73}$ or a speck of paint, ${ }^{74}$ and for small traces of elements in larger pieces of material.

NAA is also an accurate method of analysis. When elements are present in amounts well above the limit of detection, the analysis

of which are cited note 53 supra, only one paper was presented which described the use of radiochemical separations in forensic-NAA studies. V.P. Guinn \& R.H. Pinker, The World-Wide Status of Forensic Activation Analysis, Feb. 1967, at 18 (Report No. GA-7688, Gulf General Atomic, Inc., P.O. Box 608, San Diego, Cal. 92112). This is undoubtedly largely due to the need to obtain vast amounts of statistical background information in order to evaluate the probative force of a coinparison of activation analyses of two different materials for identification purposes. See part III infra. But cf. note 55 supra.

69. Normally only a sinall fraction of each elennent gets activated, so when all the induced radioactivity dies out, it is in essentially the same form as before activation. See, e.g., Wainerdi \& DuBeau, supra note 55, at 1027. But hairs become brittle if they are activated too long. A.W. Forslev, 'Nondestructive' Neutron Activation Analysis of Hair, 11 J. For. Scr. 217, 222-29 (1966).

70. Soine elements are less sensitively detected than others because they have a low probability of neutron absorption, so they are hard to make radioactive in sufficient quantities for detection unless a sizable amount is present. Others have such a long halflife that counting times required would be prohibitively long unless a sizable amount is present. Other variables are under the control of the analyst, such as the irradiation time and the decision whether to make a radiochemical separation. See generally Lenihan, supra note 19, at 314-18.

71. A table of interference-free sensitivities is given in Guinn \& Lukens, supra note 11 , at 345 .

72. Lenihan, supra note 19, at 309.

73. On the legal interpretation of activation analyses of hair, see text accompanying notes 235-309 infra.

74. A case involving specks of paint is discussed in detail in the text accoinpanying notes $96-130$ infra. 
can be done to an accuracy of about 2 percent and is normally in the $2-5$ percent range. ${ }^{75}$

\section{Errors}

There are a number of possible sources of error in an activation analysis, and the analyst must be sufficiently skillful in the technique to be aware of these possibilities and handle them properly. ${ }^{70}$ If the sample contaims appreciable quantities of an element that has a high probability of neutron absorption, that element may absorb so many neutrons that the rest of the unknown is not activated as much as expected. ${ }^{77}$ If the unknown material is large in size some of the gammarays it emits may be reabsorbed by other atoms in the sample itself, permitting fewer gamma-rays to reach the detector than are emitted in its direction. ${ }^{78}$ The problem of uneven neutron flow inside the reactor ${ }^{79}$ and the need for the unknown and the standards to have the same size and shape ${ }^{80}$ have already been discussed, as has the problem of an unstable detection system. ${ }^{81}$ In taking gamma-ray spectra the analyst must record sufficient counts for the measurement to be statistically meaningful. ${ }^{82}$ Further complications can arise when two radionuclides are present that emit gamma-rays of very nearly equal energies, ${ }^{83}$ when minor spectral peaks present in the Compton distribution of one element can be mistaken for photopeaks ${ }^{84}$ of another element, ${ }^{85}$ and when the radionuchide being measured is also created via processes other than smiple neutron absorption by the stable isotope of the same element. ${ }^{80}$

With its great sensitivity, NAA can easily detect the presence of dirt or other contamimants added to a sample before irradiation, and

75. Wahl \& Kramer, supra note 11 , at 78-79. These estimates may be slightly optimistic, however. W.S. Lyon, comments on the author's manuscript, Jan. 13, 1971.

76. See Guinn \& Lukens, supra note 11 , at 347.

77. Id.

78. Id. at 348. This is usually a very minor problem. W.S. Lyon, comments on the author's manuscript, Jan. 13, 1971.

79. See note 24 supra.

80. See text accompanying note 28 supra.

81. See text accompanying notes 65-66 supra.

82. Guinn \& Lukens, supra note 11 , at 349-50.

83. Id. at 351.

84. It is the photopeak that is used to detect the presence and concentration of the radionuclide. See note 41 supra.

85. Guinn \& Lukens, supra note 11 , at 352 .

86. Guinn \& Lukens, supra note 11 , at 354-55. For example, some radionuclides emit protons or positrons so that the atomic number drops one unit upon decay. The result can be the same radionuclide that is formed when the next lower element in the periodic table absorbs a neutron. 
this would lead to erroneous results. ${ }^{87}$ Therefore, the analyst must be trained not only in the methods of NAA itself but also in the fundamentals of microchemistry so that he does not add trace impurities. ${ }^{88}$ In forensic cases, the samples are usually handled by other people before they reach the analyst, and he often needs to know the state of the sample when discovered and its subsequent handling. ${ }^{89}$ If two unknowns that are compared to determine whether they came from a common source have both been contaminated in a similar way, it is clear that completely false poimts of similarity can result..$^{90}$ Conversely, contamination of only one of the samples can lead to a false conclusion that the two came from different sources.

II

\section{EVALUATING THE EvidENCE}

As indicated in part $I$, the result of the subjecting a piece of material to neutron activation analysis is that the material is found to contain certain elements in the measured concentrations, within experimental error. ${ }^{91}$ The next step is to determine the relevance this result has to the legal issues in the case at hand. Broadly speaking, NAA can have significance in two ways. Sometimes the legal issue depends directly on the amount of a selected element in the material..$^{22}$ For example, if the question is whether a particular death was due to arsemic poisoning, the activation analyst might measure the amount of arsenic in the victim's hair or in other tissues, and if the anount exceeds the normal amount by a considerable value, then death by arsenic poisoning has a high probability. ${ }^{93}$ In other cases the legal issue is whether a given piece of evidence came from a particular source-the identification problem. ${ }^{94}$ For example, a hair found on the body of a

87. This is one of the more common causes of error in activation analysis. Howie \& Smith, Mercury in Human Tissue, 7 J. For. ScI. Soc'y 90, 91 (1967). Postirradiation contamination does not affect the analysis [see note 53 supra and accompanying text], although it would clearly have an effect on any subsequent analysis.

88. Lyon \& Miller, Forensic Applications of Neutron Activation Analysis, 4 ISOTOPES \& RADIATION TECHNOLOGY 325, 330 (1967).

89. Schlesinger, Lukens \& Settle, The Examination of Actual Case Evidence Samples by Neutron Activation Analysis, in 1 MODERN TRENDS IN ACTNATION ANALYSIS, supra note 37 , at $265,271$.

90. The first part of the identity problem involves comparing two samples for a "match" between their respective trace element concentrations. See parts II and III infra.

91. See text accompanying notes 8-9 supra.

92. Cases of this type are discussed in part IV infra.

93. Application of NAA to toxicology is discusscd in the text accompanying notes 440-61 infra.

94. The identification problem is discussed generally in part $\Pi$, and detailed 
murder victim might be compared in its trace element concentrations to the hairs of a suspect. Then the crucial question is the degree to which the comparison singles out the suspect as the guilty party. ${ }^{95}$

In neither of these cases is the NAA evidence sufficient in itself; additional data are needed to evaluate the significance of the chemical analyses done by neutron activation techniques. In the first case it is necessary to know the normal amount of arsemic in the tissue or hair measured. More precisely, knowledge of the distribution of arsenic concentrations in hairs of the living general population is required so that one can calculate the probability that a person chosen at randoin would have an arsenic concentration equal to what was measured in the tissue or hair of the deceased. In the second case more information is needed to determine llow much more likely the hair found on the victim is to have come from the suspect than from a person chosen at random from the general population.

Although the detailed considerations are quite different in the different types of cases, the analysis in each instance depends on the existence of sufficient background information with which the evidence at hand can be coinpared; only then can the evidence be properly interpreted. Parts III and IV consider what kind of background information is needed in particular cases and how the evidence should be interpreted in the liglit thereof. This part considers some of the more general aspects of NAA evidence, particularly its application to the identification problem.

\section{A. An Example}

People v. Woodward ${ }^{06}$ provides an example illustrating many of the considerations necessary to the proper use of NAA evidence.

\section{The Fact Situation and the Trial}

In response to a silent burglar alarm, the police arrived at the scene of an attempted burglary about $1 \mathrm{a.m}$. and found the suspect Woodward not far from the door which a burglar attempted to open. ${ }^{07}$ Woodward said he had just happened by and was on the way to his car

consideration is given to the problem of matching various specific materials by trace element characterization in part III.

95. The problem of hair natching is discussed in the text accompanying notes 235-309 infra.

96. No. 108551 (Cal. Super. Ct., San Mateo County, July 7, 1964). The trial record of this case has not been transcribed. However, it is discussed in Guinn, Recent Developments in the Application of Neutron Activation Techniques to Forensic Problems, 4 J. For. SCr. Soc'x 184, 187-88 (1964) and in J. THORWald, Crume AND SCIENCE 450-51 (1966). A very brief discussion may be found in TIME, Aug. 7, 1964 , at 58.

97. Guinn, supra note 96 , at 187. 
which was parked nearby. ${ }^{98} \mathrm{~A}$ tool used for changing tires was found several feet from the doorway. ${ }^{99}$ Upon inspection of Woodward's car it was discovered that the tire tool was missing from the jack im his trunk and that the tool found near the doorway fit the jack; however, Woodward denied that the tool was his. ${ }^{100}$

Some specks of brown paint were found on the wedge end of the tire tool and a few specks of hight-blue paint were found adhering to the shaft. Visual comparison of the paints indicated that the brown specks reseinbled the paint on the doorway and the light-blue specks resembled that of Woodward's car. ${ }^{101}$ Other specks of light-blue paint were found on the floor of the car trunk, and because of the very sinall amounts of the paint on the tire tool ${ }^{102}$ NAA appeared to be the best method of chemical analysis. ${ }^{103}$ The brown paint on the tool was found to match the brown paint of the door in seven elements; no element was found in one that was not found im the other and the concentrations were the same within sinall statistical limits. ${ }^{104}$ The lightblue paint on the tool similarly matched specks found in the trunk of Woodward's car, except that only five elements were detected in each. ${ }^{105}$

Earher studies in the same laboratory that performed the analysis on the evidence specks had indicated that two similar-type paints of similar color but of different brands would contain a given element in concentrations within 10 percent of each other only about one time in five. If one assumes that the chance of finding a given anount of one element is independent of the amounts of any other elements present, ${ }^{100}$ then the chance that two similar-type paints of similar color but of different brands will match concentrations within 10 percent in eacl of five elements is $(1 / 5)^{5}$-one chance in 3,125 or 0.03 percent. Similarly, the chance of inatching in seven elements is about one in 100,000 or 0.001 percent. ${ }^{107}$ This evidence was presented at trial and the defendant was convicted. ${ }^{108}$

98. J. THORWALD, supra note 96 , at 451 .

99. Guinn, supra note 96 , at 187.

100. Id.

101. Id.

102. The specks on the tire tool weighed from 10 to 50 micrograms. Id.

103. Id.

104. The seven elements found were manganese, sodium, antimony, zinc, indium, aluminum, and titanium. Some of these were major constituents, some minor components, and some trace impurities. Id. at 187-88. This might have a bearing on the assumption of statistical imdependence of the elements. See notes 377-79 infra and accompanying text.

105. The five elements were titanium, aluminum, sodium, copper, and manganese, again ranging in amounts from major constituents to trace impurities. Id. at 188.

106. This assumption should never be made without careful investigation. See note 296 infra and accompanying text.

107. Guinn, supra note 96 , at 188.

108. Id. 


\section{Interpreting the Evidence}

Postponing discussion of the difficulties in making a probability calculation of the type used in Woodwdrd, ${ }^{109}$ we here assume that the probabilities stated are valid and ask what they mean. Since in the actual case the defendant denied that the tire tool was his, discussion can be simplified by assuming that the tool was, in fact, used by the actual burglar, thereby eliminating the need to evaluate the brown paint comparison.

The light-blue paint comparison indicates that if 10,000 hightblue cars which are painted with a brand of paint different from that of the defendant's car are chosen at random, then only three of them will be found to match the paint on defendant's car within 10 percent in all five elements. ${ }^{110}$ If this were the only consideration, and if it could be slrown that far fewer than 10,000 light-blue cars, all painted with brands of paint different from that used on defendant's car, could conceivably have been the suppher of the tire tool, then the evidence against the defendant is quite powerful. On the other hand, if more than 10,000 light-blue cars might have been involved, there are three in each 10,000 that would give the sane activation analysis results when compared with the specks on the tire tool as the defendant's car did.

There is a much more important consideration, however. Even if the activation analysis could positively identify the brand of paint, that is, even if it were 100 percent certain that the specks of paint on the tire tool were of the same brand as the paint on defendant's car, the NAA evidence in itself still does no more than reduce the number of possible culprits to those owning or somehow associated with lightblue cars painted with that brand of paint. Therefore, the NAA evidence only poimts up the defendant as being a meinber of a restricted subclass of the general population. That the defendant is singled out only as a member of a restricted subclass is a typical result of NAA evidence, ${ }^{111}$ although the size of the subclass varies greatly with the type of thing being compared. ${ }^{112}$ Before the NAA evidence can be meaningfully evaluated, it is necessary in each case to determine the size of the subclass. If, for simplicity, it is assumed in the actual Woodward case that the car which supplied the guilty tire tool came

109. See notes 367-81 infra and accompanying text.

110. See text preceding note 108 supra. A chance of one in 3,125 means three chances in 9,375 or roughly three in 10,000 .

111. See parts III and IV infra.

112. Part III is in major part a discussion of how to calculate the size of the subclass for a variety of materials. 
from the metropolitan area where the crime occurred, ${ }^{113}$ then the number of cars in the subclass of which Woodward's car was a member (those cars whose paint match the specks found on the tire tool in the way his car's paint did) is the number of liglit-blue cars in the metropolitan area which were painted with the same brand of light-blue paint plus 0.03 percent of the total number of other lightblue cars in the area. ${ }^{114}$ This number could be moderately large if the manufacturer of Woodward's car used the same brand of light-blue paint on many models, especially if the same brand were used for a period of years, ${ }^{115}$ or if the other manufacturers used the same brand of paint, or simply if there were many light-blue cars in the area.

\section{Relationship to the Reasonable Doubt Standard}

It is important to distinguish the probabilities that arise in activation analysis from general notions about the probability that a defendant is guilty. A 99.97 percent probability that a defendant is guilty might mean to many people that, in 9,997 trials out of every 10,000 which appear similar to this one, the defendant is actually guilty. ${ }^{110}$ Contrast this to the 99.97 percent probability that the brand of paint on the tire tool in the Woodward case was the same brand as the paint on Woodward's car. ${ }^{117}$ If there are 100 cars in the metropolitan area which are painted with that brand of paint, ${ }^{118}$ the NAA evidence, by

113. In principle this assumption is not necessary, but it avoids the need to estimate the probability that a crime of this type was committed by a person from the metropolitan area as opposed to a person from outside that area, and it is valid if the former probability is very much greater than the latter. Presumably, there will be very many more cars with the brand of paint in question belonging to owners who live outside the area, but if the probability that any one of those owners committed the crime is very mucl sinaller than the probability that an owner living inside coinmitted it, the size of the subclass is not affected very inuch. If the assumption is invalid, the size of the subclass must be calculated by adding the product of the probability that an owner living outside committed the crime multiplied by the number of cars belonging to outside owners to a similar product for owners living inside the area.

114. This is because every car with the same brand of paint as Woodward's will give the saine results as Woodward's car did, and three other light-blue cars out of 10,000 chosen at random will do so also. See note 110 supra.

115. Evidence that the composition of a given brand varies with time might provide a basis for cutting down the size of the subclass. In the absence of evidence to the contrary, however, it must be assumed that a given brand retains its composition over the years. For an example of a given manufacturer's glass which maintained a constant composition over a period of at least four years, see text accompanying notes 316-18 infra.

116. This is similar to the definition of the "subjective probability of guilt" given in Finkelstein \& Fairley, A Bayesian Approach to Identification Evidence, 83 HARv. L. Rev. 489, 504 (1970).

117. Guinn, supra note 96 , at 188 . See also text accompanying note 107 supra.

118. This figure does not purport to be realistic. The correct figure would re- 
itself, does not generate nearly the same degree of belief in the defendant's guilt. In fact, if the jury convicted on this evidence alone, they would be wrong 99 percent of the time. ${ }^{110}$ Therefore, it is extremely important that these differences be made clear to the trier of fact.

It appears that this was not done in the actual Woodward case. Although the trial record has not been transcribed, Time magazime ${ }^{120}$ reported the expert witness to have testified that it was " $99.98 \%$ [sic] certain" that the tire iron came from Woodward's car and "99.999\% certain" that it was used to jimmy the door. If the witness actually said this it should be clear that his testimony was totally unfounded and highly prejudicial, because the NAA measurement was not capable of singling out the defendant so unambiguously. In any event, that the reporter for Time thought the expert said this lends credence to a belief that the jury might have thought so also. Therefore, it is doubtful that the correct interpretation of the evidence was made clear to the jury.

Commentators have proposed a method permitting the trier of fact to properly relate statistical evidence of this type to the other evidence in the case. ${ }^{121}$ The jury first estimates the probability that the defendant is guilty given all the evidence in the case except the statistical evidence. They are then shown a table, based on a mathematical theorem, which tells them how much they should increase their assessment in the light of the statistical evidence. ${ }^{122}$

In the Woodward case, for example, the jury would estimate the probability of defendant's guilt in view of the evidence that he was found at the scene of the crime alone at 1 a.m., that the tire tool was found nearby with brown and blue paimt specks on it, that the tire tool was missing from Woodward's car, that his car was similar in color to the blue paint specks, that similar paint specks were found in the trunk of his car, and so forth, but the NAA evidence would be excluded. ${ }^{123}$ From the statistical evidence one then calculates the prob-

quire more data on the number of light-blue cars as well as the number of light-blue cars with the particular brand in question and would be calculated by the method discussed in the text accompanying note 114 supra.

119. The NAA evidence points up only a restricted subclass, in this case an assumed group of 100 cars. The NAA measurement tells us no more than this, so that measurement alone leaves all 100 members of the subclass equally suspect. Since defendant is only one of the 100, singling him out on the basis of the NAA results alone will be wrong 99 times out of 100 .

120. TIME, Aug. 7, 1964, at 58.

121. Finkelstein \& Fairley, supra note 116, at 502.

122. Id. at 500 .

123. In principle, the iury can be told the results of the measurement on the car paint and on the specks found on the tire tool, but they are not allowed to use the fact that they "match" to increase their estimate of the prior probability. The probative value of the "inatch" is what is given by the statistical evidence. 
ability that specks of blue paint of that type would have been found on the tire tool given that the tire tool came from a light-blue car other than the defendant's. This probability is the ratio of the number of cars in the restricted subclass (besides the defendant's) to the total number of lightblue cars in the area. ${ }^{124}$ The point of the table corresponding to the combination of this probability with the jury's prior assessment of defendant's guilt reveals how much their assessment should be imcreased. For example, if 9.97 percent of the light-blue cars in the area were painted with the same brand of paint as Woodward's car (so that the subclass is 10 percent of all hight-blue cars), and if the jury's degree of behef in the defendant's guilt is 75 percent in the absence of this statistical evidence, their new estimate of the probability of guilt is found by reference to the table to be 96.7 percent. Thus, assuming the jury's initial assessment of the probability is correct, ${ }^{125}$ instead of having one innocent man among every group of four such defendants, the statistical evidence ensures that the innocent will coinprise only about one out of every 30 .

There are obvious problems with this approach. Although obtaining fairly rehable estimates of the number of cars in a given area which are painted with the same brand of paint should not be an insurmountable barrier, ${ }^{126}$ this approach also demands that the jury quantify its prior degree of behief in the defendant's guilt. The jury is thus called upon to quantify subjective estimates essentially without guidelines, and they must do this while ignoring some of the evidence. There is no way to ensure that they go about this in a proper way. ${ }^{127}$

Perhaps a sinipler approach is to tell the jury that, if they accept

124. The assumption that the specks were automobile paint, and the fact that they were light-blue in color underlies all of the probability evidence in this case. Even the original probability calculation was predicated on data for automobile paints of similar type and color. See text following note 105 supra. Therefore, one assumes that the tire tool came froin a light-blue car and only light-blue cars enter into the calculation. If there were a chance that the paint specks were not automobile paint, either all the calculations would have to be revised to include the other possibilities or the jury would have to be told that, if they believed the specks were not automobile paint, they should disregard the probability evidence altogether.

125. The subjective probability of guilt defined in Finkelstem \& Fairley, supra note 116 , refers to the number of times a defendant actually is guilty whenever the evideuce generates the same degree of belief in his guilt. It is in this sense that the word "correct" is used here. The jury can never know the true subjective probability of guilt as defined by these commentators; it can only render its own assessment of it.

126. This assumes the manufacturers keep records of the brands of paints they use aud that different asseinbly plants use the same brands of paint on similar cars. If this is true, the estimates could be obtained by a straightforward counting survey.

127. The problem is somewhat akin to the procedure ruled unconstitutional in Jackson v. Denno, 378 U.S. 368 (1964), which allowed a jury to hear a defendant's confession as well as evidence that it was involuntary, and, if the jury found the confession was involuntary, it was to ignore the confession. 
the NAA evidence, they should consider the other evidence against defendant in the light of a restricted number of possible suspects; the guilty party is assuined to come from the restricted subclass. Thus, in Woodward, the jury could have been told that there were, say, 100 cars in the San Francisco Bay area ${ }^{128}$ which could have supplied the tire tool, and that the defendant's car was one of them. They can be reminded that the only significance of the NAA evidence is its indication that the defendant owns a car in this group of 100 cars, any one of which could have been used in the crime. The nonstatistical evidence should then be considered as singhing out, if it is sufficiently persuasive, the defendant from the people associated with the other 99 cars. ${ }^{129}$ In a case like Woodward, where the other evidence against the defendant is so strong, the jury should not have much trouble finding him guilty. On the other hand, the prosecution's case would be quite weak if, for example, Woodward had been picked up the next day at his home and the only evidence against him were that provided by NAA and perhaps his failure to produce a verifiable alibi. Here, the defense attorney could point out to the jury that anyone who lives alone and who was sleeping at the time of the crime might well not be able to verify that fact, so that the evidence against the defendant is little stronger than against any other member of the subclass (those who had access to cars with paint similar to defendant's) chosen at random. ${ }^{130}$ When the strength of the other evidence is somewhere in between, assistance can still be given to the members of the jury by discussion of these two polar examples.

\section{B. The Expert Witness}

\section{Objective Versus Subjective Opinion}

A leading cominentator has stated that expert opinion is appropriate "when the facts can be interpreted and conclusions be drawn only by a person having technical qualifications or special opportunities for knowledge not possessed by the average layman."131 Soine cases involve questions that are capable of reasonably precise defimtion and to which the expert can give firm, objective answers, includ-

128. This figure, again, does not purport to be realistic. See note 118 supra.

129. Except in unusual cases, the identity of the other members of the subclass will not be known. To find them it would be necessary to run NAA tests on all the light-blue cars in the area. Therefore, there will usually not be any additional evidence against the other members of the class.

130. When the evidence is this weak, the case probably slould not even go to the jury if the subclass has at least one member in addition to the defendant.

131. Werne, Foreword to H.W. Rogers, The LAW of ExPERT Testrmony, at $v$ (3d ed. B. Werne 1941). 
ing most particularly the limitations on his conclusions. In other types of cases, the expert may have to rely mainly on the depth of his general background in the subject, and he nnay not be able to articulate the precise foundations for his conclusions or the limitations thereon. ${ }^{132}$ Evidence derived from activation analysis provides a good example of the former type of expert opinion, and it is useful to compare this type of evidence with that produced by experts in such areas as fingerprints, handwriting, and firearms identification, all of which are examples of the latter.

Identification by trace element characterization rests on the hypothesis that inaterials of similar type but which derive from different sources ${ }^{133}$ (for example, two hairs, two pieces of glass, two blood samples) will usually be sufficiently different in their minute concentrations of trace elements that they can be distinguished, at least to sone extent. Thus, a "inatch" by NAA may tend to show that they come froin a common source. Similar considerations are involved in the other types of identification procedures. For example, the fingerprint expert compares types of characteristies, such as ridge endings and bifurcations, and their locations, and depending on the number of points of agreement he draws conclusions as to whether identification has been established. ${ }^{134}$ Similarly, the handwriting expert compares peculiarities of letter formation and the firearms expert coinpares such things as the rifling inarks on the bullets fired by a given gun. ${ }^{135}$ Yet these latter procedures differ in a fundamental way from a coinparison of the results of an NAA measurement: the characteristics which are compared are not amenable to what has been called a total-ordering. ${ }^{136}$

Basically, totally-orderable data is siniply that which can be catalogued in a systematic manner. If the results of measurements on a true random sample are thus catalogued, ${ }^{137}$ it is easy to calculate the probability that a particular ineasureinent will "inatch" froin a randoin

132. See the comparison of the testimony of an orthopedic surgeon in a personal injury suit and that of a psychiatrist in a murder trial in Diamond \& Louisell, The Psychiatrist as an Expert Witness, 63 Mich. L. Rev. 1335 (1965).

133. See text accompanying note 3 supra. In using NAA it is always crucial to be very clear as to what is meant by the "saine source." Recall in the Woodward case that the source defined by the NAA expert was the same brand of paint, not, for example, the same car. For other source-definition problems see text accoinpanying notes 312-22 infra (glass), notes 343-66 infra (soil), notes 388-95 infra (alcohol), and notes 405-32 infra (other miscellaneous materials).

134. Osterburg, The Evaluation of Physical Evidence in Criminalistics, in LAW ENFORCEMENT SCIENCE AND TeCHNOLOGY, supra note 46, at 419, 420-21.

135. Id.

136. Kingston, Statistical Concepts in Evidence Evaluation, LAw ENFORCEMENT SCIENCE AND TEChNology, supra note 46 , at $437,438-39$.

137. In some cases a partially nonrandomized sample is appropriate. Kirk \& Kingston, Evidence Evaluation and Problems in General Criminalistics, 9 J. FOR. SCr. 
choice by finding the number of measurements on the random sample which gave the same results and taking the ratio to the total number of measurements in the sample. ${ }^{138}$ Comparison techniques which are not amenable to total-ordering are necessarily somewhat subjective, at least in the sense that adequate criteria do not exist which would permit the expert to articulate the precise foundations for his conclusion that a "match" exists or that there is a certain probability of identity. Thus, one expert may feel that a positive result is established while another feels equally strongly that the same evidence does not warrant such a conclusion. ${ }^{139}$ These identifications thus depend on the "intuitive ability" and "common sense" of the expert. Numerous authors have called for more recognition and investigation of the logical processes which lie behind these methods, ${ }^{140}$ but it is not the purpose of this Comment to weigh the conflicting factors involved in the evidentiary use of such subjective procedures. The different considerations involved in the use of NAA evidence, however, are crucial. In the first place, the quantitative values of element concentrations and their respective experimental errors ${ }^{141}$ determmed by activation analysis do lend themselves well to total-ordering. ${ }^{142}$ Therefore, it is always possible, at least in principle, to build up the background data required to

434, 440 (1964). As to what constitutes an appropriate sample in hair comparisons by NAA, see text accompanying notes 271-80 infra.

138. Fingerprints provide an example of nontotally-orderable data. Although claims have been inade to the effect that millions of fingerprints have been compared with no two found to be identical [M. Houts, From Evidence to Proof 133 (1956)], other commentators lave questioned whether the number of direct fingerprint comparisons is as large as most people think. Kingston, supra note 136, at 440 . It is very time consuming to make such comparisons because there is no truly systematic way to go about it. Id. This is probably a major reason for the disagreement as to the number of points that inust "1natch" before identity is positively established. Sce M.K. Mehta, The Identification of Thumb Impressions and the Cross Examination OF FINGER PRINT EXPERTS 28 (1963), quoted in Osterburg, supra note 134, at 421. Similar problems arise in handwriting and bullet comparisons. The quotations in Osterburg [id. at 421-22] illustrate the nonobjective character of these and other types of identification procedures.

139. Kirk, Analytical Treatment of Evidence Statistics, LAW ENFORCEMENT SCIENCE AND TeChNology, supra note 46 , at $431,431$.

140. In addition to the sources cited in notes 134, 136, and 139 supra, see Kind, The Nature of the Process of Identification, 4 J. For. ScI. Soc'Y 162, 166 (1964).

141. Part $I$ of this Comment discusses the results of a single activation analysis measuremeut. See also Guinn, supra note 6, at 507.

142. Kingston, supra note 136, at 441 . This is because the results of NAA are thennselves expressed in numerical amounts. The graphs shown in the discussion of hair coinparisons [Figures 5(a) and 6(a) accompanying notes 253-59 infra] are essentially total-orderings of the results of measurements for that element (called element $A$ ), and the eleinents themselves are easy to order because they are uuambiguously defined and there are only about 100 of them. Contrast this with the essentially infinite number of ways one can deviate from the "normal" way of writing a given letter, for example. 
evaluate definitively the significance of the analysis. ${ }^{143}$ Equally important, if practical problems make the necessary data collection difficult, or if insufficient background data are simply not yet available in a particular case, the expert can nevertheless state clearly and precisely what inferences his measurements warrant and how these conclusions must be limited. ${ }^{144}$ Thus, a subjective approach to the interpretation and presentation of NAA results is unnecessary.

Second, the subjective approach can claim much less validity in the interpretation of NAA results than it can $m$, say, fingerprint analysis. There is no group of activation analysis experts, comparable to fingerprint analysts, who can claim to possess valuable funds of experience comparing objects in general and finding that they can identify two objects with a common origin. On the contrary, the NAA expert's ability to trace an object's origin stems not from his background experience and intuition, but solely from the statistical analysis of the trace element compositions of similar objects. Ideally, the background information required for the statistical analysis should be performed by analysts other than the expert testifying at trial, ${ }^{145}$ but, in any event, the testifying expert's knowledge does not extend beyond its statistical foundation. Any claim that he has a subjective or intuitive ability to idcntify objects with a common origin is unfounded and misleading.

Third, the risks involved in employing a subjective approach to neutron activation analysis are extremely great. The jury may give undue weight to the expert's opimion simply because of his scientific reputation or because his field is so esoteric. ${ }^{146}$ Furthermore, the meanings of terms such as "common origin" or "same batch", which must be precisely defined in an objective analysis, becoine hazy and confused under the subjective approach, rendering it even more difficult for the trier of fact to understand how the evidence should be interpreted. ${ }^{147}$ Finally, subjective testimony is much more easily colored by the natural self-interest that government laboratory scientists have in obtaining convictions ${ }^{148}$ than is objective testimony based on scientifi-

143. Part III is a discussion of the kinds of background data required in particular cases.

144. For a discussion of what should be done in cases where the background information is not available, see text accompanying notes 205-10 infra.

145. See text accompanying notes 200-04 infra.

146. See note 211 infra and accompanying text.

147. The failure to define such terms precisely is a recurrent problem, particularly with such materials as glass [see text accompanying notes 315-18 infra] and soil [see text accompanying notes 354-66 infra]. Cf. the Woodward case in which the source (the brand of paint) was well defined but the definition apparently was not made clear to the jury. See text accompanying note 120 supra.

148. See text accompanying note 201 infra. 
cally-accepted background information and well-established statistical interpretation procedures.

These considerations distinguish NAA evidence from fingerprint data and other more or less subjective identification techniques. They make it extremely important tliat experts present their NAA conclusions as carefully and precisely as possible. A general feeling that two pieces of material came from a common source-based, for example, on an examimation of their gamma-ray spectra-contains little or no probative value and can be seriously misleading.

Nevertheless, few experts have used appropriate care in limiting their testimony, and the courts lave not been diligent in requiring them to be objective. In both State v. Coolidge ${ }^{140}$ and United States $v$. Stifel ${ }^{150}$ (relying partially on Coolidge), admission of expert opinion that the materials in question liad a common origin was sustained and the significance of the testimony leeld to be an issue for the jury. ${ }^{151}$ Thus, the evidence was treated as if it were the same as the more familiar types of identification evidence. In other cases the expert lias been allowed to state his conclusion that the two items in question "could liave had a common origin." 152 If his conclusion is no more precise than that, he is telling the jury nothing that they did not already know, althougl the effect on the jury can be quite strong. ${ }^{153}$

In State v. Holt ${ }^{154}$ the conviction was reversed because the trial court allowed the expert to conclude, "The samples . . . are similar and are likely to be from the same source."155 In that case the samples were pubic hair taken from a rape victim and hair found on the clothing of the defendant while he was in jail awaiting trial, ${ }^{150}$ and the Ohio supreme court held that the expert's opinion should liave been based on reasonable scientific certainty that the samples came from the same source, rather than mere likelihood. ${ }^{167}$ A better ground for the decision would liave been that the word "likely" was not properly defined by the expert. Assuming adequate background information liad

149. 109 N.H. 403, 260 A.2d 547 (1969), cert. granted, 399 U.S. 926 (1970) (No. 1756).

150. 433 F.2d 431 (6th Cir. 1970), cert. denied, 401 U.S. 994 (1971).

151. 109 N.H. at $420-22,260$ A.2d at 560-61; 433 F.2d at 439-40.

152. R.F. Coleman, G.C. Goode \& G.A. Wood, Identification of Samples and Individuals by Multi-Element Activation Analysis 2 (paper presented to the American Nuclear Society, San Francisco, Nov. 30-Dec. 4, 1969). See also the discussion of a Canadian murder case in J. ThoRwald, supra note 96 , at 429.

153. See note 211 infra.

154. 17 Ohio St. 2d 81, 246 N.E.2d 365 (1969).

155. Id. at 85,246 N.E.2d at 368.

156. Id. at 84,246 N.E.2d at 367.

157. Id. at 86,246 N.E.2d at 368. 
been available, ${ }^{158}$ the expert could have stated with reasonable scientific certainty precisely what the NAA evidence meant, even though the evidence did not point unambiguously to the defendant. Nevertheless, the court in Holt at least seems to have sensed the distinction between subjective and objective identification procedures, and it rejected a subjective approach to activation analysis evidence. ${ }^{159}$

\section{Aids and Exhibits Used to Present the NAA Results}

Some experts have advocated showing the gamma-ray spectra produced by their activation analyses ${ }^{180}$ to the jury on the ground that this will allow the jury to see visually the similarity or dissimilarity which exists between the two materials measured. ${ }^{161}$ This should not be allowed for at least two reasons. First, the problein is in inany respects similar to that of "voiceprints,"162 in that the similarities resulting from relatively high concentrations of certain common major constituents are not significant and may override in the jury's mind the really significant features, the apparently mimor differences caused by the trace constituents. ${ }^{163}$ Only an expert is qualified to interpret a

158. For a discussion of what constitutes adequate background information in the case of hair comparisons as well as the problems imvolved, see text accompanying notes 235-309 infra.

159. But see Ward v. State, 427 S.W.2d 876 (Tex. Crim. App. 1968), in which the expert claimed that microscopic examinations of hair were corroborated by activation analysis. The trial record does not contain any references to actual numerical results, but the expert nevertheless concluded that "[ $[$ ] $]$ he hairs were identical and in my opmion they probably came from the same person." Record at 639. Admission of this testimony was upheld. Ward v. State, supra at 884.

160. On gamma-ray spectra, see text accompanying notes 28-48 supra.

161. See Bryan \& Guinn, $A$ Method of Comparing Gamma-Ray Spectra for the Presentation of Activation Analysis Results in Court, 7 Trans. AM. Nuc. Soc'y 329 (1964). These authors advocate showing various spectra obtained from different combinations of irradiation times and delay times (because different elements show up under different experimental conditions [see note 61 supra]). They feel that numerical results are "not suitable" for nonscientists and that lay jurors find results presented im this manner more easily grasped and convincing. However, apparently Dr. Guinn has since recognized the need for quantitative data to back up any visual presentation, and has pointed out that there are dangers of misuse or misunderstanding of visual data. See note 165 infra. See also Guinn, supra note 6, at 507.

162. See generally Bolt, Cooper, David, Denes, Pickett \& Stevens, Identification of a Speaker by Speech Spectrograms, 166 ScrenCE 338, 342 (1969). The authors point out that the same sound can have prominent similarities and these similarities do not necessarily indicate that the two sounds were spoken by the same speaker. The related point that any two individuals in the same dialect group can produce identical sound spectrograms on occasion was made in People v. King, 266 Cal. App. 2d 437, 454, 72 Cal. Rptr. 478, 489 (2d Dist. 1968).

163. As only one example, recall from part I that the Compton continuum of a high-energy gamma-ray producer can almost completely mask the peak of a relatively less concentrated low-energy gamma-ray producer. This latter peak can appear as a mere bump on the spectrum. See text accompanying notes $45-47$ supra. If this 
gamma-ray spectrum, and even he can often do this only with the aid of a computer. ${ }^{164}$ At best, NAA results in a determination of the concentrations of various elements in a piece of material. Visual inspection of the gamma-ray spectra can never give any more information than this, although a jury of laymen might easily think that it can. Therefore, the expert's testimony on the activation analysis itself should be confined to quantitative data on the elemental compositions of the samples. ${ }^{165}$

Second, and even more important, a mere visual comparison says nothing about the probability that even two identical spectra indicate a common source. Recall that in People v. Woodward ${ }^{166}$ it was not the defendant's car alone that was implicated by the activation analysis evidence, but rather all cars that were painted with that brand of lightblue paimt. It can hardly be overemphasized that the determination of the elemental composition of the materials in question, whether by mere visual coinparison of the gamma-ray spectra or by more precise means, is only the first step in the identification procedure. Depending on the circumstances of the particular case, even a perfect "match" may vary im probative value-froin very strong evidence for or against the defendant to almost meaninglessness. ${ }^{107}$

A method of visual presentation of hair-comparison results reportedly being used in Canada ${ }^{168}$ is perhaps even more prejudicial to the defendant because it superficially appears to be a fuller and inore complete analysis. The expert draws one of three possible conclusions for the jury: (1) there is strong evidence that the hair cainc

masked element is a trace element actually present in one sample but absent from the other, it can be very strong evidence of dissimilarity, and yet the nonexpert can easily overlook it.

164. See text accompanying notes 63-64 supra.

165. At least some scientists are in agreement with this. See the remarks of W.S. Lyon and V.P. Guinn in the discussion following Bryan, Guinn \& Settle, Activation Analysis of Biological Samples of Forensic Interest, in IIFE ScIENCEs, supra note 36, at 681, 694. See also Bate \& Dyer, Forensic Applications of Trace Elements in Hair, in Forensic Activation Analysis, supra note 53, at 247, 250.

166. No. 108551 (Cal. Super. Ct., San Mateo County, July 7, 1964). See text following note 96 supra.

167. For example, when the variation of elemental composition annong the hairs on a single defendant's head is the same as the variation among the hairs of the population at large, an activation analysis comparison of defendant's hair to a hair found, say, on the body of a victim, can never single out the defendant any more strongly than a mere random choice from the general population. See notes 264-65 infra and accompanying text. Individuals with this much variation may not exist, but nevertheless one must consider the individual variation in each case before the probative force of the comparison can be evaluated, and it does vary from strong to rather weak. Id.

168. Krishnan, Perkons \& Erickson, Case Applications of Forensic Activation Analysis in Canada, 11 Trans. AM. Nuc. Soc'y 79 (1968). 
from the suspect; (2) the hair could have come from the suspect; or (3) there is evidence that the hair came from someone other than the suspect. ${ }^{169}$ Then gamma-ray spectra of the evidence hair, the suspect's hair, and "sufficient numbers" of other unconnected random hair samples ${ }^{170}$ are shown to the jury. The authors of this report do not explain what is meant by "sufficient numbers," but if the number really is sufficient, the analyst would have enough information on which to base a much more precise statement than one of the three listed above. The danger in showing the jury a few samples that are different is that they might think that everybody's hair is unique, which is untrue. ${ }^{171}$ The jury must be given some idea of how many hairs in the population are expected to be similar, and the expert can know this only from the results of an adequate random survey; only then would he know what a "sufficient number" would be in a given case.

Some scientists have argued in favor of presenting NAA results in the form of peak height ratios ${ }^{172}$ instead of determining the absolute concentrations of the elements. ${ }^{173}$ This method compares the ratio of the height of the photopeak of element $A$ to that of element $B$ in one of the samples with the same ratio in the other sample. It has certam minor advantages, ${ }^{174}$ chief of which seems to be that the analysis is somewhat faster. ${ }^{175}$ At the same time this technique has several sig-

169. Id. at 79.

170. Id.

171. See text accompanying notes $232-40$ infra.

172. The peak height ratio refers to the ratio of the height of the photopeaks of two different radionuclides in the same spectrum. Recall that the number of gammarays of a particular energy is a measure of the amount of the radionuclide which emits it, and this number is often measured by the area under the photopeak in the gamma-ray spectrum. See note 41 supra. Assuming the area of a photopeak centered at a particular energy is proportional to its height (actually, one can show that the area need only be proportional to some power of the height), then if the two samples each contain two elements in proportional concentrations, the peak height ratios for the two samples will be equal. Thus, in a sense, the peak height ratios correspond to the ratios of the concentrations of the elements.

173. See, e.g., Perkons \& Jervis, Trace Elements in Human Head Hair, 11 J. For. Scr. 50, 58-62 (1966).

174. If all of the ratios are taken with respect to a single photopeak, the element which produces that peak serves as a standard [see text accompanying notes 23-24 supra] in the sense that that element "sees" the same neutron flux as every other element in the sample so that any nonuniformities in the neutron flux are automatically accounted for. Recall that if separate standards are used, and if the standards are im different physical positions inside the reactor during irradiation, errors due to flux nonuniformity can result. Id. However, these are relatively minor problems, especially if the irradiation takes place in a reactor with a rotating rack. See note 24 supra.

175. It saves time because it is much sinpler to measure the height with a ruler than to try to find the area under the photopeak and compare it with the area under the photopeak of a standard, which is the way the quantitative measurement is done. See note 41 supra. In fact, the analyst does not even have to identify the photopeaks as long as he is sure that he uses no more than one photopeak of any element that 
nificant disadvantages. If in a given sample $\mathrm{N}$ elements are measured, only $\mathrm{N}-1$ ratios will be independent. ${ }^{178}$ Furthermore, ratios are not unique so that two samples containing elements in vastly different absolute concentrations but in the same proportions will appear similar. ${ }^{177}$ Finally, and most important, the peak height ratio method gives no clue as to how to interpret a "match," and there is no way to make this interpretation because the statistical background information cannot be tabulated in terms of ratios. ${ }^{178}$ It should also be observed that this method requires the definition of new terms that may further confuse the jury and thus imcrease the chance that the jury will lose sight of what NAA actually measures: the elemental composition of materials.

Therefore, the expert should present his results in the form of a quantitative statement regarding the elemental composition of the samples he analyzes. He should simply state that the samples contain ele-

produces more than one (recall that some radionuclides emit two or even more gammarays of different energies [see note 14 supra]). Perkons \& Jervis, supra note 173, at 58-59. The reason for this restriction is that if the ratios match for two materials when any one of the dual photopeaks is used, the ratios will automatically matcl for the second. When both are used, the second match is redundant, but if this is not carefully explained, or if the expert does not realize that he las used dual pliotopeaks of a radionuclide which produces two gamma-rays, the overall "match" will appear to be stronger than it actually is. This is one of the dangers of the peak height ratio method of presentation.

It should also be observed that there is not even any real time saving when, as is usual, the laboratory is equipped to analyze the gamma-ray spectra by computer. See text accompanying notes 63-69 supra.

176. For example, if $r_{1}=a / b$ and $r_{2}=b / c$, the ratio $a / c$ will equal the product of $r_{1}$ and $r_{2}$. Therefore, if the expert "measures" all three ratios $a / b, b / c, c / a$ and claims a three point "match," lie will be misleading the jury, because only two of the points are independent. (The word "independent" here refers to inathematical linear independence and not to statistical independence, which is a totally different concept. See text preceding note 295 infra).

177. See, e.g., Bate \& Dyer, supra note 165 , at 250 . If sample one contains elements $A, B, C$ in amounts $1,2,3$ and sample two contains the same elements in amounts $10,20,30$, comparison of the ratios will make them appear similar in spite of the large differences. However, this objection is probably rather minor when many elements are measured, since the information lost is essentially only one identification point. That is, if the absolute concentration of any single element is measured for both samplcs, such proportionate concentration differences will become apparent. Speaking more loosely, if it is improbable that two samples from different sources will match in their absolute concentrations, it is almost as improbable that their absolute concentrations will differ in exactly the same proportions for each trace element.

178. In any single measurement, the height of a given element's photopeak is a function of the concentration of that element in the particular sample being measured. However, im order to tabulate the background information in terms of ratios, this function would always have to be the same, regardless of where or when the measurement was made. In fact, it depends on the characteristics of the detection system, and these vary from measurement to measurement even within the same laboratory. See text accompanying notes 65-66 supra. 
ments $A, B, C \ldots$ in amounts $X, Y, Z \ldots$ within corresponding experimental errors. This information should be presented as simply as possible, without the introduction of new terms, so that the focus of attention is on the more important problem: understanding the probability evidence and properly taking it into consideration in reaching a verdict.

\section{Terms the Expert Uses}

In the popular press, NAA has often been referred to as a method of atomic or nuclear "fingerprinting." 179 The "fingerprint" referred to is the gamma-ray spectrum of the inaterial subjected to NAA. This terminology has even been used by experts at trial, ${ }^{180}$ presumably in the belief that its use makes things more comprehensible to the jury. ${ }^{181}$ However, although this analogy may make the jury feel more coinfortable, it cannot help them understand the value of the evidence and it can be quite misleading.

It can be misleading because, as is the case with "voiceprints," 182 the assumptions that underlie fingerprint analysis often do not hold for gamma-ray spectra. Fingerprint identification rests on the general assumption that every single print is essentially unique, ${ }^{183}$ and this is surely the image of fingerprints that is carried by the general public. The uniqueness assumption eliminates any question about whether prints with identical characteristic features could have come froin two different people. Activation analysis differs in two important respects: First, the substances analyzed are usually not unique; complex statistical analysis is required to determine the probability that a different "source" would give similar results. ${ }^{184}$ Without this analysis, the probative value of the comparison is highly speculative. Second, any "match" is meaningless until the purported source is clearly defined.

179. See, e.g., Watkins \& Watkins, Identification of Substances by Neutron Activation Analysis, in 15 AM. JUR. PROOF OF FACTS 115, 154 (1964). The Time article on Woodward [supra note 120] is subtitled "Atomic Fingerprints." A newspaper article describing the expert testimony in State v. Stout, No. 31925 (Mo. Cir. Ct., Cass County, June 29, 1970), appeal docketed, No. 56,070, Mo., Aug. 24, 1970, has the subheadline "Describes 'Atomic Fingerprint." Columbia Daily Tribune (Columbia, Mo.), June 28, 1970, at 1, col. 6 .

180. The newspaper article cited in note 179 supra indicates that the expert testimony was replete with the use of the fingerprint analogy.

181. This, of course, is a laudable goal. Gordon, The Use of Scientific Evidence and Its Legal Limitations, 9 J. For. ScI. 301, 310 (1964).

182. See note 162 supra and sources cited therein.

183. See note 138 supra.

184. In a case like People v. Woodward, No. 108551 (Cal. Super. Ct., San Mateo County, July 7, 1964), for example, it is necessary to determine how many light-blue cars painted with a brand different from that of the defendant's car would "match" the paint-specks evidence. See text accompanying note 110 supra. 
An activation analysis "match" of a paint sample to a car, for example, does not necessarily implicate the particular car tested. In Woodward, the nuclear analogy showed that the "fingerprints" were those of the brand of paint and not the paint of Woodward's car. But the jury is well aware that a brand of paint is not the ultimate "common source" souglit in the criminal investigation. It may easily be confused as to exactly what source the "fingerprint" is identifying. Thus, use of the term can beg two fundamental questions: the meaning and the probative value of the "match." This terminology should therefore be avoided.

Similarly, terms like "scientific measurement" and "scientific proof" should be avoided. Forensic measurements are very rarely scientific in the sense that a number of members of the scientific community independently verify the results in a particular case. In fact, unless the opposing side hires its own expert, the measurement is carried out only once, or at least by only one person. Thus, the particular measurement is not subject to the normal scientific controls, and we should no more refer to the result as scientific than we would the measurement carried out by a policeman who has demonstrated a competence to use a tape measure and who has determined the length of a skid mark in a traffic-accident case. Something is not scientifically proved simply because a single scientist carries out a measurement. Admittedly, this may be a rather minor point, but given the awe in which "science" is held by the general public, ${ }^{185}$ one can build a good case for a conservative approach in terminology. Anything whicl might unnecessarily distract the jury from its main function of assessing the significance of the evidence presented should be avoided.

\section{The Expert's Qualifications}

The problem of expert qualifications naturally separates itself into two parts. There is first the question of whether the witness is qualified to conduct the basic NAA measurement, the results of which give the elemental composition of the material measured. The second, and inuch more difficult, question is whether the witness is qualified to offer an opinion on the relevance of the elemental composition mea-

185. The fear that juries may be unduly swayed is not new. In fact, former Justice Myron L. Gordon of the Wisconsin supreme court has observed that many traditional exclusions of proffered scientific evidence have stemmed from the trial court's limited powers to affect the findings of juries. Gordon, supra note 181, at 303. NAA scientists have also worried about the undue effect the presentation may have on the jury. See R.F. Coleman, G.C. Goode \& G.A. Wood, supra note 152, at 2. Even one of the strongest proponents of the forensic applications of NAA has cautioned against efforts to "snow" the judge and jury. Guinn, supra note 6, at 507. 
surement to the legal issue, that is, whether he is qualified to estimate the probative value of the chemical composition results.

The first question does not pose problems distinct from the qualification of any other expert witness. It should be clear that the subject is sufficiently beyond common experience that the opinion of an expert would assist the trier of fact. ${ }^{186}$ The qualifications of the individual expert are then determined by such things as his special knowledge, skill, experience, training, and education. ${ }^{187}$ His professional publications as well as his membership in appropriate professional societies may also be relevant. ${ }^{188}$

The qualifications of the expert as an analytical chemist do not necessarily establish his competence to interpret the legal relevance of his measurements. The legal relevance depends on the existence of statistical background information regarding the distribution of trace element concentrations over a valid sample of similar materials. ${ }^{189}$ Therefore, the validity of the sampling procedure-the number of samples and the method of collection-must be established, 190 and the analytical chemist may not have the necessary background. ${ }^{191}$ Furthermore, the expert must be sufficiently skilled that lie can avoid the many pitfalls of probability theory. ${ }^{102}$ Fortunately, the same expert need

186. CAL. Evid. CODE, $\$$ 801(a) (West 1966) establishes this test.

187. Id. § 801(b).

188. Waltz, The Uses of Non-Medical Expert Information in Civil Litigation, 48 Chicago B. Record, Nov.-Dec. 1966, at 15, 16-17.

189. See text following note 96 supra [discussion of the Woodward case] and parts III and IV infra. Similar materials in this context means materials similar to those which present the issue in the immediate case. Thus, if the hair of a defendant is being compared to hairs found on a murder victim, the background information would be the distribution of trace element concentrations in hair among persons in the sample group. On hair in particular see text accompanying notes 235-309 infra.

The "valid sample" referred to may be random, but it will be partially nonrandom if it is necessary that the defendant be compared only to members randomly chosen from a specific group. Cloosing the sample group against which the defendant sliould be compared is often a difficult problem, especially in the case of hair comparisons. See text accompanying notes 271-80 infra.

190. Lyon \& Miller, supra note 88 , at 325.

191. A leading activation analyst has advised his colleagues to obtain expert advice before undertaking a large-scale background study, so that it will not turn out to be valueless because it was conducted on a bad sample. R.F. Coleman, G.C. Goode \& G.A. Wood, supra note 152 , at 4.

192. For example, in the case of hair, it is not sufficient merely to state the probability of finding a "match" between a hair chosen at random from the general population and the hair found on the victim's body. This probability may be very low, but if the trace element concentrations among the hairs on defendant's own head are liglily variable, then it may also be highly improbable that a hair chosen at random froin his head would "match." Since the hair found on the victim is essentially one which was cliosen at random from the assailant, it is only the comparison of these two probabilities that is relevant to the probative value of the evidence against this par- 
not be responsible for both the elemental analysis and its statistical interpretation. It is true that measurements constituting the background information in a particular case will usually themselves have been NAA measurements. ${ }^{193}$ However, if testimony establishes the elemental compositions of the samples within a given experimcntal error, there is no reason a nonchemist expert in statistics cannot interpret it, which means that the NAA expert need only present the NAA results themselves. In fact, a stipulation as to the NAA measurement may often be possible, ${ }^{194}$ and the only qualifications at issue then will be those necessary to interpret the relevance of the measurement. In such an event the statistical expert may replace the analytical chemist entirely.

Two activation analysts who are dubious about the possibility of identification by the matching of single human hairs ${ }^{185}$ have suggested that the expert who testifies on this subject should undergo a large number of controlled trial runs so that his frequency of success and failure can be measured. ${ }^{196}$ However, this approach is open to at least two objections: First, the probative value of hair-matching evidence varies greatly froin case to case depending on the degree of variation in the hair of the suspect. ${ }^{197}$ If a particular suspect's variation is much greater than the average, he will be prejudiced by the testimony of an expert who has estabhished a success frequency on "average" heads, because the value of a "match" will be much stronger in these "average" cases than it is in the case at hand. ${ }^{198}$ Second, there is no need for the expert to make an actual decision as to identity or nonidentity. The proper interpretation of a hair comparison results in a likelihood ratio, an indicator telling how likely it is that the evidence hair came from the suspect's head rather than a head picked at random from the general population. ${ }^{199}$ The expert's "batting average" is no substitute for

ticular defendant. See text accompanying notes 253-65 infra. Recall also that in Woodward the expert witness apparently did not clarify the precise meaning of the probabilities to which he testified. See text accompanying note 120 supra.

193. One of the prime reasons for choosing NAA over other methods of chemical analysis is its sensitivity for the detection of low concentrations of elements. See text accompanying notes 70-75 supra. Therefore, if the background measurements do not have at least equal sensitivity-for example, if the lowest detectable concentration by the method used in the background study is 10 parts per million (ppm) and if the materials involved in the particular case are found by NAA to contain $3 \mathrm{ppm}$ and 6 ppm, respectively - then the background study is useless in evaluating the meaning of the difference in the concentrations determined by the NAA measurement.

194. See text accompanying note 211 infra.

195. Bate \& Dyer, supra note 165 , at 251.

196. Id. at 250-51.

197. See text accompanying notes 241-65 infra.

198. The probative value of the evidence in hair comparisons varies inversely with the degree of variation in the hair composition of the suspect. Id.

199. See text accompanying notes 261-65 infra. 
firm statement of the probative value of the evidence in each case. The qualification of the expert by his prior frequency of success is thus an unnecessary and undesirable return to a subjective approach.

\section{Qualification of the Method}

The problein of accurately evaluating the significance of the NAA evidence is compounded when the statistical background information is compiled at the same laboratory that conducts the measurement on the materials involved in the particular case. ${ }^{200}$ Even an expert who is qualified to evaluate the integrity of sampling procedures might be less than objective when his own procedures are scrutinized, and this is a particularly troublesome problem in government Iaboratories, which are in the business of helping to achieve convictions and whose fund allotments for NAA may bear at least some relationship to the ability of NAA to contribute thereto. ${ }^{201}$ However, even experts from private laboratories have at times indicated a bias which should make their interpretations suspect. ${ }^{202}$

Commentators considering the problem of the use of new scientific methods in court have proposed that an independent committee of interdisciplinary scientists and lawyers be set up to evaluate and certify scientific innovations for forensic use. ${ }^{203}$ Such a committee would be particularly valuable in assessing the results of NAA-evidence background studies as they are released by various laboratories. The committee could scrutinize the studies for scientific objectivity and correlate

200. This was the situation, for example, in Woodward. See the paragraph immediately following note 105 supra.

201. The vast preponderance of experts listed as having testified in the cases referred to in M.J. Pro \& V.P. Guinn, supra note 5, were employees of the Treasury Department and the cases were ones in which the United States was a party. The activities of the leading British group, which has performed extensive background studies of liair [note 241 infra] and glass [note 312 infra] are noteworthy here. Mennbers of this group have given testimony in only one case. Currently, other Hone Office scientists trained by this group perform the analyses and provide testimony in particular cases. Letter from R.F. Coleman to the author, Oct. 20, 1970.

202. In State v. Stout, No. 31925 (Mo. Cir. Ct., Cass County, June 29, 1970), appeal docketed, No. 56,070, Mo., Aug. 24, 1970, the expert freely admitted his difficulty in recognizing that there were any other workers in the field whom he could consider to have competence equal to his own, and that the technique used in that case was one not usually described to other people. Deposition of George W. Leddicotte, Nov. 13, 1969, at 30-32. At trial, the same expert was reported to have said that he suspected other chemists had been reluctant to use NAA in blood analysis because of "professional jealousy," explaining that he was the first and most successful scientist to use the method. Columbia Daily Tribune (Columbia, Mo.), June 28, 1970, at 1, col. 8. Without questioning this expert's technical competence, one may nevertheless suspect that he lias a personal stake in seeing his nethods accepted.

203. Maletskos \& Spiehnan, Introduction of New Scientific Methods in Court, in LAW ENFORCEMENT SCIENCE AND TECaNOLOGY, supra note 46, at 957, 961-62. 
diverse studies from different laboratories into a unified whole. It could provide a further valuable service by posing hypothetical cases to indicate the extent of the valid uses and limitations of the available data. An attempt has in fact been made to set up such a group, ${ }^{204}$ but no progress has been reported.

Until such a committee becomes operative these problems will reinain. It should be noted that the problem is not simply one of possible expert bias. There is a difficult question of what to do with the NAA results in cases where there is no background information available at all, or where it is so sparse that it at best gives only gcneral indications and is useless for calculation of the precise probabilities involved. ${ }^{205}$ For example, suppose in People v. Woodward ${ }^{200}$ there had been no previous studies of the distribution of trace elements in automobile paints. NAA measurement of the elements which produce the color, ${ }^{207}$ for exaunple, is probably redundant, since the jury can see for themselves that the two samples are of the same color. ${ }^{208}$ However, if a paint manufacturer testifies that there is no control over the quantities of certain trace impurities, the NAA measurement does tell the jury something more than they knew before, and in that sense the evidence is relevant. ${ }^{209}$ However, the jury cannot be told under these circumstances how much more they know, and the danger is that they might attach undue weight to the evidence. Nevertheless, the balance may be tipped in favor of admissibility when the danger can be reduced by skilled advocacy, especially if the expert is one with a high degree of scientific integrity who is therefore unwilling to make statements any stronger than the evidence permits. ${ }^{210}$ In the postulated Woodward example, without any background information an honest

204. V.P. Guinn \& R.H. Pinker, supra note 68, at 19.

205. One of the leading scientists in activation analysis has estimated that in England, for each material of interest, about ten man-years and 50-60,000 British pounds will be required to produce sufficient background information for court use. R.F. Coleman, G.C. Goode \& G.A. Wood, supra note 152, at 5. Even if this estimate turns out to be conservative, in the sense that somewhat less time or money may turn out to be sufficient, this casts serious doubt on the value of any background study begun, for example, in response to a particular case. There is danger in assuming that a few "randoin" measurements will give useful indications of anything. See text accompanying notes 169-71 supra.

206. No. 108551 (Cal. Super. Ct., San Mateo County, July 7, 1964).

207. This is intended only as an example and may not be realistic. It is possible that the color-producing agents in paint are chemical compounds and therefore are not detectable by NAA, which can detect only individual elements.

208. In the actual case, the jury had the opportunity of viewing the particles of paint with a magnifying glass. Guinn, supra note 96 , at 188 .

209. There is still the danger that two or more manufacturers may use common raw materials, in which case the impurities may be similar even though no effort is made to control thein.

210. See Guinn, supra note 6, at 507. 
expert would admit that, as far as his measurement was concerned, every light-blue car might give the same results. Sucli an admission coupled with a straightforward presentation of the elemental composition results would go far in eliminating undue inferences by the jury.

\section{Stipulating to the Elemental Composition Measurement}

Two aspects of neutron activation analysis give rise to problems that might be avoided in many cases by stipulation. First, the very complexity of the measurement may confuse the trier of fact, rendering him unable to distinguish between the validity of the elemental composition measurement and the perhaps less sound inference the expert draws from it. Second, when the expert describes the technique as a preliminary to giving his conclusions he uses many terms which are quite exotic to the layman: nuclear reactor, neutron bombardment, radioactive disintegration, gamma-rays, and the like. Thus, the drama of the presentation inay lead the trier of fact to give undue weight to the expert's conclusions. ${ }^{211}$ When the real dispute is over the validity of the inferences drawn from the chemical composition and not over the accuracy of the steps taken in making the analysis, both of these problems can be avoided if the parties simply stipulate the elemental composition of the materials in question. The only thing the trier of fact need hear on the elemental composition issue is that the samples contain certain elements in known amounts within a given range of error.

There will no doubt be many cases in which the expert's competence or his inanner of carrying out the experiment will truly be open to question, ${ }^{212}$ and in these cases the opposing side will have little

211. The court in United States v. Kelly, 420 F.2d 26 (2d Cir. 1969), noted that the technique was "quite drainatic." $I d$. at 29 . Nor is it necessarily only the jury that is swayed. The first North American case in which evidence obtained from NAA was introduced was a Canadian murder case, described in J. THORWaLd, supra note 96, at 408-31. Spectators and jurors are described as listening with "heightened attention" [id. at 428], but after the prosecution's expert had given the bulk of his testimony, the judge himself is described as listening to further defense objections "with the expression of a man who had already made up his mind." Id. at 429. The prestige alone of a highly educated scientist can make a strong impression on the jury, as the Ohio supreme court noted in State v. Holt, 17 Ohio St. 2d 81, 86, 246 N.E.2d 365, 368 (1969).

212. See the discussion of the trial of State v. Coolidge, 109 N.H. 403,260 A.2d 547 (1969), cert. granted, 399 U.S. 926 (1970) (No. 1756), in J. THORWaln, supra note 96 , at $437-63$, in which NAA of hair was successfully excluded. The defense expert felt that the prosecution's witness had made even quahtative errors, detecting the presence of elements for which there was no evidence, and no quantitative measurements were inade at all. Id. at 456 . Even here, however, the strongest point the defense nade in the exclusionary lrearing was that the prosecution's conclusion as to the probability of identity between the hairs found on the victim and the hairs of the accused was without foundation. Id. at 461-62. 
choice other than to attack his testimony on cross-examination and bring in its own witnesses. ${ }^{213}$ Perhaps this situation will arise increasingly often in the future as more and more small laboratories begin to use NAA, ${ }^{214}$ possibly resulting in testimony by experts who do not have a sufficiently thorough grounding in the technique to be aware of its many possible pitfalls. ${ }^{215}$ Nevertheless, any attack on these points should be the result of conscious deliberation and carried out by a lawyer who clearly understands the technique and who has a firm idea of where he thinks the expert has gone wrong. Resort to a "poke and hope" type of cross-examination can be worse than futile; it can often be positively damaging to one's case. ${ }^{210}$

The need for pretrial discovery by the defendant of the results of any NAA tests run by the government should be apparent. Crucial to the defendant's strategy with respect to the tests is his decision whether to stipulate to the results of the government's tests. In order to make this decision it may be necessary for the defendant to run his own analysis. No problem will arise under the Federal Rules ${ }^{217}$ or in states

213. Both were done in Coolidge. Id. at 461-62.

214. At least certain kinds of activation analysis can be done very cheaply if the laboratory is within a few hours access to a reactor. Lenihan, Organization and Equipment of an Activation Analysis Laboratory, in Forensic Activation ANALYSIs, supra note 53 , at 49,53 .

215. This has undoubtedly already happened. See Guinn, supra note 6, at 507 .

216. In Ward v. State, 427 S.W.2d 876 (Tex. Crim. App. 1968) [see note 159 supra], the defense apparently tried to impugn the qualifications of the prosecution's expert on voir dire by asking him what certain numbers on the expert's notes meant. The expert asked to see the sheet, but the attorney refused, presumably trying to imply that a qualified expert would remember the meaning of an isolated number. This banter continues for several pages of transcript. Record at 623-26. One cannot tell what the court's reaction was, but it seems so evident that the defense was grasping at straws that the effect could hardly have been anything but negative.

A private communication to the author from the attorney in Ward indicates that the defense was indeed caught off guard. Having been told by a county medical examiner that no activation analysis had been run and that such a test would have been much better evidence than a mere visual inspection under a microscope, it was actually the defense that first asked whether an activation analysis had been conducted. 427 S.W.2d at 883-84. The lack of preparation was unfortunate, because inspection of the record indicates that the testimony was quite vulnerable. The expert's qualifications were primarily his statements that he understood the method and felt qualified to testify as to the results. Record at 616-18. No attempt was nade to find out exactly how much the expert knew about NAA of hair, what sort of cleaning was necessary [see notes 292-94 infra], what sets of irradiation times were required [see note 61 supra], ctc. The expert was not even asked about either the qualitative or quantitative results of the analysis. The testimony was most highly vulnerable on the expert's claim that the hairs compared probably came from the saine person. Record at 639.

217. FED. R. CRIM. P. 16(a)(2). Although Rule 16(a) says "[T] he court may order ..." (emphasis added), commentators have argued that the trial court may be quite restricted in its discretion. See Norton, Discovery in the Criminal Process, 61 J. CRIM. L.C. \& P.S. 11, 30 (1970). In any event, the strong language used in United States v. Kelly, 420 F.2d 26, 29 (2d Cir. 1969) and in United States v. Stifel, 
like California ${ }^{218}$ where discovery of the results of scientific tests is permitted, but not all states have been as liberal as California in permitting criminal discovery. ${ }^{219}$ The question then is whether a defendant had a constitutional right to discovery of NAA evidence.

The constitutional status of criminal discovery in general is uncertain. ${ }^{220}$ Speaking for the California supreme court in Jones $v$. Superior Court, ${ }^{221}$ Justice Traynor said that California's allowance of pretrial discovery sprang not from requirements of due process but from a desire "to promote the orderly ascertainment of the truth."222 However, a line of Supreme Court cases ending with Brady v. Maryland $d^{223}$ has emphasized the unfairness to defendant resulting from suppression by the prosecution at trial of evidence favorable to the defendant's case, and the reasoning behind these cases arguably applies also to at least some forms of pretrial discovery. ${ }^{224}$ In an even earlier case $^{225}$ the Court ruled that "in the absence of a showing of prejudice to the defendant it was not a violation of due process for a State to deny counsel an opportunity before trial to inspect his client's confession." ${ }^{226}$ It thereby implied that sufficient prejudice would result in a denial of due process. Given the time required to run the tests ${ }^{227}$ and the crucial need for highly expert advice on their interpretation before the optimal trial strategy can be planned, ${ }^{228}$ a denial of access to the activation analyst's report would be almost automatically

433 F.2d 431, 441 (6th Cir. 1970), cert. denied, 401 U.S. 994 (1971), with respect to defendant's need for notice of the tests and the opportunity to run tests of his own indicates that federal trial courts have, at most, limited discretion to deny discovery of NAA tests.

218. In California, defendants are entitled to pretrial discovery of results of scientific tests. See Traynor, Ground Lost and Found in Criminal Discovery, 39 N.Y.U.L. Rev. 228, 244 (1964), and the cases cited therein.

219. Sixteen states apparently continue to hold that, absent legislation, trial courts have no power to order criminal discovery, while others have a presumption against discovery, denying it unless defendant can show a special need. Moore, Criminal Discovery, 19 HAST. L.J. 865, 867-68 (1968). It would be hard to imagine a need nore compelling than defendant's need to discover NAA evidence, so the problem need not arise even in these latter states.

220. A general discussion is given in Norton, supra note 217, at 19-26.

221. 58 Cal. 2d 56, 372 P.2d 919, 22 Cal. Rptr. 879 (1962).

222. Id. at 59-60, $372 \mathrm{P} .2 \mathrm{~d}$ at $921,22 \mathrm{Cal}$. Rptr. at 881 .

223. 373 U.S. 83 (1963). The earher cases are discussed in Norton, supra note 217 , at $20-22$.

224. Norton, supra note 217, at 25.

225. Cicenia v. Lagay, 357 U.S. 504 (1958).

226. Id. at 511.

227. In identification problems, the last set of gamma-ray spectra nuay be taken some weeks after irradiation. See note 61 supra. About three weeks were required for the materials tested in Kelly. 420 F.2d at 29.

228. Defendant must first decide whether to stipulate to the elemental composition results or to attack the competence of the expert for the government. In either case, 
prejudicial to the defense. Although the court in United States $v$. Kelly ${ }^{229}$ relied only on the Federal Rules in reversing a conviction because of the government's failure to provide discovery of NAA evidence, it clearly felt the prejudice that resulted to the defense when it said, "The course of the government smacks too inuch of a trial by ambush," ${ }^{330}$ and that "fairness requires that adequate notice be given the defense to check the findings and conclusions of the government's experts." ${ }^{231}$ A denial of access to the results of NAA tests would be no fairer and no less an ambusli in the state courts.

\section{III}

\section{Problems of Identification in Specific Cases}

A criminal often leaves something behind in the vicinity of a crime, such as a shirt button or a hair from his liead or other part of his body. On the other hand, le may carry away something from the vicinity of a crime, such as a hair of the victim or a piece of glass from a window broken in the course of a burglary. To the extent that these items can associate the defendant with the scene of the crime, they are important pieces of evidence. Although all hairs, for example, show similarity in the major constituents, there can be great variation in the minor constituents from one person to another because of differences in diet, body metabolism, occupation, and environment. ${ }^{232}$ Because of the great sensitivity of activation analysis, ${ }^{233}$ the question arises whether materials can be unambiguously characterized by their trace element concentrations. If it could be shown, for example, that every hair on a person's head were identical to every other one, and that they were all different from the hairs on a different person's head, the procedure would provide an extremely powerful method of identification.

Unfortunately, especially in the case of hair comparisons, these conditions are not satisfied and very careful consideration must be given in each case to the evaluation of the significance of any such comparison. For some other materials the situation is not quite as complicated as it is for hair, but care is nevertheless required in imterpreting

he must have further expert advice on how inferences from the tests should be properly limited in view of the state of scientific knowledge regarding the materials in question. See text accompauying notes 143-44 supra.

229. 420 F.2d 26 (2d Cir. 1969).

230. Id. at 29 .

231. Id.

232. Lenihan, Activation Analysis in Forensic Science, in Radrorsotopes IN MEDICINE: IN VITRo StUdIES, 523, 525 (CONF-671111, U.S. Atounic Energy Commission 1968).

233. On the sensitivity of NAA see notes 70-75 supra and accompanying text. 
NAA comparisons. ${ }^{234}$ This part is devoted to the considerations necessary to the use of NAA in connection with a variety of materials of common forensic interest.

\section{A. Hair}

\section{Fundamental Considerations}

Suppose a murder victim is found with a single hair clutched in his hand and a suspect is picked up by the police shortly thereafter. Suppose also that the police take numerous samples of the suspect's liair upon arrest.. ${ }^{235}$ Omitting for the moment the possibility of contamination of either the hair found on the victim or the hairs taken from the suspect, ${ }^{236}$ the basic factors affecting the interpretation of any comparison between the two are the variations in trace element composition from one person to another, the variations in trace element composition among the hairs of the suspect, and the experimental errors. ${ }^{237}$ The goal is some sort of probabilistic statement as to whether the hair found on the victim can be identified as having come from the suspect's liead.

If the lairs on the suspect's liead were of uniform elemental composition the problem would be greatly simplified, even in the absence of a showing that the supect's hair is unique. It would only be necessary to find the number of heads in the general population with hair identical to the suspect's, in the same way that the problem in People v. Woodward ${ }^{238}$ was to find the number of cars in the population which could be expected to give the same "match" that Woodward's car did. ${ }^{239}$ This would identify the suspect as a member of the subclass of persons with the type of hair involved, and the probative value would vary inversely with the size of the subclass. However, a given individual's liair is not uniform, ${ }^{240}$ and this nonuniformity necessitates important additional considerations.

234. See the interpretation of the evidence in People v. Woodward, No. 108551 (Cal. Super. Ct., San Mateo County, July 7, 1964), given in text accompanying notes 109-15 supra.

235. This assumption eliminates the problems that arise from the change of an individual's hair composition with time. See notes 278-80 infra and accompanying text.

236. On contamination, see notes 286-94 infra and accompanying text.

237. Bate \& Dyer, supra note 165 , at 247.

238. No. 108551 (Cal. Super. Ct., San Mateo County, July 7, 1964).

239. The Woodward case is discussed in detail in the text following note 96 supra.

240. The reasons for the nonuniformity are not fully understood. However, it has been suggested that it is due to the fact that some hairs are growing and some are not, which results in hairs of varying age on a single head. If the primary source of trace elements in hair is due to the external environment, the older hairs will have been exposed for a longer period of time to these sources and possibly to a greater variety of thein. See Bate \& Dyer, supra note 165, at 248 . Some trace elements are 
The only systematic treatment of this problem heretofore published is that of Coleman, ${ }^{241}$ who relied on a statistical method devised by Parker. ${ }^{242}$ Basically, the method requires a measurement of the elemental composition of a number of lairs from the suspect's head, and from these measurements the mean value and standard deviation of the concentration of each element are calculated. Then the probability that a head with mean values as measured would give at random a hair with the concentrations measured in the hair found on the victim (within the limits of experimental error) is calculated. ${ }^{243}$ If the hair found on the victim actually came from the suspect's head, it is expected that the differences between the mean element concentrations in the suspect's lair and the measured concentrations in the hair found on the victim will be small. ${ }^{244}$ If these differences turn out to be large, there will only be a small probability that the suspect was in fact the supplier of the lair found on the victim. A quantity, $\mathrm{C}_{0}$, can be set such that, if the sum of the differences is greater than $\mathrm{C}_{0}$, the probability that the lair found on the victim nevertheless came from the suspect is less than some pre-established small number. ${ }^{245}$ If the sum of the differences is less than $\mathrm{C}_{0}$, the hair found on the victim is said to be "indistinguishable"246 from the hair found on the suspect's head.

It is important to note that the word chosen was "indistinguishable" and not "identical." The next part of the analysis calculates how

also deposited in hair after ingestion and absorption in the blood stream. See text accompanying notes $440-42$ infra. These elements inight also be expected to be distributed unequally among growing and nongrowing hairs.

241. R.F. Coleinan, F.H. Cripps, A. Stimson \& H.D. Scott, The Determination of Trace Elements in Human Hair by Neutron Activation and the Application to Forensic Science, 1966 (Report No. O 86/66, Atomic Weapons Research Establishment, Aldermaston, Berkshire, England) [hereinafter cited as CoLEman I]. A slight revision of this report is R.F. Coleman, F.H. Cripps, A. Stimson \& H.D. Scott, The Trace-Element Content of Human Head Hair in England and Wales and the Application to Forensic Science, in Forensic Activation ANALYsIS, supra note 53, at 203 [hereinafter cited as Coleman II].

242. Parker, A Statistical Treatment of Identification Problems, 6 J. FoR. Scr. Soc'y 33 (1966).

243. The method assumes that the probability functions involved are normal (Gaussian). Id. at 35.

244. Actually, one always works with the squares of the differences divided by their standard deviations. Id. Dividing by the standard deviations is necessary for normalization, and using the squares insures that everything can be added up to get a single measure of the total "difference." Otherwise, differences of some elements which are greater than the respective inean values would be cancelled out by the negative differences of the elemeuts which are present in amounts less than their respective inean values.

245. Coleman I 5; CoLEMAN II 205. In this study, the small number was cliosen to be 0.01. Coleman I 6; Coleman II 204.

246. Coleman I 6; Coleman II 204. 
many other heads in the general population would also be labelled "indistinguishable" froin the hair found on the victim. This number depends on the distribution of the mean values of the trace element concentrations throughout the general population, a calculation requiring statistical background information. Coleman's group gathered 750 samples of hair from people all over England and Wales, ${ }^{247}$ and measured the mean values of the trace element concentrations in each of these samples. ${ }^{248}$ Assuming that this is a true random sample, one can calculate how many other heads in the population would also show a sum of the differences which is less than $\mathrm{C}_{0}$. This number of other heads in the population will also be "indistinguishable" from the hair found on the victim.

Note that if $\mathrm{C}_{0}$ is set very low it does not take a large total difference before the suspect's head is labelled "distinguishable." Thus, low values of $\mathrm{C}_{0}$ increase the chance that a truly guilty suspect will escape detection by this method. However, it will also decrease the number of other "indistinguishable" heads, so that the evidence agamst any party who does coine within the test will be quite strong. ${ }^{249}$ On the other hand, a high value of $\mathrm{C}_{0}$ will more readily implicate the suspect (whether he is in fact guilty or not), but the evidence will be less strong because the number of other "indistinguishable" heads will be large. In Coleman's study, $C_{0}$ was chosen such that the actual guilty party's hair would be designated "distinguishable" only one time in $100,{ }^{250}$ and some simulated cases were made up. ${ }^{251}$ It was found that the number of people in the population of England and Wales with heads similar to the suspect's varied in the ten simulated cases from 18 to 100,000 , even though in both of these extreme cases the suspect's head was found "indistinguishable" from the "guilty" hair (which, in fact, had been chosen from the suspect). ${ }^{252}$ These simulated cases show the importance of a quantitative measure of the evidentiary value of the coinparison. Even weak additional evidence might be sufficient to convict the suspect who is similar to only 18 other people chosen at random froin all over England and Wales, whereas considerably stronger additional evidence would be required if there are 100,000 similar heads.

247. Coleman I 9. Coleman II 207 reports the sample size to be about $70 \%$ of 1,200 .

248. The distribution of the mean values of the twelve element concentrations measured for this population are shown graphically in CoLeman I 25-36 (Figures 1 through 12).

249. Coleman I 6; Coleman II 206.

250. See note 245 supra.

251. Coleman I 13-14; Colleman II 210-11.

252. Coleman I 13; Coleman II 211. 
Parker's statistical method, used by Coleman, thus makes an explicit decision as to whether the guilty hair "matches" the suspect's head and then calculates how many other heads in the population will also "match" the guilty hair. There is another approach to the problem which appears to be equivalent to Parker's but which is not subject to the same restrictions and which may be easier to visualize and to apply to materials other than hair. The result of this approach is a figure termed the likelihood ratio which tells how much more likely it is that the guilty sample is associated with the suspect than with a random member of the population.

Suppose that a valid random sample of hairs has been chosen from the general population and the concentration of each trace element measured..$^{253}$ The distribution of these concentrations can be portrayed graphically, as in the hypothetical distribution for a single element shown in Figure 5(a). ${ }^{254}$ Similarly, numerous hairs are chosen from the head of the suspect and the distribution of trace element concentrations over the suspect's head portrayed graphically, as shown hypothetically in Figure 5(b). These curves are drawn so that the total area under each is unity, so they are susceptible to the following interpretation: The probability that a hair chosen at random from the general population will have element $A$ present in a concentration lying between any two given values will be the area under the element $A$ curve between the two values. For the simple curve shown in Figure 5(a), the probability that such a hair will havc element $A$ present in a concentration somewhere between 1.5 and $2.5 \mathrm{ppm}$ is shown by the shaded area in Figure 5(a) and is equal to 1/5. Similarly, the probability that a hair chosen at random from the suspect will have a concentration of element $A$ in the same range is the area under the suspect's element $A$ curve. In Figure $5(\mathrm{~b})$ this probability is $1 / 2$.

In order to determime the likelihood ratio we must make similar calculations for each of the elements measured. For simplicity, suppose that only five elements are involved and that they are all distributed over the general population and the suspect's head in the same way that element $A$ is. If the hair found clutched in the victim's hand is ineasured by NAA and found to contain $2.0 \mathrm{ppm}$ of each element within an experimental error of $\pm 0.5 \mathrm{ppm}$, we ask how strongly this im-

253. In Coleman's study, concentrations of twelve trace elements were considered. See note 248 supra.

254. The uniform (flat) distributions shown in Figures 5 and 6 were chosen for the sake of clarity in the numerical examples, and they do not purport to be realistic. The actual distributions will be similar to the results shown by Coleman [supra note 248], but will be normalized so that the total area under the curve is unity in order to make them probability distributions. The appropriate areas are then found by integration over the range of the experimental error. 


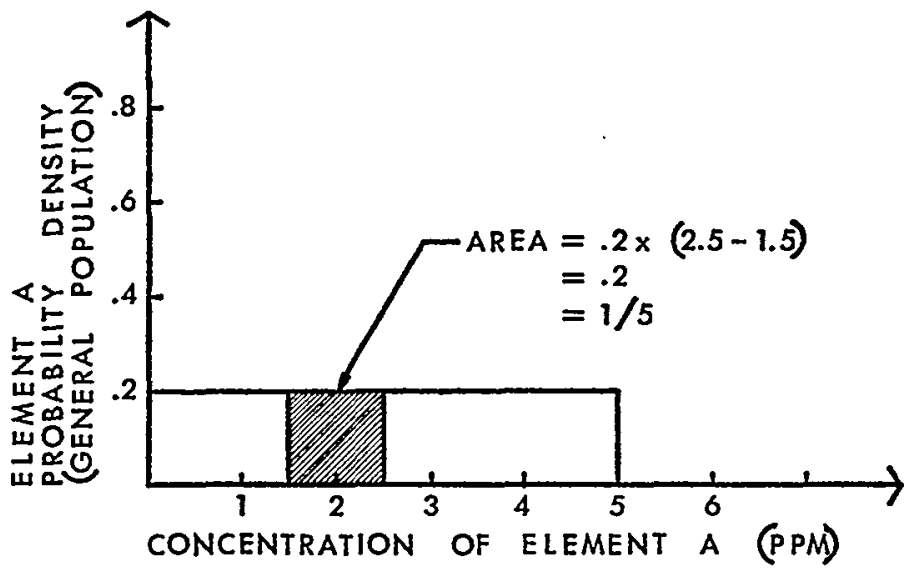

Figure 5(a). Probability of Choosing a Hair at Random from the General Population that has Element $A$ Concentrated in a Given Range.

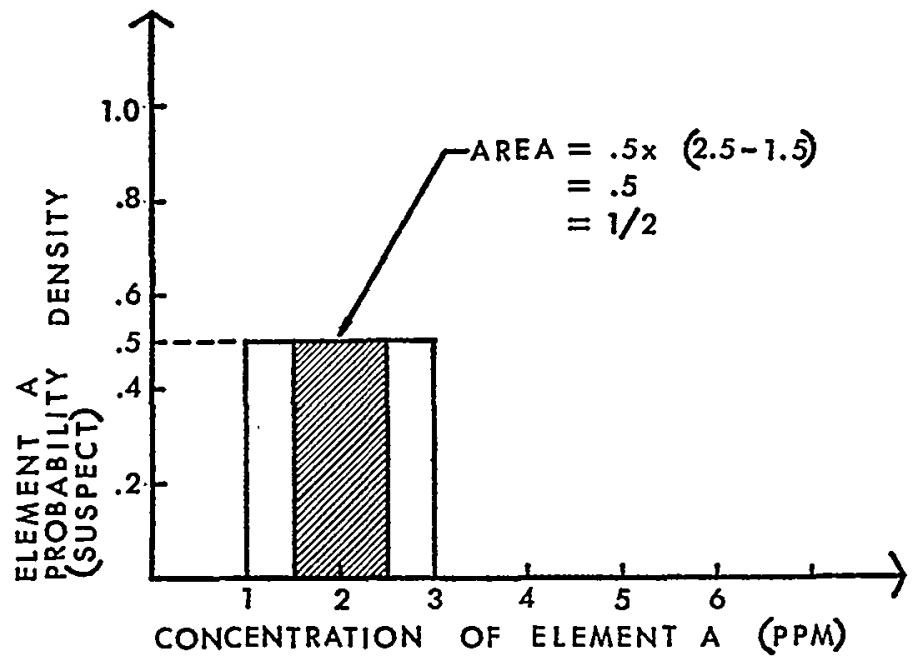

Figure 5(b). Probability of Choosing a Hair at Random from the Head of the Suspect that has Element $A$ Concentrated in a Given Range.

plicates the suspect. Assuming that all the concentrations are independent of each other, ${ }^{255}$ it is clear that the probability of choosing such a hair at random from the general population is the product of the individual probabilities, ${ }^{256}$ or $(1 / 5)^{5}=1 / 3,125$. However, we may assume that the hair in the victim's hand was randomly chosen so that

255. It is easy to modify the method if the concentrations are not independent, as long as the dependence is known. See note 303 infra. On the question of statistical independence generally, see notes 295-305 infra and accompanying text.

256. The product rule is often taken as the definition of independence. See, e.g., A. Papoulis, Probability, Random Variables, and Stochastic Processes 40 (1965). 
even if the suspect is the guilty party, the probability that the victim would have pulled out a hair with those particular concentrations is only $(1 / 2)^{5}=1 / 32$. Thus, the suspect is approximately 100 times more likely to produce a hair with those concentrations than a random member of the population. But it must be carefully noted that this does not, in itself, strongly imphicate the suspect. For every 100 others in the general population there is one who is as equally implicated by the NAA results as the suspect himself. If the population in question is large, ${ }^{257}$ this can be a sizable number.

Continuing the example, suppose the hair recovered on the victim is found to contain $3.25 \mathrm{ppm}$ of all five elements within the same range of error, $\pm 0.50 \mathrm{ppm}$. The probability of clroosing a hair at random from the general population which contains element $A$ in a concentration between $2.75 \mathrm{ppin}$ and $3.75 \mathrm{ppm}$ is given by the shaded area in Figure 6 (a) and is again equal to $1 / 5$. Therefore, the probability that a hair chosen at random will fall in this range for all five elements is again equal to $1 / 3,125$. For the suspect, there is zero probability $^{258}$ that a lair from his lead will have element $A$ concentrated in aunounts between $3.0 \mathrm{ppm}$ and $3.75 \mathrm{ppm}$, but because the lair found on the victim might actually contain element $A$ in a concentration between 2.75 and $3.0 \mathrm{ppm}$, it is still possible that this hair came from the suspect. The probability that a hair chosen at randoin from the suspect's head will fall into the range $2.75 \mathrm{ppm}$ and $3.75 \mathrm{ppin}$ is shown by the shaded area in Figure $6(\mathrm{~b})$ and is equal to $1 / 8$. Since, by liypothesis, all five elements measured have the same distribution as element $A$, the probability that the suspect could supply a hair witl the saine measurements as the guilty hair is $(1 / 8)^{5}=1 / 32,768$. Thus, the suspect in this case is about 10 times less likely to have supplied the guilty hair than a random member of the population. This does not clear the suspect, ${ }^{250}$ but it shows that no weight at all can be given to the fact that the hair could have come from the suspect, and in fact it is slightly favorable to him. ${ }^{260}$

257. We have been assuming that the suspect should be compared with the general population, but in fact there are other groups which may be more appropriate in a particular case. See text accompanying notes 271-80 infra.

258. Realistic probabilities of this type will never actually be zero. The zero probability results here because of the simplified form of the probability functions assumed in Figures 5 and 6 . See note 254 supra.

259. Certainly it does not mean that there is only one chance in 32,768 that the suspect is guilty. If the distribution of concentrations over the suspect's head is fairly widespread, the probability of choosing a hair of any particular values within a narrow range will be very small.

260. The jury should be told that they should consider the other evidence against the defendant as if it occurred against a "background" population 10 times as large as the actual population. However, it is perhaps questionable whether this would cause 


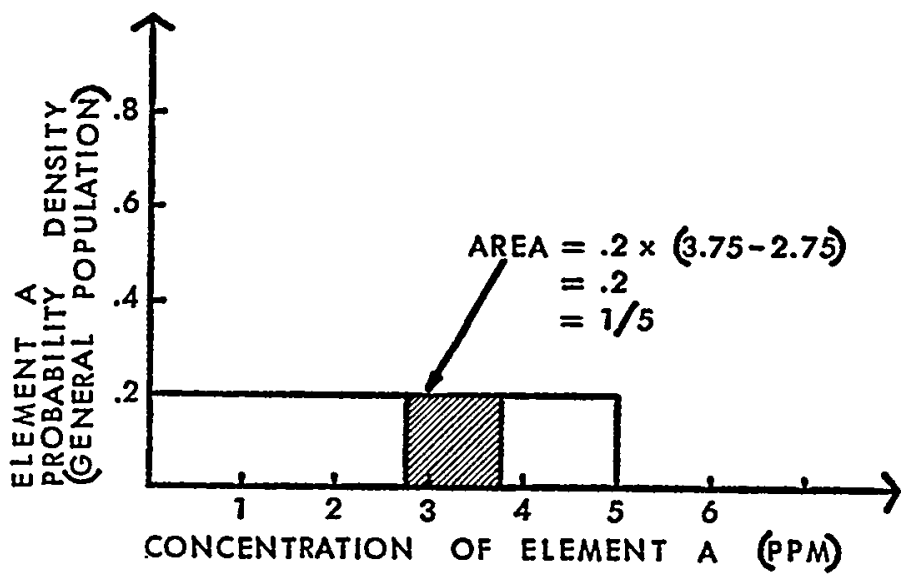

Figure 6(a). Probability of Choosing a Hair at Random from the General Population that has Element $A$ Concentrated in a Given Range.

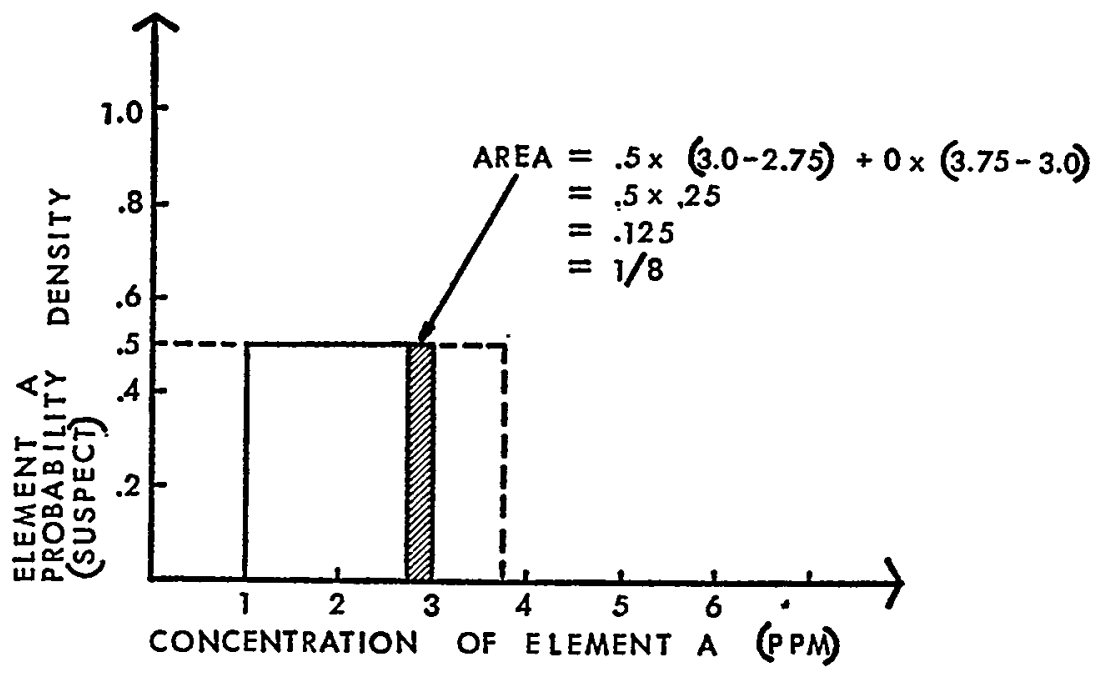

Figure 6(b). Probability of Choosing a Hair at Random from the Head of the Suspect that has Element $A$ Concentrated in a Given Range.

This method ${ }^{261}$ differs from Parker's in that it does not explicitly

them to make any significant changes in their approach. See the discussion of the Woodward case [text following note 127 supra] where the evidence went against the defendant.

261. The approach discussed in the text accompanying notes 253-60 supra appears to be a special case of Bayes' theorem. In its simplest form, this theorein states that if $A$ and $B$ are probabilistic events then $P(A \mid B)=P(B \mid A) P(A) / P(B)$, where $P(A)$ and $P(B)$ are the individual probabilities of events $A$ and $B$ and the notation $P(A \mid B)$ means the conditional probability that event $A$ has occurred given that event $B$ has occurred (similarly for $\mathrm{P}(\mathrm{B} \mid \mathrm{A})$ ). A. PApoulrs, supra note 256, at 38-39. Let $\mathrm{A}$ be the event that the defendant committed the crime and let $B$ be the event that a hair 
make a choice between "distinguishable" and "indistinguishable" heads. ${ }^{262}$ Instead of a simple yes-no answer, the result is given in terms of a likelihood ratio: how nnuch more or less likely it is for the measured hair to have coine from the suspect than froin a nnember chosen at random from the general population. Since this is a continuous variable, we know how strong the "yes" or "no" is. Furthermore, this approach does not require the assumptions that underhe Parker's method, ${ }^{263}$ and it seems to set forth in a inore straightforward way the relationship among the three basic factors involved. ${ }^{264}$ It is clear that if, in a particular case, the variation over the suspect's head is identical to the variation over the general population, the likelihood ratio will be unity. This means that the suspect is no more likely to have suppled the hair than a random meinber of the population, and the NAA evidence is therefore useless. If the suspect's head is uniform and his hair identical to that found on the victim, the likelihood ratio will be very large, so that the evidence agamst the suspect will be very damning. On the other hand, if the suspect's head is uniform and different in most concentrations froin the hair found on the victim, he will be almost completely exonerated. ${ }^{265}$

with the measured elemeutal composition was left at the scene. If we assume that that hair was left by the actual criminal (whoever he was), $P(B)$ is the probability that a hair with the measured composition would be chosen from a random member of the general population (that is, assuming that the criminal left a hair behind, $P(B)$ is the probability that a randomly chosen criminal would leave this particular kind of hair). $\mathrm{P}(\mathrm{A})$ is the probability that the defendant committed the crime, but without any of the information resulting from the activation' analysis. $\mathrm{P}(\mathrm{B} \mid \mathrm{A})$ is the probability that such a hair would be left behmi assuming that the defendant did commit the crime and left a hair randomly chosen from his head. The ratio $P(B \mid A) / P(B)$ is termed the likelihood ratio [see J. Kaplan, Decision Theory and Criminal Process 25-28 (uupubhished manuscript, partially published in D.W. LouTsell, J. Kaplan \& J.R. WALTZ, CASES AND MATERIALS on EVIDENCE 42-44 (1968))] because it is a measure of how much one should increase his estimate of the probability that the defendant committed the crime $(P(A))$ to obtain the probability the defeudant committed it given that a hair of that particular composition was left by the criminal ( $P(A \mid B)$ ). If we ignore any other evidence against the defendant, $P(A)$ will simply be the inverse of the total number of people in the population, and the likelihood ratio tells us how much more the statistical evidence points up the defendant as the criminal over a member of the general populatiou chosen at random.

262. See notes $245-52$ supra and accompanying text.

263. The most important restriction on Parker's method is that the probability distributions must be normal [see note 243 supra]. In Coleman's study the assumption was found to be roughly satisfied. Coleman I 9; Coleman II 207.

264. See the discussion in the text accompanying note 237 supra.

265. The approach taken here also shows how improvements in the experimental error will affect the result. In calculating the probabilities required for the likelihood ratio from Figures 5 or 6 , one multiplies the value of the probability function by the experimental error, which forms the base of each rectangle. In calculating the ratio, the experimental error cancels out because it is present in both the numerator and the denominator. In general, of course, the cancellatiou will not be complete because the ordinary probability curve will not be "flat" like the curves shown in Figures 5 and 
Whichever approach is used to evaluate the evidence, essentially the same result is achieved. The suspect is singled out only as a member of a restricted subclass of the general population. It will be only the extremely rare case in which activation analysis will provide haircomparison evidence sufficient in itself to sustain a conviction. In most cases the evidence will have some probative value, but this value can only be assessed if the appropriate background studies have been carried out. ${ }^{268}$ If these studies are not available and the limitations of the measurement are not made clear, there is grave danger that it will mislead the jury. ${ }^{207}$

It should be observed that the probative value of a "match" increases as the intraperson person variability decreases, that is, as the suspect's head becomes more nearly uniform. One way apparently to reduce the imtraperson variability is to use small bundles of hair, which annount to at least a partial average over a suspect's head. Such an approach, however, can only be used in cases where several hairs are also found on the victim and there is good reason to believe that all the hairs caune from the same person. It has been pointed out that in most cases all the hairs found at a crime site cannot a priori be assumed to have come from one person. ${ }^{288}$ This approach also requires that the statistical background information be built up out of measurements on bundles from the general population, because the concentration deviations anong individual hairs is likely to be somewhat greater than the deviations of the averages. ${ }^{269}$

Very little has been published on the distribution of trace element

6 which were chosen that way for simplicity. In general, the appropriate probabilities will be the integrals under the curves over the range of the experimental error, but it is clear that all the probabilities calculated in the general situation represented here by Figures 5 and 6 will increase with increases in the experimental error (because the areas will increase) and will decrease with decreases in the error. Therefore, both the numerator and the denominator of the likelihood ratio change in the same way with changes in the error. This means that once the error is small compared with the increments of concentration variation over which the probability density varies significantly, further improvenents in the accuracy of the NAA measurement will not result in any better estimate of the likelihood ratio.

266. There are other problems with hair comparisons by NAA which make it difficult to carry out the appropriate background study, or even to define what kind of study would be appropriate. See text accompanying notes 271-85 infra.

267. See note 211 supra.

268. Bate \& Dyer, supra note 165 , at 250.

269. As a simple example, if one person's head has values running from 0 to 5 , average 2.5, and another person's runs from 5 to 10 , average 7.5, then their averages only run from 2.5 to 7.5 and not from 0 to 10. This is important, because the curve of the averages thus tends to be more pushed up in the middle, making it more likely that a person at randon will produce a bundle at those values. This lowers the probative value of the evidence against a suspect whose bundle "matches" the hairs found on the victim. 
concentrations in pubic hair or hair from other parts of the body. 270 Until such studies are made, courts should be very circumspect in admitting evidence based on comparisons of these materials.

\section{The Background Study: Defining the General Population}

The evidence tends to show that there is considerable variation in hair trace element concentration from one locale to another. ${ }^{271}$ Furthermore, people of similar backgrounds have less variation in trace element concentrations than people of diverse backgrounds. ${ }^{272}$ Coleman reported that some of the samples in his study contained unusually high concentrations of certaim elements that could be attributed to the occupations of the hair donor--high copper concentration in the hair of brass workers, for example. ${ }^{273}$ Similar reports have been made by others. ${ }^{274}$ These findings have a large bearing on the representative sample against which a given suspect is to be compared. For example, if a murder occurs in a town in which many persons work at a similar job and one of them becomes a suspect, it may be unfair to compare him against the population of the whole United States. Even if the general sample which purports to cover the entire United States is a valid random sample, so that people who work at that particular job are properly imcluded, any local variations in the concentrations from the national average due to the particular occupation of the large number of townspeople will be quite diluted when averaged together with the rest of the country. Therefore, it might appear quite unlikely that the hair found on the victim would have come from a random member of the United States population, but it can be relatively much more likely to have come from a randomly chosen townsman. Therefore, if there is good reason to believe that

270. A.K. Perkons, P.A. Vlossack, N. Erickson \& R.E. Jervis, Further Development to Forensic Activation Analyses 2 (1962) (Attorney-General's Laboratory and University of Toronto, unpublished report) states simply that pubic hair has "similar conposition to head hair, but has generally considerably higher concentrations." Body hair was found to have quite a few points of similarity to head hair, although the authors conclude that it has a different composition. Id. No data are presented. In the same report it was found that hair from one person taken at different times "shows almost exactly the sane composition." Id. This has since been found to be untrue, and some scientists feel that comparisons are worthless if the hairs compared are taken niore than about 70 days apart from each other. See text accompanying notes 278-79 infra.

271. Lyon \& Miller, supra note 88, at 329.

272. Id.

273. Coleman I 13; Coleman II 210.

274. Lima, Shibata \& Atalla, Activation Analysis Applied to Forensic Investigation, in 1 RAdIOCHEMICAL Methods of ANALYSIs 119, 122-23 (STI/PUB/88, International Atomic Energy Agency, Vienna 1965). 
some local party is guilty, the suspect would be unfairly prejudiced when compared against the population at large.

Thus far there have been no general studies on the size of a locale beyond which regional variations become important. Information on this question is necessary to ensure that a suspect is not unfairly prejudiced by comparison against a background study which embraces too large a geographical area. ${ }^{275}$ Coleman reported that his group found no obvious variations for most elements in different parts of England and Wales, ${ }^{276}$ but this conclusion may not be applicable to a country with the environmental diversity of the United States. ${ }^{277}$

Another factor important in obtaining a valid sample from general population is the variation in trace element concentrations with time. Two authors interpreting some of Coleman's results ${ }^{278}$ feel that it is useless to compare two samples taken from the same individual more than 70 days apart. ${ }^{279}$ Not only does this rapid time variation prevent the establishment of a library of hair analyses analogous to a fingerprint library, ${ }^{280}$ but it can also liave a bearing on the validity of a background study performed a number of years earlier. The average characteristics of the general population might be expected to change much more slowly than those of any given individual, but they nevertheless might cliange. If so, it is prejudicial for a suspect to be compared against the old random sample. Thus, a hair which today has many characteristics common to the present population, and which therefore would be relatively likely to liave come from a person cliosen at random, might appear quite unlikely to have come from a random individual under the old general population survey.

\section{Variation Along the Length of a Hair}

Even a single hair varies greatly in trace element composition with distance fron 1 the root; ${ }^{281}$ in fact, the variation is of the same order as

275. The size of the appropriate geographical area should be expected to vary from element to element, because the variation in dietary sources, for example, cannot a priori be assumed to be the same as the variation in climatic or other environmental sources. The snspect's attorney must be sensitive to these possibilities, which can transform a large likelihood ratio, when the suspect is compared to the population of a large geographical region, into a relatively small one with respect to a smaller region.

276. Coleman I 13; Coleman II 210.

277. See Lyon \& Miller, supra note 88, at 329.

278. COLEMAN I 11-12; COLEMAN II 209.

279. Lyon \& Miller, supra note 88, at 329. Coleman himself has drawn a similar conclusion. Coleman, Nuclear Techniques in Forensic Science, 6 J. BRT. NUC. ENERGY Soc'y 134, 137 (1967).

280. COLEMAN I 12; Coleman II 209.

281. Lyon \& Miller, supra note 88, at 329. 
the variation from hair to hair across a single head. ${ }^{282}$ This indicates that in comparisons for identification purposes, the two hairs being compared should not only be of identical length, but their correspondmg end points should also be the same distance from the scalp. Assuring correspondence can be particularly difficult if the hair left at the scene of a crime is one which for some reason was cut somewhere in the middle rather than pulled out by the root. ${ }^{283}$

In criminal cases it might appear that neglecting the hair's variation along its length could only favor the defendant, because if the top end of one hair is coinpared to the whole or the root end of another, any variations between the root end and the upper part would tend to show dissimilarity. However, it must be remembered that the hair found at the scene of a crime is not compared only with the defendant's hair. In order to evaluate the probative significance of the comparison, the hair found at the scene of the crime must also be compared with a background study of an appropriate sample group. ${ }^{284}$ If all of the hairs used in the background study are whole hairs, or whole hairs cut to a uniform length, then the guilty hair may also appear less likely to have come from a random member of the sample group. It is not clear which of these factors, if either, would predominate. Coleman has speculated that the error here would not be large, ${ }^{285}$ but there have been no careful studies of the question. Therefore, it cannot be assumed that whatever error is introduced by this factor will always be favorable to the defendant.

\section{Contamination Problems}

The problem of sample contamination through improper handling is a general one in activation analysis, because even minute contamination can cause large errors when the quantities being measured are also minute. ${ }^{286}$ However, there are even further contamination considerations which are necessary in the case of hair analysis. Because it is necessary to control the sampling closely, ${ }^{287}$ surface contamination froin such things as dust should be removed by careful washing in building up the background information necessary for hair comparisons. ${ }^{288}$ This

282. COLEMAN I 12.

283. Lima, Shibata \& Atalla, supra note 274, at 122, 125.

284. See text accompanying notes 253-60 supra.

285. CoLEMAN I 12.

286. Smith \& Lenihan, Biological Applications of Activation Analysis, in III Methods of Forensic Science 69, 78 (A.S. Curry ed. 1964). See also text accompanying notes 87-90 supra.

287. Lyon \& Miller, supra note 88 , at 327.

288. Bate \& Dyer, supra note 165, at 251; Bate \& Dyer, Trace Elements in Human Hair, 23 Nucleonics, Oct. 1965, at 74, 80. 
has been done in the major studies that have been reported. ${ }^{289}$ It is then also necessary to clean both the suspect's hairs and the hair found at the scene of the crime before they are analyzed. Otherwise, the failure to remove surface contamination from the hair found at the scene of the crime will make the hair appear less likely to have come from a random member of the sample group.

Coleman has noted that such washings may remove material of evidential value, ${ }^{290}$ and this is especially true if the suspect is apprehended very shortly after the crime, essentially before he has had time to wash his hair. The same author has also pointed out, however, that the wash solutions can be retained and studied separately from the clean hair, and that the evidential value of the contamination can only be determined through a study of such things as dust. ${ }^{291}$ Therefore, this is properly treated separately from the clean hair comparison, and comparisons of uncleaned hairs should not be permitted. Washing techniques can have a large effect on the trace element concentrations of hair, ${ }^{292}$ and it is therefore important that the saine method be used not only for the suspect's hairs and the hair found on the victim but for the hairs used in the background study as well.

Another important discovery is that it is possible to add trace elements to hairs by soaking them in solutions containing ions of the elements one desires to add. ${ }^{293}$ These elements are not easily removed by washing, ${ }^{294}$ and the extremely careful criminal who is not apprehended immediately after the crime might give himself hair treatments as a precautionary device against possible future hair comparisons by NAA. This discovery also imdicates that new hair dyes and rinses, for exainple, may tend to skew the results of the general background survey over time.

\section{Correlations}

Whenever one calculates the probability of a compound event from the probabilities of the simpler events which compose it, it is necessary to consider the ways the simpler events are connected with each

289. Colleman I 8; Coleman II 206; A.K. Perkons, Individualization of Human Head Hair, in Forensic Activation ANALYSIS, supra note 53, at 221, 221-22.

290. Coleman I 8; Coleman II 206.

291. Coleman I 8; Coleman II 206.

292. Depending on the washing method, fractions of some trace elements, sometimes very large fractions, can be removed. See Perkons \& Jervis, Individualization by Neutron Activation Analysis, in LAW ENFORCEMENT SCIENCE AND TECHNOLOGY, supra note 46, at 257, 257-59; Bate \& Dyer, Trace Elements in Human Hair, supra note 288, at $76-78$.

293. Bate \& Dyer, Trace Elements in Human Hair, supra note 288, at 78-80.

294. Id. 
other. For example, it is generally assumed that the probability of throwing heads on one coin toss is not related to the probability of throwing heads on a second toss of either that coin or another one. In that case, the probability of throwing heads on both attempts is determimed by the product of the two simple probabilities; it is $1 / 4$ if the two individual probabilities are each $1 / 2$. However, if each time the coin tosser throws a head he picks an apple off a nearby tree, the probability for the simple event "throwing heads" is the same as the probability for the simple event "pick an apple," but the probability for the combined event "throw heads and pick an apple" is still $1 / 2$ and not $1 / 4$, because each always accompanies the other. In probabilistic language, the two events are dependent. ${ }^{205}$

There is judicial recognition of need for adequate proof of statistical independence before probabilistic calculations based on the product rule are introduced into evidence at trial. ${ }^{296}$ In the case of trace

295. The concept of independence is discussed in every book on probability theory. See, e.g., A. PAPoulis, supra note 256, at 40-44.

296. See, e.g., People v. Collins, 68 Cal. 2d 319, 438 P.2d 33, 66 Cal. Rptr. 497 (1968). However, the California supreme court was not always so enlightened. In People v. Trujillo, 32 Cal. 2d 105, 194 P.2d 681 (1948), two accused murderers were convicted almost entirely on the basis of a "fiber transfer" comparison. Part of the trial record is reproduced in Houts, The Law of Probability in the Courtroom, in LAW ENFORCEMENT SCIENCE AND TECHNOLOGY, supra note 46, at 433-35. The expert's theory was that as clothes fibers wear out, small pieces break off and are easily transferred to another piece of cloth with which the clothes come into contact. Fibers associated with the clothing of the deceased were compared with some fibers found adhering to a piece of one defendant's clothing, and eleven different types were found to match. By making a "conservative" estimate that the probability of a single match in fiber type was one in ten, the expert concluded that eleven types would be found to match on clothing chosen at random only once in 100 billion times.

This is a case in which one should be very suspicious of the independence of the individual matches. It is not unreasonable to expect that certain fibers might be used together in certain types of material, and if this is found to be the case the probabilities will be much larger.

It is worth noting the other errors involved in admitting the evidence im this case because of the similarity of the problem to that of activation analysis evidence. The purported match was intended to show that the defendant's clothing had come into contact with that of the deceased. As such, the evidence would then be no stronger than that against anyone else who had come into contact with the deceased's clothing, and the chance that someone else had done so must be greater than one in 100 billion. Probably even more important, it was the deceased's clothing that was the purported source of the fibers, and therefore any clothing made of identical material might equally have been the source. A similar problem of source definition is involved in many comparisons by NAA. See note 133 supra. If the manufacturer made many items of clothing out of this material, the subclass of which defendant is a member could be rather large, consisting as it does of everyone who has rubbed against a person who was wearing clothing made of this material. Reasonably strong additional evidence should be required, especially in this case since fibers from the defendant's clothing were taken ten months after the crime was committed. $32 \mathrm{Cal} .2 \mathrm{~d}$ at 112,194 P.2d at 685 . However, in addition to the testimony of an alleged ac- 
element concentrations, the question is to what extent a given amount of one element affects the probability that a given amount of any other element will be found. If large amounts of element $A$, for example, are always associated with large amounts of element $B$, and vice versa, one cannot give independent value to the measurement of both elements.

Although some hair studies have reported that no dependence of the element concentrations on one another was observed, ${ }^{297}$ others have found that some dependence does in fact exist. ${ }^{298}$ Only Coleman has presented numerical results, however, for the correlations between the concentration of each trace element and that of each other element measured in his survey. ${ }^{299}$ Although he found that about half the correlations were statistically significant, he ignored them in his simulated studies because the error was small. ${ }^{300}$

Ignoring the statistical dependence of the element concentrations over the public at large has the result of making the evidence agamst the suspect appear stronger than it actually is. ${ }^{301}$ Therefore, in making the background studies, the extent of the correlations should be measured, ${ }^{302}$ and accounted for when appreciable. ${ }^{303}$ It may be harder to measure correlations between element concentrations in the hairs of a single head because of the necessarily limited sample of liairs avail-

complice (insufficient to convict under CAL. PENAI CODE $\$ 1111$ (West 1957) [see 32 Cal. $2 \mathrm{~d}$ at 110,194 P.2d at 684]), there was only an expert's statement that the fatal bullet "could have come" from Trujillo's gun, the statements of two witnesses besides the accomplice that a scarf found on the victim had been seen in Trujillo's room, and a statement of one witness besides the accomplice that a screwdriver found at the scene had been in Trujillo's possessiou. 32 Cal. $2 \mathrm{~d}$ at 109-12, 194 P.2d at 684-85. Therefore, it is certamly possible that the jury attached great weight to the fallacious expert testimony. Nevertheless, defendant Trujillo was executed in the California gas chamber. Houts, supra at 435.

297. Bate \& Dyer, Trace Elements in Human Hair, supra note 288, at 81.

298. Perkons \& Jervis, supra note 292, at 259; ColEMAN I, supra note 241, at 11; COLEMan II 209.

299. Coleman I 20.

300. Id.

301. Recall that the NAA comparison gives information on how inuch inore likely a hair of the type found at the scene of the crime would be to come from the head of the suspect as opposed to the head of a member chosen at random from the sample group. See text accompanying notes 253-67 supra. If dependence of element concentrations among hairs in the sample group is ignored, the product rule for compound probabilities [see text accompanying note 295 supra] gives a sinaller probability that the guilty hair came from a random member of the sample group than would otherwise result. The smaller this probability is, the greater is the likelihood ratio and, therefore, the stronger is the probative force of the evidence against the suspect. See text accompanying notes 253-67 supra.

302. If the sample is large enough, this is mainly jnst a matter of bookkeeping, a problem well-snited for rapid solution by compnter.

303. Parker's method for accounting for the correlations is given in Parker, 
able. ${ }^{304}$ However, ignoring the dependence of the elements in this case is not prejudicial to the defendant, because it then appears less likely than it really is that the hair found on the victim would be randomly chosen from the suspect's head. ${ }^{305}$

Correlations between certain trace element concentrations and other properties have also been discovered. ${ }^{306}$ Especially interesting is Coleman's discovery that the distributions of trace element concentrations is significantly different between male and female hair, and he estimates that these differences would allow identification of the sex of the supplier of an unknown hair about 90 percent of the time..$^{307}$ Correlation of certain element concentrations with occupations has already been noted. ${ }^{308}$ These results may be useful in the investigatory stages of crime detection in helping the police to narrow the search. Other commentators have reported finding correlations between certain ele-

The Mathematical Evaluation of Numerical Evidence, 7 J. FoR. Scr. Soc'y 134 (1967). The approach suggested in the text following note 253 supra is fairly easily adaptable if the multiple-element probability densities can be accurately determined, and this should be possible if the sample is large enough. Instead of finding the area under each of the individual-element probability curves, it is necessary to integrate the multiple-element probability densities, for those elements whose concentrations are dependent on one another, over the ranges of experimental error of the dependent eleinents. Even if such extensive background data are not available, one should at least be able to estimate the maximum reduction in probability that might result from dependence of the concentrations. Then, if this maximally-reduced probability figure is used in all the calculations, the defendant can claim no prejudice.

304. If a valid randoin sample for measuring the probability distributions requires $\mathrm{N}$ members, then many inore than $\mathrm{N}$ members (about $\mathrm{N}^{2}$ as a very rough approximation) are required to get valid measures of the first-order correlations. To see this, consider the dependence of the concentration of element $B$ on the concentration of element $A$. It is necessary to get independent measures of the distribution of element $B$ at each concentration level of element $A$. The measurement of each of these distributions requires about $\mathrm{N}$ members (by hypothesis) so it is necessary to ensure that each concentration level of element $A$ is represented about $\mathrm{N}$ times. Assuming the number of concentration levels is of the same order as the minimum number of members of the randoin sample (within a factor of two or three), about $\mathrm{N}^{2}$ members are required to get accurate measures of the first-order correlations. Thus, if 20 hairs suffice to measure the individual distributions over a single head, a number on the order of hundreds may be required to measure the correlations, and an ordinary suspect might balk at having to give up so much of his hair. Furthermore, there would be a fantastic increase in the cost of the tests.

305. The numerator of the likelihood ratio [see text acconpanying notes 261-63 supra] is the probability that a hair with characteristics of the guilty hair would be randomly chosen from the suspect's head. Ignoring the statistical dependence of the concentratious over the suspect's head makes this probability appear lower than it is, so the likelihood ratio also appears lower.

306. Coleman I 12-13; COLEMAN II 209-10.

307. Coleman I 12; Coleman II 210. However, F.F. Dyer has questioned whether this result remains true today (five years after Coleman's study) now that the average length of men's hair is considerably longer. F.F. Dyer, comments on the author's manuscript, Jan. 13, 1971.

308. See notes 273-74 supra and accompanying text. 
ment concentrations and heavy smokers or frequent drinkers of alcoholic beverages. ${ }^{309}$ It remains to be seen whether these results will find practical application.

\section{B. Glass}

Glass, like many other nonbiological materials, does not have as many disadvantages for NAA comparisons as biological materials such as hair, which change in elemental composition with time. ${ }^{310}$ Furthermore, it is known that window glass, for example, does not vary in trace element composition over a sample the size of a single window, ${ }^{311}$ so that problems analogous to the variation of hair over the head of the suspect are absent. Nevertheless, it is still necessary in every case to be very careful in evaluating the probative force of the comparison.

At present there are no reported large-scale studies of glass comparisons, ${ }^{312}$ although preliminary work indicates that the variations in trace element concentrations are considerably less in glass than in hair. ${ }^{313}$ One reason for the small variation appears to be the small number of independent manufacturers involved. ${ }^{314}$ It is very important to obtain detailed information on the trace element variations, because if they truly are small the probability of a random "match" will be higher, weakening the probative value of the evidence.

Suppose a window is broken during a burglary and later a suspect is found with a small piece of glass adherimg to his clothing or hair. The police would like to connect the piece of glass found on the suspect with the particular window that was broken during the burglary, but NAA will be capable of doing this only to the extent that that window can be shown to be measurably different in trace element composition from all other possible sources of small pieces of glass with which the suspect might have coine in contact. Unfortunately, however, it appears that there might be many sources of glass with identical trace element concentrations. One study found that the glass of a single

309. Perkons \& Jervis, supra note 292, at 259-61.

310. Leniban, supra note 232, at 527.

311. See R.F. Coleman, G.C. Goode \& G.A. Wood, supra note 152, at 3. See also Schmitt \& Smith, Identification of Origin of Glass by Neutron Activation Analysis in a Forensic Case, 15 J. For. Scr. 252, 255 (1970).

312. But cf. G.C. Goode, G.A. Wood \& R.F. Coleman, Interim Report on the Multi-Element Analysis of Glass Fragments by Neutron Activation Analysis and the Application to Forensic Science, Nov. 1969 (AWRE Report No. O 54/69, United Kingdom Atomic Energy Authority). This report gives the preliminary results of a major background study of glass in Eugland. When the final report is available, even if it is not directly applicable to United States cases, its conclusions should give very iniportant clues as to precisely what information is needed in a given case.

313. A.K. Perkons, P.A. Vlossak, N. Erickson \& R.E. Jervis, supra note 270, at 5.

314. Lenihan, supra note 232 , at 528. 
large manufacturer showed only very small variations in uranium content over all the years froin 1924 to 1966 , even though uranium is an impurity which the manufacturer made no effort to control. ${ }^{315}$ Similarly, in a recent civil case, it was known that the glass in question was supplied by one of four manufacturers. A broken sample from the scene of the accident compared almost exactly with glass made by one of the four companies at least four years after the latest time the broken sample could have been made. ${ }^{318}$ Upon seeing the NAA results, the company admitted that it manufactured the particular window, ${ }^{817}$ but smce the company's glass apparently remained relatively uniform for at least four years, there must be much more "matching" glass in existence. Thus, in some cases, NAA may be able to do no better than pick out the manufacturer of the glass, and in such a case it must be made quite clear to the trier of fact that any statements about the compared glasses coming from a "cominon source" do not refer, for example, to the window of the burglarized building. ${ }^{318}$

These considerations, of course, apply only to the evidentiary impact of the NAA measurement in itself. That the suspect has a piece of glass adhering to his clothing at all, especially if he cannot explaim it, will be at least moderately damaging to him, ${ }^{310}$ whereas no evidentiary value ordinarily attaches to the fact that a suspect has hair, for example. Nevertheless, the jury and not the NAA expert decides the weight to give to the suspect's story, in the light of the evidence regarding how much glass of the type in question is in existence.

315. Coleman, The Application of Neutron Activation Analysis to Forensic Science, 6 J. For. ScI. Soc'y 19, 23 (1966).

316. Schmitt \& Smith, supra note 311 , at 253-58.

317. Id. at 255 .

318. A Brazilian hit-and-run case involving NAA comparisons of glass from the struck car's wimdshield, which was broken during the collision, and glass fragments found on the suspect truck two days later is described in Atalla \& Linna, An Actual Case of Glass Debris Identification by NAA in an Automobile Accident, 3 RAdrochEM. \& RADIOANaLYTICAL LetTERS 13 (1970). The report does not say how this evidence was put to legal use; however, the only tests described are those that indicate a "match" between the compared samples, and the conclusion is that the tests indicated a "common origin," with no attempt to explain what was meant. Id. at 17. If this evidence were to be used in court, it provides a good example of evidence to which the opposing side should seriously consider stipulating. See notes 211-16 supra and accompanying text. A stipulation that the two samples had the same manufacturer would ensure that the trier of fact was not confused by the wealth of detail involved in the coinparisons and could foeus properly on the unresolved issue-how much more glass exists that is identical to both samples?

319. Nickolls, Glass as Evidence, 6 J. For. ScI. Soc'y 180, 180 (1966). Of course, if the suspect has an explanation, comparisons can possibly be made with his claimed source. If these also match, the NAA results will have no weight at all. Even if the suspect's claimed source cannot be located, and if the piece found on hin matches the window, it still might be possible to ascertain whether the nnanufacturer of the window glass also makes the type of glass the suspect claims to be the source. 
The civil case discussed above is a good example of how the value of NAA evidence depends on the legal issue. ${ }^{320}$ That case was a strict hability action against the manufacturer of allegedly defective glass. ${ }^{321}$ The local source of the glass was known, and that source had only four manufacturer-suppliers during the year in which the glass in question was purchased. ${ }^{322}$ Thus, the NAA problem was to identify the manufacturer, a much easier problem than linking a small piece of glass with a particular window.

Certain commentators have pointed out ${ }^{323}$ that NAA will probably be a method which complements the present physical methods of glass comparison, the most valuable of which are index of refraction and specific gravity comparisons. ${ }^{324}$ While many of the element concentrations measured by NAA may bear no relationship to these other physical properties, ${ }^{325}$ some of these properties may be at least partially determined by the composition, so it may be redundant, and hence prejudicial, to make comparisons of too many properties in addition to an NAA comparison. ${ }^{326}$ A study currently being conducted in England should throw some light on this question when it is completed. ${ }^{327}$

\section{Blood}

Very few positive results have been reported on the use of activation analysis of blood for identification purposes. ${ }^{328}$ Even some of the leading proponents of forensic activation analysis have concluded that NAA blood analyses will usually be of little use because blood specimens taken from the scene of a crime are usually too contaminated with such materials as dirt or cloth; there is no known way to separate the contaminating inaterials physically. ${ }^{329}$ Furthermore, large amounts of sodium and chlorine in blood obscure many of the shorter

320. See text accompanying notes 316-17 supra.

321. R.A. Schmitt, Recollections of a Federal Trial Involving the Case of Susan Brizendine v. Visador et al., Nov. 1968, at 2. See also The Portland Oregonian, Sept. 19, 1969, at 9, col. 6.

322. Schmitt \& Smith, supra note 311 , at 252.

323. G.C. Goode, G.A. Wood \& R.F. Coleman, supra note 312, at 9.

324. Nickolls, supra note 319 , at 181.

325. G.C. Goode, G.A. Wood \& R.F. Coleman, supra note 312, at 9.

326. Kirk \& Kingston, supra note 137, at 441.

327. G.C. Goode, G.A. Wood \& R.F. Coleman, supra note 312 , at 7.

328. Apparently there are methods of blood identification other than activation analysis which might be exploited but on which there is also insufficient research. See Kirk, Blood-A Neglected Criminalistics Research Area, in LAW ENFORCEMENT SCIENCE AND TeChNOLOGY, supra note 46, at 267.

329. See V.P. Guinn, supra note 38, at 11. See also Bryan, Guinn \& Settle, supra note 165 , at 692 . 
lived radionuclides ${ }^{330}$ in gamma-ray spectra. ${ }^{331}$ Finally, the nonessential trace elements in blood can vary widely in very short periods of time because of new food or drink inputs. ${ }^{332}$ At present, there are no reported studies on the distribution of trace elements in blood that would allow calculation of the probability that a given combination of trace element concentrations would occur in a randomly chosen sample. ${ }^{333}$

The rapid changes in trace element concentrations over time would clearly render suspect any purported comparison between blood found at the scene of a crime and blood taken at a later time from a living person. However, this problem should not arise if the comparison is between blood found on a victim's clothing and blood discovered later on the clothing of a suspect. This apparently was the situation in State v. Stout, ${ }^{334}$ in which blood spots on the shirt of the accused were compared with bloodstains on the bedsheets of the murder victim. ${ }^{335}$ In that case, the expert attempted to solve the contamination problem by a new method, ${ }^{336}$ which apparently involved subtracting the NAAdetermined elemental composition of a nonbloodstained part of the shirt from that of a stained part and doing the same thing for the sheet. ${ }^{337}$

The information available on the Stout case does not make clear low the interference problem due to sodium and chlorine was solved, or how many element concentrations were found to "match" by the new technique. Nevertheless, the expert testimony in this case is deficient in at least two ways. First, the new subtraction technique has not yet been subjected to scrutiny by other scientists, so that it cannot be said to have met the test set in Frye v. United States, ${ }^{338}$ namely, to have achieved "general acceptance in the field in which it belongs."

330. See V.P. Guinn, supra note 38, at 11; Bryan, Guinn \& Settle, supra note 165, at 692. This general type of interference is discussed in the text following note 45 supra.

331. On gamma-ray spectra see note 47 supra and accompanying text.

332. V.P. Guinn, supra note 38 , at 11.

333. Some general results of trace element analysis of blood are summarized in Guinn, The Current Status of Neutron Activation Analysis Applications, in 2 MODERN TRENDS IN ACTivatron ANALYSIS, supra note 37, at 679, 693-94.

334. No. 31925 (Mo. Cir. Ct., Cass County, June 29, 1970), appeal docketed, No. 56,070, Mo., Aug. 24, 1970.

335. Columbia Daily Tribune (Columbia, Mo.), June 28, 1970, at 1, col. 6.

336. Deposition of G.W. Leddicotte, Nov. 13, 1969, at 32-34, State v. Stout, No. 31925 (Mo. Cir. Ct., Cass County, June 29, 1970), appeal docketed, No. 56,070, Mo., Aug. 24, 1970.

337. This is an inference from the expert's testimony that the analysis could be performed as long as one has a "portion of the environment where the test sample is taken from." Id. at 34 .

338. 293 F. 1013 (D.C. Cir. 1923).

339. Id. at 1014. Two scientists at Oak Ridge National Laboratory have indicated the most serious doubts about the analytical procedure used in Stout. They feel that 
Second, even if the technique is valid for the elemental analysis of blood, there was no statistical background against which the analysis could be compared to justify the reported claim of the expert that he could say with "scientific certainty" that the blood spots on the accused's shirt was blood of the victim. ${ }^{340}$ At best, the expert's special knowledge would allow him to make statements as to the elemental compositions of the two samples. Assuming there had been no problem regarding the general scientific acceptability of the method used in this case, such restricted statements should be admissible even in the absence of detailed background information, ${ }^{341}$ and it should be left to opposing counsel to bring out the limitations which must be placed on any inferences about identity which may be made. ${ }^{342}$ Lacking back. ground statistics the expert's claim in Stout was completely unfounded and extremely prejudicial.

\section{Soil}

Even before the development of forensic activation analysis, some commentators observed that the individuality of samples, the very trait used to establish common origin in most contexts, is so exaggerated in soil comparisons as to render them useless except in rare circumstances. ${ }^{343}$ Unfortunately, the imdividuality of soil extends also to its trace element concentrations, which vary widely over very small distances. ${ }^{344}$ This raises problems similar to those resulting from the variation of hair composition over a single head. If the suspected source is highly variable, its nonuniformity must be taken into consideration in interpreting the meaning of any "match."

In spite of these difficulties, results of soil activation analyses have been introduced into at least 14 trials, $^{345}$ so it is very important that the legal profession be aware of the possible pitfalls of such analyses.

few qualified analytical chemists would expect to get correct results from this background-subtraction technique even in normal laboratory problems and that much more care should be used in forensic investigations. W.S. Lyon \& F.F. Dyer, comments on the author's manuscript, Jan. 13, 1971.

340. Columbia Daily Tribune (Columbia, Mo.), June 28, 1970, at 1, col. 6.

341. See text accompanying notes 208-10 supra.

342. Even when sufficient background information exists it is only the probability that can sometimes be calcnlated with "scientific certainty" and not the identity. See the discussion of the Holt case [text following note 154 supra].

343. M. HouTs, supra note 138 , at 337.

344. V.P. Guinn, supra note 38, at 11. A related problem is that soil is not homogeneous, so that even to characterize a single "spot" on the earth it is necessary to take relatively large samples (samples considerably larger than one milligram). V.P. Guinn \& R.H. Pinker, supra note 68, at 22. Thus, much of the advantage of NAA's sensitivity, which is often a primary consideration in forensic studies where small samples are all that is available [see text accompanying notes 70-75 supra] is lost.

345. See cases cited in M.J. Pro \& V.P. Guinn, supra note 5. 
In one case, ${ }^{346}$ soil from the vicinity of a whiskey still was compared with soil found on a vehicle suspected of transporting the moonshine. Apparently the variation of the soil near the still was not too great, because two samples from the truck were compared with six samples from the still and rather close agreement was found among all samples. ${ }^{347}$ Unfortunately, almost no details of the activation analyses used in any of the other cases have been published. However, a recent study by Internal Revenue Service research chemists is worth analysis both because it shows the great variability that can be found in soil samples taken from a single small area and also because it is an example of faulty, or at least misleading, analysis by authors who have testified in many cases involving NAA. ${ }^{348}$

In this study, samples of soil were taken from 29 positions over grids 400 yards square in three states: Georgia, Texas, and Washington. ${ }^{349}$ Visual inspection would have led one to expect that the individual areas would not be greatly variable in trace element concentrations. ${ }^{350}$ Nevertheless, within each grid very large variations were found, ${ }^{351}$ and the authors calculate that the inaximum probability of matching two random samples ${ }^{352}$ from the same grid, within given concentration ranges for each of the 15 elements measured, would be

346. The case is discussed very briefly, without naming it, in Lyon \& Miller, supra note 88 , at 332 .

347. Results given show only the gamma-ray spectra and a table of peak height ratios [see note 172 supra] instead of the actual elemental compositions, but assuming a valid random sample was taken, they appear close enough that a high degree of similarity cannot be denied. A background study of many soils from all over the country is necessary to determine the probability that the soil on the truck actually came from near the still. Nevertheless, if the soil near the still was unusually uniform, the evidence must be given at least sonie weight even though the precise probative value cannot be calculated.

348. Hoffman, Brunelle \& Snow, Forensic Comparisons of Soils by Neutron Activation and Atomic Absorption Analysis, 60 J. CrIM. L.C. \& P.S. 395 (1969). A8 its title implies, this study made use of atomic absorption in addition to NAA. This combination has been found useful to extend the number of measurable concentrations when high concentrations of certain elements obscure the detection of certain others by NAA alone. See, e.g., Pro \& Hoffman, Advanced Instrumentation in Forensic Examinations, 50 J. Ass'n Official Anal. Chem. 1041, 1043-44 (1967). Since the result of either method is the determination of trace element concentrations, and since we are here concerned with the interpretation of that result, the difficulties with NAA alone as a method of soil analysis can be ignored.

349. Hoffman, Brunelle \& Snow, supra note 348, at 397.

350. Id. at 399.

351. See id. at 398. The table shown indicates that magnesium in the Georgia grid varied by a factor of 200 , a few other elements varied by factors of ten or greater in some grids, and many elentents varied by factors of three to five over a single grid.

352. The term maximum probability lere means the probability of matching a sample containing elements in the most common concentration ranges. The probability of matching a sample with element concentrations in the less common ranges will be smaller. Id. at 399 . 
one in $190,000 .^{353}$ This shows the tremendous variability of the soil over a range as small as 400 yards square.

Froin these results the authors conclude that it is "obvious" that the probabilities of within-grid inatching would get progressively sinaller as the grid got larger, and therefore that soils froin two different locations can be distinguished from each other. ${ }^{354}$ At no point do these authors state what they nean by a "location," but they nevertheless conclude that the inethod of analysis used "can provide the analyst with the information necessary to establish the common origin of soils."

It would be serious error to accept this conclusion unqualifiedly, because the authors have not made clear the "common origin" that they claim can be established. The type of location with which the police seek to associate a suspect varies with the fact situation, and in fact the results of this study indicate that the association can properly be made only in a relatively small number of cases. Even if we ignore the author's failure to consider the possible statistical dependence of the element concentrations at different locations over a single grid, ${ }^{356}$ their results indicate that soil comparisons can be useful only when the location with which the investigator seeks to associate the suspect is a very sinall area within a single grid, on the order of one square yard. This is because the grid itself contains a total area of only 160,000 square yards; if the identifiable locations were, say, ten square yards in area, there would be only 16,000 locations within the grid and the maximum probability of a random match would have to be at least as great as $1 / 16,000 .^{357}$ Thus, locations nuch larger than about one square yard in area are incompatible with the $1 / 190,000$ maximum-

353. Id. at 399. Apparently no effort was made in this study to measure the correlations of the element concentrations for statistical dependence, and therefore this result is suspect.

354. Id. at 399.

355. Id. at 401.

356. See note 353 supra.

357. If it could be shown that each of the 16,000 locations were completely distinguishable from every other location, the conditional probability that two random samples would "match" given that they came from different locations, which is the probability the investigator seeks, would be zero. However, the hypothesis of complete distinguishability could be demonstrated only by measurements on all of the 16,000 locations and not a mere 29 samples as was done in this study. Therefore, it must be assumed that at least some locations may give results identical to some others; this means that the maximum probability of a random match must be at least as great as the inverse of the total number of identifiable locations.

The authors state that "soils taken from a three foot radius contain the same elements in approximately the same concentrations." Hoffman, Brunelle \& Snow, supra note 348 , at 398 . If they mean to imply that the distinguishable locations are circles of radius three feet (slightly over three square yards), then there are only about 50,000 distinguishable locations within the grid, which is incompatible with the claimed maximum probability figure of $1 / 190,000$. 
probability figure claimed. Therefore, even assuming that one-squareyard locations can be unambiguously identified, ${ }^{358}$ it is questionable whether there are nany realistic legal problems which involve the association of a suspect with such a small area. For example, suppose that the whiskey still in the above case ${ }^{350}$ had been located somewhere within the Georgia grid. Assuming that the truck had been used to transport illicit whiskey from the still, and that the soil found on the truck did actually come from somewhere in the vicinity of the still, ${ }^{309}$ the investigators would have an almost impossible task trying to find out exactly which one-square-yard area the soil came from, ${ }^{361}$ if, in fact, it came from a single such location and was not a combination built up as the truck rolled over many locations both inside and outside the grid. ${ }^{362}$ The identifiable locations are simply too small to be of much value in a practical case.

The more usual problem will involve associating a suspect with a location the size of which is a significant fraction of the entire grid area used in the study discussed above (160,000 square yards). This would be the situation, for example, if the still were in the Georgia grid and the suspect claims he was in an entirely different county or state. Then there are two possibilities which should be considered separately. In the first, the suspect might claim he knows exactly where the sample found on his truck came from, in the sense that he can pinpoint it to an area about the size of the Georgia grid. This is a problem well suited to activation analysis, because a series of measurements over the two locations involved-the Georgia grid and the alibi area-will allow calculation of the probabilities that the sample

358. Rational explication of the shortcomings of the study discussed in the text requires that they be dealt with one at a time. We are liere considering the authors' failure to define what they mean by an identifiable location. Once a location is properly defined it will still be necessary to measure the variation of the soil over the location-in this case, the one-square-yard area with which the investigator is trying to associate the suspect-to obtain the likelihood ratio, and it is only this latter ratio that gives a meaningful estimate of the probative value of the evidence. See text accompanying notes 253-65 supra. This problem, as well as the authors' failure to measure the statistical dependence of the element concentrations [see note 353 supra], is being ignored here only for simplicity and not because it is unimportant.

359. See text accompanying note 346 supra.

360. When the truck is not discovered near the still the investigators must consider the possibility that the soil on the truck came from outside the grid. Probably NAA tests would not be run unless the soils showed similarity by microscopic or other procedures. Hoffman, Brunelle \& Snow, supra note 348, at 401.

361. The truck itself ordinarily would span an area of 10-20 square yards. Presumably there would be a number of places inside the grid over which it might have been run (entering the vicinity, parking, turning around, leaving) so there are probably lundreds of possible one-square-yard areas which might be the source.

362. M. Houts has noted that samples of dirt or soil on shoes or automobiles most likely are counbinations from inany "sources." M. HouTs, supra note 138, at 337. 
found on the truck could be randomly chosen from each of the two locations. If the Georgia grid probability is much greater than the alibi-area probability, the suspect will be strongly implicated. ${ }^{363}$

The second possibility, however, is likely to be the more usual. Here the suspect claims he was driving his truck around a large area, say a county, which does not contain the grid where the still is located, but he does not know where in the county the soil on his truck came from. This raises problems very similar to those of hair comparisons. As background information it would be necessary to know the distribution of element concentrations in soils over the alibi county, ${ }^{364}$ so that the probability of randomly choosing a particular combination of concentrations could be calculated. This probability would be divided into the probability of choosing such a sample from the crime location to obtaim the likelihood ratio. ${ }^{365}$ This ratio imdicates how much more likely it is that the sample found on the truck canne from a location in the grid than from a location of equal area chosen at random from somewhere in the alibi county. When a crime has occurred in one county and the suspect says he was in another, even if the investigators are lucky enough to stumble on an exact "match" to a sainple of soil from the crime site, the high variability of the soil at the site is a factor strongly favoring the defendant, for the saine reason that variation of a suspect's liair over his own head is a factor in his favor. High variation over the purported source results in a small probability that such a sample would be randomly chosen from the source, and this probability goes into the numerator of the likelihood ratio. Thus, when the purported source is the Georgia grid, the likelihood ratio decreases by a factor of 190,000 from what it would be if the grid were uniform. Unless there is solid evidence, based on a systematic background sur-

363. The study discussed in the text [Hoffman, Brunelle \& Snow, supra note 348] does not give the comparative probability of choosing a given sample from different grids, but the results given in their Table 3 [id. at 398] on the ranges of the elennent concentrations for the three grids involved in the study indicate that there is sufficient absence of overlap for at least some elements that each grid could be clearly distinguished from the other two. Thus, in this unusual case where the search has been narrowed down to a few possibilities it appears that NAA can be of considerable value.

364. If the background sample covers an area inuch larger than the alibi county the result will be prejudicial to the suspect, again because of the tremendous variability of soils. Minnesota soils, for example, can be expected to differ radically froin Georgia soils, and if the background study covers the entire United States, the imclusion of Minnesota would make it appear less likely that the soil associated with the suspect would have been randomly picked up by him, in spite of the fact that he demies being in Miunesota or anywhere near it. This in turn erroneously increases the likelilood ratio. The need to restrict the background sample in this way will probably be a very serious factor in limiting the forensic applications of NAA comparisons of soils, because it may require essentially a new background study for each case. The time and money required may make new studies impossible im most cases. See note 205 supra.

365. See text accompanying notes 253-64 supra. 
vey of the alibi county, that the denominator of the likeliliood ratio is much smaller than $1 / 190,000$, an attempt to match any sample to sucli a variable source would be nearly meaningless. Reasoning identical to that used in the case of laair ${ }^{368}$ indicates that if the variation over the alibi country is identical to the variation over the Georgia grid the evidence has no probative value. Furthermore, it should be noted that soil found on a defendant's truck, like hair found on his head and unlike a piece of glass found in his cuff, is not intrinsically damning, because it is not at all unusual for a truck to have dirt on it. Thus, it is all the more important that the NAA evidence be accurately assessed, so that the jury can get a clear understanding of how much more evidence is needed in order to convict.

\section{E. Paint}

Paint is in many ways similar to glass: there are relatively small variations between paints coming from a common source, but the common source may liave produced many more items than the particular one under consideration in a given case. In the case of glass, it is not possible to identify individual windows by NAA and it may not be possible to pin down many samples any further than that they come from the same manufacturer. ${ }^{367}$ Similarly, paint samples seem to be identifiable by brand. ${ }^{368}$ The interpretation of this identification has been discussed in detail in connection with the Woodward case ${ }^{360}$ and will not be repeated here.

To date, no detailed reports on the distribution of trace elements in paint analogous to Coleman's work on hair ${ }^{370}$ and glass ${ }^{371}$ have appeared, but a study is reportedly in progress. ${ }^{372}$ It may be recalled that in Woodward the analyst assumed that the individual element concentrations would "1natch" with probability $1 / 5$ and that these individual probabilities were independent of each other. ${ }^{373}$ Both of these assumptions should be verified by more complete study before being allowed into general use. It is true that the apparent uniformity of paint by

366. See text accompanying note 265 supra.

367. See text accompanying note 318 supra.

368. Bryan, Guinn \& Settle, High-Flux Neutron Activation Analysis as an Investigative Tool in the Field of Criminalistics, in LAW ENFORCEMENT SCIENCE AND TEChNoLogy, supra note 46, at 371, 376; Guinn, A-State-of-the-Art Report on Forensic Activation Analysis, in LAW ENFORCEMENT SCIENCE AND TECHNOLOGY, supra note 46, at 379, 381; V.P. Guinn \& R.H. Pinker, supra note 68, at 10.

369. See text accompanying notes 109-30 supra.

370. See note 241 supra.

371. See note 312 supra.

372. V.P. Guinn \& R.H. Pinker, supra note 68, at 9-10 (reporting that Mr. D.E. Bryan of Gulf General Atomic is performing a study of some 1,000 paint samples).

373. See text accompanying note 106 supra. 
brand usually gives a "match" some probative value even without a detailed background study. ${ }^{374}$ However, it would be desirable to know precisely what that value is, and this is not possible without such a study. The probability estimates used in Woodward were very rough and perhaps not even as "conservative" as was thought. For example, Bryan, Guinn, and Settle ${ }^{375}$ have given the distribution of mangenese in a sample of 32 house paints: 18 had concentrations of $0-10 \mathrm{ppm}$, five of $10-20 \mathrm{ppm}$, three of $20-30 \mathrm{ppm}$, and two, one, or zero paints had concentrations in the higher ranges up to $100 \mathrm{ppm}$. It is clear that a probability of $1 / 5$ might be a fair average probability, but if the samples in a particular case have all their elements present in the most common concentration ranges (the range $0-10 \mathrm{ppm}$ in this case), a very unfair estimate of the overall probability can result. ${ }^{376}$

Furthermore, it is important to verify the assumption that the concentrations of the imdividual elements are in fact independent of each other. ${ }^{377}$ The measurements on both the brown paint and the lightblue paint in Woodward involved not only the trace constituents, which the manufacturer does not attempt to control because they do not affect the properties of the paint and for which random variations imight be expected, ${ }^{378}$ but also some major constituents, ${ }^{379}$ which the manufacturer does control. Therefore, it would be surprising if correlations, at least among the major constituents, were not found.

Finally, in any particular case involving paint, at least some minor sampling should be done to see low much variation there is in the suspected source. ${ }^{380}$ Studies heretofore have been on paints directly out of the can, and none have involved paint scraped off actual autoinobiles, for exanple. It is at least conceivable that exposure to rain, soot, auto wax, and other substances, as well as internal corrosion froin the automobile body, can introduce extra variables into the paint. The defendant in Woodward's position can reduce the evidential impact of the NAA comparison to the extent he can show variation in the trace element content of the paimt over his own car. ${ }^{381}$

374. See text accompanying notes 206-10 supra.

375. Bryan, Guinn \& Settle, supra note 368 , at 376.

376. Of course, the Woodward case mvolved automobile paint, not house paint. This example merely shows the need for the actual distribution.

377. On statistical independence generally, see text accompanying notes 295-305 supra.

378. See, e.g., Lenihan, supra note 232 , at 527-28.

379. See notes 104-05 supra.

380. "Suspected source" liere refers to the actual object the police are trying to associate with the crime, such as Woodward's car, and not the more general "source" pointed up by the NAA measurement, such as a given brand of paint.

381. This lowers the probability that a paint sample taken at random from his car will liave the same concentrations as the sainple in question. This is favorable to 


\section{F. Alcohol and Drugs}

A number of activation analysts have referred to the need to detect illicit spirits and drugs and to trace them to their points of origin. ${ }^{382}$ This can serve such purposes as protecting the consuming public from lead poisoning due to poorly controlled manufacture of moonshine ${ }^{388}$ and helping to trace out and close drug distribution routes. ${ }^{384}$ To the extent that NAA comparisons are used for purely imvestigatory purposes, there is less need for concern about the degree to which a common origin can be inferred from a "match" of two given samples. However, in a recent narcotics conspiracy case, ${ }^{385}$ the prosecution used NAA to show that two samples of cocaine came from the "saine batch." In such cases detailed consideration of the meaning of any purported match is necessary. ${ }^{387}$

A study of 151 samples of illicit whiskey has been carried out, ${ }^{388}$ and a wide distribution of trace element concentrations was found, probably due to the crude methods of manufacture. ${ }^{880}$ Assuming the sainple was representative, and that the trace element concentrations are reasonably independent of each other, ${ }^{800}$ this study indicates that the probability that two randomly cliosen samples of illicit whiskey will "match" both in the type of elements ${ }^{391}$ found and in their concentrations is quite small. ${ }^{392}$ However, it must be remembered that the

the defendant in the same way that variation of hair over the suspect's head is. See text accompanying notes 253-65 supra.

382. Lenihan, supra note 232, at 528; Lyon \& Miller, supra note 88, at 334; Schlesinger, Pro, Hoffman \& Cohan, Activation Analysis of Drugs, 48 J. Ass'N OfFicint Agric. Chem. 1139, 1139 (1965).

383. Hoffman, Brunelle, Pro \& Martin, Determination of Trace Component Distribution in Illicit Spirits by Neutron Activation Analysis (NAA), Atomic Absorption $(A A)$, and Gas-Liquid Chromatography $(G L C), 51 \mathrm{~J}$. Ass'N. Offictal ANAL. Chem. $580,585-86$ (1968). The presence of lead apparently is conclusive proof that the origin is illicit. Lenihan, supra note 232, at 528 .

384. Perkons \& Jervis, supra note 46, at 263.

385. United States v. Kelly, 420 F.2d 26 (2d Cir. 1969).

386. Id. at 28.

387. Kelly did not pass on the reliability of the NAA tests or on any inferences therefrom. The conviction was reversed because of the government's failure to provide discovery. See text accompanying notes 229-31 supra.

388. Hoffman, Brunelle, Pro \& Martin, supra note 383. As the title of this article implies, methods other than NAA were also used to uncover some of the elements determined in this study.

389. Id. at 580.

390. No findings were given as to statistical correlations.

391. In total, the concentrations of 22 elements in each sanple were measured. Hoffman, Brunelle, Pro \& Martin, supra note 383, at 582. If such a large number of elements can be measured in every case, and if a source reasonably uniform in trace element concentrations can be defined, then a high probability of identity or nonidentity can be achieved.

392. For sample individual-element-concentration probabilities, see id. at 584 . 
variation over the source must always be considered in attempting to identify by trace eleinent characterization. ${ }^{393}$ Because whiskey is a liquid, there is at least a good chance that a given "batch" will be quite uniform, but in illicit operations it seems quite possible that additional contamination could occur after packaging for distribution. Furthermore, there is no reason to assume that different "batches" from the same still will closely match, again because of the crude methods of manufacture or variations in raw materials. If in a particular case it is not possible to check the degree of uniformity of the supposed source, it would still be helpful to have some knowledge of the degree of variation generally observed in the type of source in question. ${ }^{394}$ If the variation over similar sources has been observed to be small, then one can calculate a likelihood ratio, ${ }^{395}$ indicating how much more likely the samples are to have come froin a common source than froin different sources, using the maximum observed variation. This gives a minimum estimate of the likelihood ratio, giving the fullest protection to the defendant. The ratio, however, might nevertheless be quite large if a large number of element concentrations have been measured.

Much less research has been carried out on drugs, and no definite probability statements about common origins can be made. In fact, in some cases the outlook appears rather dim. For example, one group of authors found measurable differences among 22 batches of marijuana, but the origins of the batches were unknown, so the experiment was essentially uncontrolled. ${ }^{396}$ Another author has noted that for the majority of regions the natural variations of the soil withm a region from one year to the next are as large as the differences between regions, ${ }^{307}$ and it is the different soils, waters, and related factors that are considered responsible for many of the differences in trace element concentrations in similar plants grown in different regions. ${ }^{398}$ A similar problein has been found in the case of opium..$^{309}$ Marijuana has the

393. See notes $235-65$ supra and accompanying text.

394. As always, it is very important to define the source carefully. If it means a particular still, then considerably more variation may be expected than if it means a single "batch" from a given still, assuming this latter term can be defined. Also, the source must be properly defined with respect to the legal issue, so that in attempting to associate a suspect with a still, without regard to a particular batch, it is not legitimate to use results which tend to show uniformity throughout a single batch.

395. This term is defined in the text accompanying notes 262-63 supra.

396. Bryan, Guinn \& Settle, supra note 165 , at 686.

397. Coleman, supra note 279 , at 138.

398. Bryan, Guinn \& Settle, supra note 165, at 686.

399. Lyon \& Miller, supra note 88, at 336. Others have found region-to-region differences. See, e.g., Perkons \& Jervis, supra note 46, at 262-63. But almost no information is given on the variations within regions, so that the degree of discrimination cannot be determined. 
additional difficulty that it is often diluted with parsley, which is a source of many of the trace elements found in marijuana-sample analyses. Furthermore, the leaf, stalk, and seed of marijuana show considerable variation in trace element concentrations. ${ }^{400}$

Other drugs, such as heroin ${ }^{401}$ and phenobarbital, ${ }^{402}$ have been studied slightly, but there appears to be far too little information on which to base definite conclusions.

\section{G. Miscellaneous Materials}

Numerous other materials have been studied for their possible forensic value, ${ }^{403}$ but sufficient background information has not been compiled for any of them to give more than a vague indication of susceptibility to NAA identification. Nevertheless, NAA evidence on essentially unstudied materials has been introduced and accepted in many trials, ${ }^{404}$ and in such cases it is important to be extremely careful that the expert does not testify outside the area of his expertise. In United States $v$. Wolfson ${ }^{405}$ the trial court denied a motion for a new trial after holding an evidentiary hearing on defendant's clain of newly discovered evidence allegedly showing that incriminating docuinents were forgeries because the watermarks on them came into use after the dates on the documents. ${ }^{406}$ At the hearing the Government brought in an expert who had subjected the papers to activation analysis. ${ }^{407}$ On the basis of his finding that the eight sheets of paper contained the same elements in essentially the same concentrations, he gave his opinion that they were products of the same manufacturer and from the same gross production batch. ${ }^{408}$ On cross-examination he admitted that a "batch" was essentially undefined, ${ }^{409}$ and he finally stated the only justifiable conclusion he could make given the limited background information available: that the papers contamed the same elements in essentially

400. Lenihan, supra note 232, at 528 .

401. See, e.g., Perkons \& Jervis, supra note 46, at 263.

402. See, e.g., Bate \& Pro, Application of Activation Analysis to Forensic Science-II. Drugs, 15 INT'L J. ApP. RADIATION \& Isotopes 111 (1964).

403. See, e.g., V.P. Guinn, supra note 38 , at 11.

404. Cases cited in M.J. Pro \& V.P. Guinn, supra note 5, involved such materials as automobile putty and adhesive tape, grease, bullets, galvanized wire, pipe-joint compound, safe insulation, gun metal, copper tubing, wheat paste, rope, and solder.

405. 297 F. Supp. 881 (S.D.N.Y.), aff'd, 405 F.2d 779 (2d Cir. 1968), cert. denied, 394 U.S. 946 (1969).

406. Id. at 881 .

407. Joint Appeudix at 387, United States v. Wolfson, 405 F.2d 779 (2d Cir. 1968), cert. denied, 394 U.S. 946 (1969), aff'g 297 F. Supp. 881 (S.D.N.Y. 1968) [hereinafter cited as Joint Appendix].

408. Id. at 395 .

409. Id. at 409. Just earher, however, he had stated that batch-to-batch differences could be detected. Id. 
the same concentrations, and that he considered the deviations present to be very small. ${ }^{410}$ However, on redirect he again began speculating beyond the scope of his measurement, stating that he thought it "reasonable to assume" that changes in raw materials would cause variations over a period of time on the order of one year, ${ }^{411}$ and that the variations would be greater than those he observed in the sheets in question. ${ }^{412}$ As has been pointed out, statistical background data for activation analysis is not a field of subjective expertise, and therefore statements such as these should be excluded. ${ }^{413}$ This expert in fact did not know enough about how paper varies in trace element concentrations to make any well-defined statements, and the "reasonable assumptions" of the type made are for the trier of fact, hopefully aided by drfense counsel's cautionary advice. ${ }^{414}$

In United States $v$. Stifel ${ }^{415}$ the defendant was convicted of murdering his former girl friend's fiance by sending a bomb through the mail which exploded upon opening. ${ }^{416}$ A prosecution expert testified concerning the neutron activation analysis ${ }^{417}$ of pieces of the bomb debris (the mailing label, the cardboard mailing cylinder, the metal top, and some vinyl tape) and the coinparison of the results with tests on similar items available to defendant in the stockroom of his place of employment. ${ }^{418}$ The other evidence in the case was largely circumstantial. $^{419}$

The expert stated that the mailing label and cardboard tube fragments matched their counterparts in elemental composition and that "within reasonable scientific certainty" they were "of the same type and same manufacture." 420 He found that the vinyl tape and metal cap fragments were of the "same manufacture" as their counterparts and

410. Id. at 417 .

411. Id. at 418-19. It is not clear whether he was aware of reports that glass, for example, appears to remain very constant in trace element concentration over the years. See notes 315-17 supra and accompanying text.

412. Joint Appendix, supra note 407, at 419.

413. See text accompanying notes 131-44 supra.

414. The motion for a new trial was denied, but the court did not place the activation analysis evidence in the balance because an eminent defense expert testified that the reliability of the test was open to question. $297 \mathrm{~F}$. Supp. at 888 . The expert for the defense felt that insufficient background information had been collected on paper. Joint Appeudix, supra note 407, at 423.

415. 433 F.2d 431 (6th Cir. 1970), cert. denied, 401 U.S. 994 (1971).

416. Id. at 431 .

417. Atomic absorption tests were also made as part of the analysis. Id. at 436. Since the results of either test are the elemeutal concentrations, the considerations involved in the legal interpretation of the results are identical. See notes 1, 348 supra.

418. 433 F.2d at 434 .

419. Id. at 435 .

420. Id. at 436 . 
that they were from "the same batch," which he defined as the general equivalent of one day's manufacturing production. ${ }^{421}$ The Sixth Circuit felt that the admission of this testimony could not be ruled harmless error, ${ }^{422}$ and therefore faced the issue of its admissibility. The court ruled that sufficient evidence was presented on NAA's general scientific acceptance that the results were not madmissible as a matter of law, and that the trial court had not abused its discretion in admitting the testimony in this case. ${ }^{423}$

Although the Sixth Circuit opinion only briefly describes the trial court proceedings, it appears that the defendant injured his own cause by attacking on too many fronts. First, he attacked the expert's test methods, so that the full complexity of the technique was developed before the jury. ${ }^{424}$ For some reason, testimony was admitted concerning the civil and commercial applications of $\mathrm{NAA}^{425}$ possibly because of defense arguments that the method was too new and untried to provide conclusive proof of identity of the materials tested. ${ }^{420}$ Finally, defendant placed additional einphasis on the claim that NAA provided "inconclusive evidence for court use." observed that the experts' competence is a jury question ${ }^{428}$ and that conclusiveness is not the requirement for admissibility. ${ }^{429}$

A better defense strategy probably would have been to stipulate to the elemental coinposition measurement. ${ }^{430}$ The jury could then have focused its attention on what apparently should have been the primary issue, namely, the invalidity of the expert's claims that "within a reasonable scientific certainty" the items measured were of the same manufacture and that he liad identified the metal cap and vinyl tape fragments to within one day's production batch. No comprehensive background studies have been published on any of the materials involved in this case. The expert was an employee of the Post Office Department Inspection Service ${ }^{431}$ and the case involved the United States as a party. The Sixth Circuit opinion does not say whether the expert attempted to substantiate his claims with purported background studies carried out in government laboratories, but the avail-

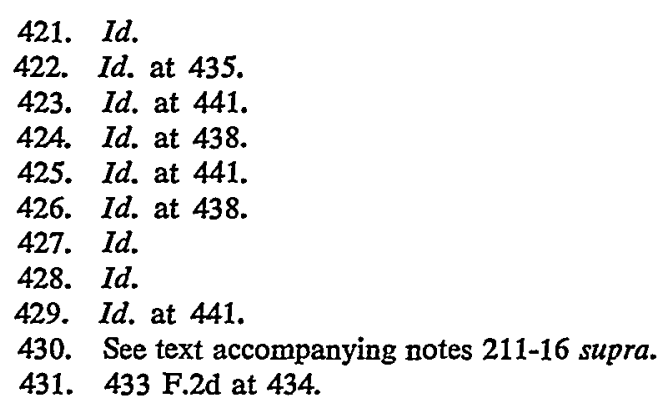


able evidence indicates that such studies should in any event be regarded with suspicion. ${ }^{432} \mathrm{Had}$ the defense limited its attack to this primary issue, it could have been made abundantly clear in the trial court that the expert had no scientific grounds for any of his testimony beyond the results on the elemental composition. Had the trial court admitted the testimony in the face of a showing by the defense that, although NAA is a valid scientific technique for elemental analysis, its use in identifying cardboard containers or their metal caps has not achieved scientific respectability, the admission should have been ruled reversible error.

IV

\section{Single Element ANd Selected Multi-Element NAA}

The identification problem discussed in part III involves the detection of the concentrations of as many trace elements as possible in the samples in question, because each concentration gives an additional point of comparison and thus heightens the probability of identity or nonidentity. The important factor is the extent to which the concentrations in the two samples match each other. In contrast, there are other applications of NAA which involve only an interpretation of the absolute amounts of certain specific elements in a single sample. These applications have a number of advantages in the actual measurement process. First, since the analyst knows precisely what elements he is searching for, and since their number is usually quite limited, ${ }^{433}$ he can often make use of radiochemical separations ${ }^{434}$ either to speed up the analysis or to make it more accurate by eliminating interfering radionuclides. $^{435}$ Furthermore, in these applications the sample itself is usually not required for courtroom presentation ${ }^{436}$ so the destruction

432. This is not only because of the possible conflict of interest mentioned in the text accoinpanying note 201 supra. The study of soil discussed above [see text accoinpanying notes 343-66 supra] provides an exaunple of extreinely loose interpretation of their own work by employees of a Treasury Department laboratory. They concluded that they could identify the common origin of soils [see text accompanying note 355 supra], whereas their study actually indicated that soil comparisons would be useful only in rather unusual cases. See text accompanying notes 356-66 supra.

433. For example, in arsenic poisoning cases only the amount of arsenic is of interest. See text accoinpanying notes $442-55$ infra. In gunshot residue cases, ouly the amounts of barium and antimony are presently being used. See text acconpanying notes 462-82 infra.

434. On radiochemical separations, see notes 52-59 supra and accompanying text.

435. The analysis can be speeded up because it is not necessary to wait for the shorter-lived radionuchides that otherwise inask the element of interest to die out before detection begins. On masking hiterferences, see notes 45-48 supra and accoinpanying text.

436. If tissue or hair of a corpse is examined for arsenic content, the particular piece of tissue or hair examined is of no more interest for courtroom presentation than 
of the sample inherent in radiochemical separations is not a serious problem. ${ }^{437}$ Finally, the danger of pre-irradiation contamination ${ }^{438}$ can be reduced, because knowledge of the element being sought permits choosing handling techniques specifically designed to reduce such danger. ${ }^{439}$ However, the need for careful interpretation of the result of the measurement remains.

\section{A. Toxicology}

The ingestion of even small amounts of certain elements such as arsenic, selenium, nercury, and thalliun can be highly toxic to a human being, and in cases of suspected poisonings the sensitivity of NAA makes it one of the few techniques capable of detecting the small amounts which are deposited in the tissues after ingestion. ${ }^{440}$ However, if abnormal ingestion is to be inferred from the later content of the element in a piece of tissue, it is necessary to know the normal amount found in similar tissues. Since records are not usually kept on particular individuals until after suspicious symptoms have arisen, it is usually necessary to compare the amount found with that which one would expect to find in the tissues of a randomly chosen member of the population. ${ }^{411}$

Arsenic appears to be the most widely studied element in this context, and hair, which absorbs arsemic from the blood stream, ${ }^{142}$ has been the nrost popular tissue. This popularity results from its easy removability for study and because under soine circumstances the distribution of arsenic along the length of a hair can give an indication of the time sequence of ingestion in cases of slow chronic poisoning. ${ }^{443}$

the corpse itself. Contrast this with the light-blue paint samples in Woodward [see text following note 96 supra], which the jury could exannine for color and composition similarities. See note 208 supra.

437. The sample is not preserved for subsequent tesis, of course, but since there is nothing special about the particular piece of tissue or liair cliosen, the opposing side can perform its own tests on other samples of the same type.

438. Contamination after irradiation does not affect NAA measurements. See note 53 supra and accompanying text.

439. Smith, The Distribution of Antimony, Arsenic, Copper and Zinc in Human Tissue, 7 J. For. Scr. Soc'x 97, 97 (1967).

440. Jervis, Perkons, Mackintosh \& Kerr, Activation Analysis in Forensic Investigations, in Proceedings of the 1961 INTERnational Conference on Modern Trends IN Activation ANalysis 107, 108-09 (1961). See also Lenihan, supra note 19, at 322; Smith, The Interpretation of the Arsenic Content of Human Hair, 4 J. For. ScI. Soc'y 192, 192 (1964).

441. Jervis, Activation Analysis in Forensic Science, in LTFE SCIENCES, supra note 36 , at 645,649 . Mere knowledge of the toxicity levels, which might be obtainable from experiments on animals, may not be sufficient. This would be the case, for exainple, when the victim does not dic but attempted poisoning is suspected.

442. Smith, supra note 440, at 192.

443. Coleman, supra note 279 , at 135 . 
The most comprehensive study has been reported by Smith, ${ }^{444}$ who found that 99 percent of over 1,000 samples of hair chosen at random from living subjects had concentrations less than $4.5 \mathrm{ppm}^{445}$ After eliminating those hairs with high arsenic contents known to be due to large external contamination, he concludes that whenever hair is found with arsenic concentration greater than $3 \mathrm{ppm}$, arsenic poisoning should be considered a definite possibility. ${ }^{446}$

Smith also discovered, however, that high concentrations of arsenic im hair do not result only from ingestion. In fact, very high concentrations were discovered to have resulted from absorption of arsenic-containing dusts and certain hair-washing detergents. ${ }^{447}$ Therefore, such possibilities should always be investigated whenever extraordinarily high arsenic concentrations are found. Smith points out that external contamination can often be distinguished if the hair is analyzed in sections, because external contamination usually results in rather uniform arsenic concentrations along the length of a hair, while in chronic poisoning cases there is an irregular pattern of high and low concentrations along its length. ${ }^{488}$ In the case of sudden, acute poisoning, a definite peak is found. ${ }^{449}$

In acute exposures nost of the arsenic is concentrated in the root end of the hair, so if the entire hair is nueasured at once, the high concentration at the root end may be averaged out by low amounts in the rest of the hair. ${ }^{450}$ This provides another reason for carrying out the analysis section-by-section. Furthermore, the sectional analysis can give information as to the time of various ingestions, especially if the growth rate of the individual's hair is accurately known. ${ }^{451}$

Therefore, it appears that proper analysis can result in an accurate estimate of the probability that arsenic poisoning has or has not occurred. Jervis has reported on five cases im which this type of analysis was carried out. ${ }^{452}$ In two, suspicion of poisoning was alleviated by a finding of normal arsenic content, another was ambiguous and

444. Smith, supra note 440. These measurements were carried out in England, and it is important not to extrapolate them blindly. For example, it is known that the normal inercury contents of hair differ by a factor of five or six between Japan and North America. Jervis, supra note 441, at 649. However, arsenic experiments on about 800 North Americans have shown that about the same distribution range apphes here as was found by Smith. Id. at 647-48.

445. Smith, supra note 440, at 192.

446. Id.

447. Id. at 195.

448. Id. at 197.

449. Id.

450. Id. at 195-96.

451. Id. at 196-97.

452. Jervis, Perkons, Macintosh \& Kerr, supra note 440, at 109. 
further police investigation was required, and in two others arsenic poisoning was strongly suggested. Erickson ${ }^{453}$ has also reported on soine cases. In one, arsenic poisoning was ruled out at an inquest after NAA evidence was presented, while in another, detailed sectional analysis was presented to help ascertain the number of times the victim had received arsenic and also the relationship of ingestion times to the time of hospital admission. ${ }^{454}$ In this case charges were brought, the evidence presented in court, and the defendant convicted. ${ }^{455}$

The distribution of other poisonous elements in hair and other tissues is not as well studied. ${ }^{456}$ Smith lias given some preliminary reports on antimony, arsenic, copper, and zinc in liair and many other tissues, ${ }^{457}$ and has done a similar study on mercury distribution. ${ }^{458} \mathrm{Jer}-$ vis has given a general review. ${ }^{458}$ When sufficient data are available on these other elements, it is likely that NAA can provide valuable information in those types of cases also.

An interesting related application of NAA occurred in a civil suit ${ }^{460}$ in which an oat supplier was accused of having caused the deaths of valuable race horses due to mercury poisoning. While the tissues of the dead animals apparently were not involved, the mercury content of the oats was measured by NAA and found to be too low to lave caused the deaths. Defendant presented this evidence and avoided liability. ${ }^{461}$

\section{B. Recent Firing of Handguns}

Bariun and antimony compounds are constituents of most cartridge primers made in the United States and in many foreign countries, and small amounts of these elements are deposited on the back of the gunhand when a handgun is fired. ${ }^{462}$ If the suspect is captured

453. Erickson, Arsenic in Hair, in Forensic Actrvation ANALYsis, supra note 53 , at 279.

454. Id. at 282. For a very impressive time profile of the arsenic concentration in the hair, see $i d$. at 286. This latter case is also discussed in Lucas, Optics and Instrumentation in Forensic Science, 8 APPLIED OPTICs 15, 19 (1969).

455. Erickson, supra note 53, at 282.

456. Jervis, supra note 441, at 649.

457. Smith, supra note 439.

458. Howie \& Smith, supra note 87.

459. Jervis, supra note 441 , at 646-49.

460. This case was probably Wells, dba Glcn Eyre Farms v. Kempton Co-Operative Grain Co., Civil Action No. CV66-22-D (S.D. Ill. May 28, 1968), cited in M.J. Pro \& V.P. Guinn, supra note 5. It is discussed in Schlesinger, Lukens \& Settle, supra note 89 , at 270 .

461. Id.

462. V.P. Guinn, supra note 38 , at 8 . See also Bryan, Guinn \& Settle, supra note 368 , at 372 ; Lenihan, supra note 232 , at 525 . 
before he washes his hands, ${ }^{463}$ these residues can be removed ${ }^{464}$ and measured by NAA, ${ }^{465}$ abnormally large amounts of barium and antimony indicating a high probability that the suspect has recently fired a handgun. Again it should be noted that only a probability is involved, but if enough background information is built up on the distributions of antimony and barium on the backs of hands that have not recently fired a gun, this probability can be accurately estimated.

A major study of handblank levels (the levels of barium and antimony on the backs of hands that have not recently fired a handgun) has been undertaken. ${ }^{466}$ Some preliminary results have been published, ${ }^{407}$ and a later stage of investigation is reportedly in press. ${ }^{468}$ Even when the results of a background study on a valid random sample become available, however, the interpretation of the measurement in a particular case will require considerable care.

The major problem is caused by an overlap between the higher range of values obtamed from measurements on "blank" hands and the lower values obtained from hands that have recently fired a handgun. ${ }^{400}$ The difficulty arises when the suspect's hand is in this overlap range. ${ }^{40}$ In such cases it is not enough to state simply that the

463. Ordinary washing removes the primer residues. Guinn, supra note 96 , at 189.

464. The favored method of removal seems to involve applying molten paraffin, peeling it off after solidification, and activating everything. After activation, the barium and antimony are separated cheinically [see text accompanying notes 52-59 supra] and placed in the detectors for counting. V.P. Guinn, supra note 38, at 8 . Other removal techniques have been suggested also. See Hoffunau, A Simplified Method of Collecting Gunshot Residue For Examination by Neutron Activation Analysis, 18 IDENTIFICATION News, Oct. 1968, at 7. Whatever removal technique finally becomes generally acceptable, it should be the same for both the background study and any measurements that will be compared against the background study, because there may be differences in efficicncy betweeu the various methods of removal.

465. Lead is also deposited on the back of the firing hand, but lead is not easy to detect by NAA. M.J. Pro, Detection of Firearm Discharge Residue by Neutron Activation Analysis-A Review 2 (undated report of the National Office Laboratory, Alcohol, Tobacco and Firearms Division, Internal Reveuue Service).

466. Bryan, Guinn \& Settle, supra note 368 , at 373.

467. Id. at 372-73.

468. V.P. Guinn reports that this work, Guinn, Schlesinger \& Settle, A Large-Scale Study of Gunshot Residues by Neutron Activation Analysis, will appear in a second volume of LAW ENFORCEMENT SCIENCE AND TECHNOLOGY [note 46 supra]. V.P. Guinn, Forensic Activation Analysis as Applied to the Work of the Coroner, Oct. 1969, at $6 \mathrm{n} .9$ (Report No. GA-8839, Gulf General Atomic, Inc.). In a private communication to the author, S.S. Krislinan has indicated that this new volume has already beeu published by the IIT Research Institute (S.T. Cohen ed. 1968).

469. Bryan, Guinn \& Settle, supra note 368 , at 373 . This study found very little overlap in the case of antimony, but the number of samples taken was so small (107 handblanks were compared with 20 single firings of 0.38 caliber revolvers) [id. at 374, Figures 2, 4] that the results cannot be considered conclusive. The overlap in the case of barium was significant even for the small number of samples taken. Id. at 373 .

470. Conceivably, the background studies will show that amounts can be set be- 
amounts of barium and antimony on his hand are consistent with the hypothesis that he has recently fired a handgun, because it may be equally, or more, consistent with the hypothesis that he has not. The proper interpretation in this case is similar to that necessary in hair matching. Since the suspect must be considered randomly chosen from the general population, ${ }^{471}$ the probability that he would have the measured amounts on his hand even though he had not fired a handgun recently can be determined from the data of the background study. Similarly, the probability that he would have the measured amounts given that he had recently fired a handgun can be calculated from a similar study on people who had recently done so. ${ }^{472}$ The ratio of these two probabilities indicates how much more likely it is that the suspect has recently fired a handgun than that he has not.

When the weapon used is known, the above procedure is not adequate, because the amounts of barium and antimony deposited varies greatly with the type, caliber, and condition of the gun. ${ }^{473}$ Tests should be conducted on the actual weapon under various conditions, ${ }^{474}$ so the probability that the suspect would have the measured

yond which there is essentially zero probability that the measured hand has not recently fired a handgun. More likely, however, a thorough study will show almost total overlap, in the sense that there are at least a few people in the population who have not fired a handgun recently and who nevertheless have bariun and antimony present in amounts approaching the highest values recorded for those who have recently fired one. Then all cases must be handled in the manner discussed below [see text accompanying notes $471-75$ infra].

471. There will usually be no record of the normal variations of barium and antimony on his hands, and it is clearly impossible to compile such a record after he has come under suspicion, because the variations will not then be "normal."

472. These probabilities are calculated in the same way as the probabilities involved in hair comparisons [see notes 253-60 supra]. For example, if the amount of barium on the suspect's hand is found to be $0.3 \pm 0.05$ micrograms, the barium probabilities are the areas under the respective barium probability densities between 0.25 and 0.35 micrograms. Assuming there is no statistical dependence between the handblank levels for the two elements, the probability that both elements would be found on a "blank" hand is the product of the probabilities for bariun and antimony individually. See text preceding note 295 supra. It is important to note, however, that the barium and antimony levels will not be statistically independent for hands that have recently fired a handgun, because both are almost always found after a firing, so this correlation will have to be considered in calculating the probability that the suspect would have the measured amounts given that he had recently fired a handgun.

473. Guinn, supra note 96 , at 189.

474. The amount deposited also depends on such variables as the wind velocity and probably the brand of aminunition, the firing angle, and the degree of perspiration on the skin. Id. The tests should try to reproduce the original conditions as closely as possible, but quite obviously many of them will be unknown. Therefore, tests should be conducted over a range of values of these unknown conditions. A very useful experiment would be one which indicates whether it is legitimate to have only one person do the test firings, washing his hands between shots, and to add the results linearly to the distribution curves for the handblank values of the population as a whole. Hopefully, the resulting curve would be identical to the curve expected if the tests were car- 
amounts on his hand given that he had fired that gun can be determined. The likelihood ratio will then tell how much more likely it is that the suspect has fired that particular handgun than that he has fired none. ${ }^{475}$

Some correlations have been found between handblank values and certain occupations, although the results are only fragmentary. ${ }^{476}$ It seems that painters, plumbers, automobile mechanics, and graphic artists, at least, may have considerably higher handblank values than the overall average in at least one of the two elements. ${ }^{477}$ In these cases the presence of the other element can be used to calculate the likelihood ratio, which will be lower than if both elements could be used, ${ }^{478}$ but the problem in an actual case will be to recognize that the particular suspect could be expected to have unusually large handblank values of, say, barium, so that that element will be eliminated from consideration. Careful investigators will have to learn more about the other ways these elements are deposited on hands. It will be necessary for the attorney involved to familiarize himself with these methods so that he can prevent the court from drawing improper inferences from his client's abnormally high concentrations.

In one case a husband was freed from suspicion of the murder of his wife when the residue measurements tended to show his hands within

ried out using many different people who do not wash their hands before firing. The assumption underlying this approach is that the total amount of barium and antimony on the hand is the sum of what was there before the firing and what was deposited by firing the weapon. That this assumption may not be correct is indicated by experiments which show that the ainounts deposited do not increase linearly with the number of firings, the later firings apparently blowing off some of what was there from earlier firings. Guinn, supra note 96 , at 189.

475. Tests with the actual weapon will not necèssarily be helpful to the defendant, because it nay be more likely that the measured amounts would be deposited had he fired the actual weapon than if he had fired a handgun essentially chosen at random. The tests are needed simply to make the procedure more accurate.

476. Bryan, Guinn \& Settle, supra note 368 , at 373-74.

477. Id. at 374 .

478. The number that appears in the denominator of the likelihood ratio, the probability that the measured amounts would be found on a random hand that had not recently fired a handgun, is the product of the two individual probabilities for barium and antimony, assuming statistical independence. See note 472 supra. Since probabilities are always less than unity, this product is always less than either of its imdividual factors. On the other hand, the numerator of the likelihood ratio, the probability that the measured amounts would be found given that the suspect had fired a weapon (or the weapon as the case may be), would not be expected to increase in the same proportion, because of the statistical dependence of the two probabilities involved. See note 472 supra. To see this, suppose the two elements showed total dependence on one another for persons who had recently fired a gun. Then eliminating one of the elements from consideration would not change this latter probability. When there is partial dependence, there will be sonie change, but the increase will not be as great as if there were total independence. Therefore, since the denominator of the likelihood ratio increases by a greater percentage than the numerator, the likelihood ratio will decrease. 
the normal range and the wife's hands within the range typical of firing a handgun. ${ }^{479}$ In another, although the suspect's hands could not be tested, murder was indicated because the victim's hands were well within the normal range. ${ }^{480}$ In a third, the high levels of the two elements tended strongly to indicate the firing of a handgun, and the suspect confessed. 481 This type of evidence has been admitted in at least two trials, ${ }^{482}$ but no details have been reported.

\section{Identification of Bullet Holes and Firing- Distance Detection}

Antimony and other metallic elements are deposited in the vicinity of the bullet hole when a bullet enters an object. ${ }^{483}$ Since antimony is a relatively rare element not found in many materials, ${ }^{484}$ this provides a possible means of distinguishing a bullet hole from an ordinary rip or tear, which can be important for materials in which bullet holes do not ordinarily conform to the shape of the bullet. ${ }^{485}$ Basically, the analyst simply cuts out the piece of material containing the sus. picious hole and another piece which is used as a control. If considerably more antimony ${ }^{486}$ is found on the piece with the hole, a bullet hole is indicated. More precise statements are difficult to justify since the amount deposited varies with the type of gun, the ammunition, the shape of the bullet, and other factors. ${ }^{487}$

In one case a gas station attendant fired at an attempted burglar, and three hours later a suspect was found with two holes in his shoe, although no gunshot wound was detected. ${ }^{488}$ In a case of this type, search for bullet residues can at least serve either to alleviate suspicion or to encourage further investigation. In another case, new evidence arose twenty years after what was believed at the time to be an accidental death. ${ }^{489}$ The remains of the victim were exhumed, and the area

479. Schlesinger, Lukens \& Settle, supra note 89 , at 267 . The conclusion was suicide.

480. $1 d$.

481. Id.

482. See M.J. Pro \& V.P. Guinn, supra note 5.

483. Krishnan, Distance Determination of Gunshot Firings by Neutron Activation Analysis, in Forensic Activation ANaLYsis, supra note 53, at 177.

484. Id. at 181.

485. Schlesinger, Hoffman \& Pro, Identification of Bullet Holes by Residue Transfer, 50 J. Ass'n Official ANal. Chem. 376, 377 (1967).

486. Copper is often measured also. $1 d$. at 379.

487. Id. at 378-79.

488. The fact situation is described id. at 377. Unfortunately, no details, not even the conclusion drawn, are given.

489. This case is described in Lucas, supra note 454 , at 19 . Unfortunately, again no details are given on subsequent use of the evidence. 
near a hole in the skull was compared with a control portion. Antimony was found that was not present in the control. ${ }^{490}$

Closely related is the measurement of antimony and other metalhic elements in the material as a function of radial distance from the bullet hole. Certain materials, possibly scraped off the bullet as it passes through the barrel, ${ }^{491}$ and possibly primer residues and material from the inside of the cartridge case, ${ }^{492}$ travel along with the bullet after it leaves the muzzle, but they spread out with increasing distance. ${ }^{493}$ Therefore, if a bullet is fired at close range the distribution of these elements would be expected to drop off very rapidly with distance from the bullet hole, and to drop off less rapidly as the firing distance is increased.

Some experiments have been performed to test this theory, ${ }^{494}$ and it is claimed that the inethod is inore accurate and effective at greater firing distances ${ }^{495}$ than the old test based on an estimation of gunpowder residues around the bullet hole. ${ }^{496}$ The amount of gunpowder residues is greater than the antimony and copper deposits, but the great sensitivity of NAA for the detection of metallic elements is said to more than compensate for the difference. ${ }^{497}$ The procedure is to fire test shots at various firing distances with the saine gun, ammunition, and target material ${ }^{498}$ to determine the patterns around the bullet hole produced by each particular combination. The analyst then compares the results for the actual hole with these. Some simulated cases under laboratory conditions gave fairly accurate results for firing distances under three feet. ${ }^{499}$

As an application of firing distance determinations, commentators

490. Id.

491. Krishnan, supra note 483 , at 180.

492. V.P. Guinn, supra note 468 , at 9 .

493. Id.

494. Krishnan, supra note 483 , at $179-80$.

495. Id. at 181 .

496. Id. at 177 .

497. Id. at 177-78.

498. The patterns vary with all these factors as well as the shooting angle. Krishnan, Firing Distance Determination by Neutron Activation Analysis, 12 J. For. ScI. 471, 473-75 (1967).

499. Krishnan's work has been interpreted as being reliable for firing distances up to ten feet. See V.P. Guinn, supra note 468, at 9-10. However, in Krishnan's simulated tests, the analyst was only able to determine that the firing distance was greater than 37 inches when the actual firing distance was 57 inches, and this was the only test in which the actual firing distance was greater than three feet. See Krishnan, supra note 498 , at $477-80$. In determining whether suicide or struggle is a possibility, of course, accuracy greater than three feet is not necessary. In any event, antimony can under some circunstances be detected at greater firing distances, up to four feet for .22 rifles and up to ten feet in the case of .357 Magnum revolvers, but the error increases with the distance. S.S. Krishnan, private communication. 
suggest that it might be possible to rule out suicide or accidental discharge of a weapon during a struggle if the measurement shows that the firing distance was much greater than about three feet. ${ }^{500}$ The state of the art at present is that such measurements may be useful in investigations, but so few materials, types of ammunition and guns have been studied that attempts to use evidence of this type in court should be scrutinized very carefully. Again, it is not the ability of NAA to detect antimony in the material surrounding a bullet hole that urges caution. Rather, it is the interpretation of the ineasurements relative to the facts of a particular case.

\section{CONCLUSTON}

Neutron activation analysis is a well-accepted technique of elemental analysis, and, properly apphed, it can be a valuable forensic tool. However, the interpretation of the analysis presents difficult legal problems that depend almost entirely on the circumstances of the individual case. The analytical chemist is qualified to present the results of the analysis, but his subjective interpretation, as a chemist, is worthless; an expert in statistics is required to present a legal interpretation of the analysis. The expert must have a sold, objective basis (usually, carefully compiled statistical background data) for any statement beyond the composition of the measured samples, and the burden of laying an objective foundation for the testimony should rest on the party seeking to introduce the results of the tests. The expert must use well-defined terms which fit the legal issue presented by the facts of the case. Most miportant, the expert must present his testimony in such a way that the trier of fact clearly understands the limitations of the analysis.

Dennis S. Karjala

500. V.P. Guinn, supra note 468, at 10; Krishnan, supra note 483, at 177. 